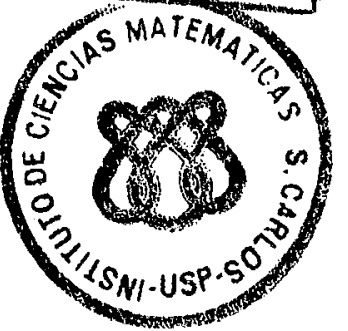

"DESENVOLVIMENTO DE SOFTWARE BÁSICO

PARA GERENCIAMENTO DE UM SISTEMA

MULTIUSUARIO DISTRIBUfDO"

Agma Juci Machado Traina

Orientador:

Prof. Dr. Jan Frans Willem Slaets.

Dissertạ̧ão apresentada ao Instituto de Ciências Matemáticas de São Carlos da Universidade de são Paulo, para obtenção do Título de MESTRE EM CIÊN CIAS DE COMPUTAÇÃo E ESTATISTICA.

\title{
São Carlos
}


Dedico este trabalho:

Ho Caetano, pelo incentivo, carinho e compreensa em todos momentos de nossa vida juntos.

A Tatiana por tanta felicidade que nos trouxe

Hos meus pais por sempre poder contar com seu apoio em minha vida. 


\section{AGRADEEIUENIDS}

Ao Prof. Dr. Jan Frans Willem Slaets, meu orientador, que tudo fez para que eu pudesse concluir este trabalho, desde obter recursos que ofinanciassem, ate o auxilio pessoal e compreensa en todas as horas diffceis por que passei.

Ao meu marido, Prof. Dr. Caetano Traina Júnior, pelo auxilio, dedicafá, incentivo e ideias que tanto contribuiram para o bom andamento deste trabalho.

A Maria Benedita, desenhista do Grupo de Instrumentaça Eletrónica, pela elaboraça dos desentios apresentados riesta dissertaça.

Ao Prof. Gonzato Travieso, pela ininterrupta prontidao en auxiliar-me sempre que precisei.

Aos demais integrantes do Laboratorio de Instrumentaça Eletrónica, pelo auxilio na utilizaço dos equipamentos de que precisei.

As secretarias Neuri e Lia pela constante boa vontade e paciencia em atender aos meus pedidos.

Aos meus pais, Maria Conceifro e Agapito pela dedicacáo e incentivo em toda a minha carreira; e agora principalmente, juntamente com os meus irmas Eduardo e Daniel, no cuidado com minha filha Tatiana para que eu pudesse ter a tranquilidade necessária ao meu trabalho.

A todas as demais pessoas que, direta ou indiretamente, contribuiram para concretizasao deste trabalho. 
Agradeço tambem ao Instituto de Dufmica de 58o Carlos, I

que me possibilitou acesso a sus dependencias, nas quais pude realizar este trabalho, bem como ao Instituto de ciencias Matemáticas de Sto Carlos. A FAPESP, FINEP e ao CNPq pelo apoio financeiro. 


\section{$\underline{\underline{D}} \underline{\mathrm{I}} \underline{\underline{E}}$}

1. - INTRODUৎ̧O

1.1 - Consideraços Gerais $\quad . \quad$. . . . . . . . . . . . . . 1

1.2 - Apresentaçăo . . . . . . . . . . . . . . . . . . . . . 4

2. - UM SISTEMA DE PROCESSAMENTO DE DADOS DISTRIBUADO

2.1 - Introduçăo . . . . . . . . . . . . . . . . 7

2.2 - Conceituaça de Sistema de Processamento de Dados Distribuido . . . . . . . . . . . . . . . .

2.2.1 - Conceituação de 5 istema de Processamento de Dados Distribuido segundo Enslow . . . . . 9

2.2 .2 - Conceituaçáo de Sistema de Processamento" de Dadoș Distribuido segundo Fathi e Krieger. .

2.2.3 - Conceituagăo de Sistema de Processamento de Dados Distribuido segundo Tanenbaum e Van Renesse. . . . . . . . . . . . . . . 14

2.2 .4 - Comparaço entre as Conceituagres Apresentadas . . . . . . . . . . . . . . . . 16

2.3 - A Arquitetura Distribuida Utilizada . . . . . . . . 17

2.3.1 - Memória das Estaçoes de Trabalho . . . . . 20

2.3.2 - Memória do Processador Central . . . . . . 23

2.3.3 - A Comunicaçáo entre as Estaçdes de Trabalho e o Processador Central . . . . . . . . . . . 25

2.3.4 - Mecanismo de Transferência de Dados entre as Estaçbes de Trabalho a o Processador Central. 
3. - alocaçã e proteça de hrouivos

3.1 - Introdução . . . . . . . . . . . . . . . . 35

3.2 - O Problema da Identificaça de Usuário . . . . . 36

3. 3 - Formas de Acesso a Arquivos . . . . . . . . . . 37

3.4 - Organização de Arquivas . . . . . . . . . . . . . . 40

3.4.1 - Estrutura de Diretorio .......... . 41

3.4.2 - Armazenagem de Arquivos Através de Listas. . 42

3.4.3 - Armazenagem por Pre-Alocaça de Arquivos . . 44

3.4.4 - O Mapa de Bits (Bit Map) . . . . . . . 46

3.5 - Acesso Simultâneo a um Arquivo .. . . . . . . . 47

3.5.1 - Semáforo . . . . . . . . . . . . 47

3.5.z - Monitor... . . . . . . . . . . 48

3.6 - Exemplos em alguns Sistemas Existentes ....... . 49

3.6.1 - CPIM . . . . . . . . . . . . . 49

3.6 .2 - co0s da Cromemco . . . . . . . . . . 51

3.6.3 - UNIX . . . . . . . . . . . . . . 52

3.6 .4 - R5X-11M da Digital Equipment Corporation .. 53

3.7 - Conclusres . . . . . . . . . . . . . . . 56

4 - ESTRUTURA DE CACHE

4.1 - Conceito Geral . . . . . . . . . . . . . 59

4.2 - Tamanho da Memoria Cache . . . . . . . . . . . 61

4.2.1 - Tamanho de Bloco de uma Memória Cache . . 62

4.3 - Algoritmos de Busca . . . . . . . . . . . . . . . 64 
4.4 - Algoritmos de Localizaçăo . . . . . . . . . . . .

4.5 - Algoritmos de Reposicăo . . . . . . . . . . . . 69

4.6 - Tipos de Implementaçáo do Cache em Sistema de Multiprocessador . . . . . . . . . . . . . . . 71

4.6.1 - Cache Privativo ............. 71

4.6 .2 - Cache Compartilhado . . . . . . . . . . 72

4.7 - Cache para Dispositivos Periféricos . . . . . . . 74

4.8 - A Implementaçăo de Cache Realizada . . . . . . . . 77

4.8 .1 - Consideraçбes Gerais . . . . . . . . . . 77

4.8.2 - Estrutura de Dados Utilizada. . . . . . . 78

4.8.3 - Algoritmo de Gerenciamento do [ache . . . . 84

4.9 - Conclusogs . . . . . . . . . . . . . . . . . . . . . . 88

5 - A IMPLEMENTAÇĀO DO SISTEMA CP/M REALIZADA

5.1 - Consideraçóges Gerais . . . . . . . . . . . . . . . . 89

5.2 - Apresentaça das Estruturas Internas do CP/M . . . . 91

5.3 - Organizaf̧a de um Disco Padrăo em CP/M . . . . . . . 101

5.3.1 - Mapeamento dos Registros de um Arquivo em Disco

5.4 - Organizaçăo de um Disco de Formato Genérico em CP/M.

e Conclusojes Obtidas Experimentalmente : . . . . . 107

5.4 .1 - AUtilização dos Bytes do a d15.do FCB . . 107

5.4 .2 - Como os "Extents" sao Armazenados nas. Entradas de Diretorio . . . . . . . . . 108

5.4 .3 - Como săo Usados os Campos re e ex do FCB . . 110

5.4 .4 - O Uso dos [ampos 51 e 52 de un F[B . . . . . 112

5.4 .5 - D.Uso do Campo "EXM" de uma DPB . . . . . 113

5.4 .6 - D U50 do Campo CK5 da DPB . . . . . . . . . 114 
5.5 - A Implementaça do CCP Efetuada

5.5.1. - Descriça Sumária dos Comandos do CCP, tal Como Implementados... . . . . . . . . 116

5.6. - Ambiente de Teste do 5istema Operacional CP/M-LIE . 119 5.6.1. - Avaliaçres Efetuadas no CP/M implementado . 125 5.7 - Expansao do Sistema para uma Versáo Multiusuário - . 126 5.7.1. - Como o Esquema de Proteçáo foi Implementado. 127 5.7.2. - Tipos de Proteçăo . . . . . . . . . . 130

5.7.3. - Descriça do Arquivo de Usuários . . . . . 131

5.7.4. - Palaura de Proteçáo Padráa da area . . . 132

5.7.5. - Programas Utilitários Desenvolvidos . . . 133

5.7.6. - Estenszes ao BDos. . . . . . . . . . . 137

5.7.7. - Alteraģ⿸s no CCP . . . . . . . . . . . . . 140

5.8 - Conclusges . . . . . . . . . . . . . . . . . 140

6 - CONCLUSOES E LINHAS DE FUTURAS PESQUISAS

6.1 - Introduça . . . . . . . . . . . . . . . . . . 143

6.2 - Conclusges Gerais . . . . . . . . . . . . . . . . . 144

6.3 - Linhas de futuras Pesquisas . . . . . . . . . . . . 145

6.3 .1 - Substituifăo do Microprocessador . . . . . . 146

6.3 .2 - Otimizar o Uso de Unidades de Disco . . . . 146

6.3.3 - Acesso a Bases de Dados Distribuidas . . . 147

6.3.4 - Desenvolvimento de Prociessadores de Comando Alternativos . . . . . . . . . . . . . . 148 
APENDICE 1 . . . . . . . . . . . . . . . . 149

APENDICE 2 . . . . . . . . . . . . . . . . . . . . . . . 185

APENDICE 3 . . . . . . . . . . . . . . . . . . . . 201

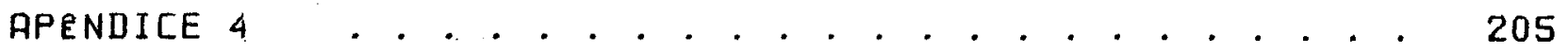

BIBLIOGRAFIA . . . . . . . . . . . . . . . . . 211 


\section{RESUMMO}

No infcio deste trabalho foi realizado un estudo bibliografico sobre sistemas de processamento de dados distribuido, sistemas de gerenciamento de arquivos, memoria cache, as principais exigencias que um sistema de processamento de dados multiusuario requer quando da sua implementaço. Neste trabalho descrito o desenvolvimento a a implementacao de um sistema operacional para uma arquitetura multiusuaria, onde o tratamento dos aplicativas executado em estaçres de trabalho autonomas, o gerenciamento e armazenagem de arquivos să realizados pelo processador dedicado.

Esse sistema operacional foi elaborado compativel com o sistema operacional CPIM, a fim de aproveitar a vasta variedade de software que existe disponivel para esse sistema. Nesse sentido, descreve-se varias caracteristicas do sistema CP/M que nă şo documentadas, a a implementaço da versao multiusubria do sistema operacional construldo.

Apresenta-se tamben um algorltmo para o gerenciamento de memória cache para dispositivos perifericos (disco). Esse algoritmo representa uma aglutinaca dos tradicionais -metodos de substituigaro de registros do cache - LFU (Least Frequently Used) e LRU (Least Recent(y Used)- que mostrou-se bastante eficiente na aplicagăo em que foi utilizado. 


\section{ABSIBACI}

In the present work we describe a bibliographic study of distributed parallel computers, file management systems and cache memories, including the principal aspects and implementations related to multiuser systems.

Based on the previous study, a description of the development and implementation of an operating system for a multiuser environment, where the execution of the application programs is done on individual and independent workstations and the file management by a dedicated processor, is given.

The operating system was built based on the CPIM specifications, making it suitable to process all the existing application softwares available for this operating system. To keep the developed system compatible with CP/M a lot of nondocumented features are also described.

The final version includes additional routines to support a multiuser environment.

The file management system and more specifically the cache memory management used for the disk driver are based on a combination of: Least Frequently Used and Least Recently Used algorithms. Which proved to be very efficient for this application. 


\section{INTRODUGXO}

1.1 - Consideragres Gerais.

Os problemas que se tem solucionado com o auxilio de computadores, têm continuamente apresentado crescentes exigencias de desempenho, capacidade de memória, disponibilidade da máquina, etc. Sempre que maior capacidade exigida das maquinas disponiveis, existem apenas duas soluçäes que podem atender. à essa crescente necessidade:

- Aumentar a capacidade das maquinas disponiveis, ou seja, desenvolver computadores de maior porte;

- Colocar varios computadores juntos, somando esforcos para resolver os problemas.

A escolha da soluço a ser adotada depende da avaliaça das necessidades de cada caso em particular. No entanto, existem alguns casos classicos onde uma determinada soluço costuma apresentar vantagens. E'o caso, por exemplo, de um sistema que deve ser capaz de processar rapidamente um grande volume de operafbes, mas com reduzido fluxo de entrada salda, em que 
normalmente adota-se a soluço de se utilizar computadores de grande porte. Por outro lado, se as operaçes necessarias precisam de dados colhidos ou ormazenados em diferentes locais, porem com alta disponibilidade, entyo sistemas de processamento de dados distribuldos se mostram mais atraentes.

A utilizaço de sistemas de Processamento de Dados envolvendo diversas UCPs, tem se tornado cada vez mais atraente, devido a reducgo do custo de computadores baseados em microprocessadores. Alem disso, un sistema distribuldo pode ser mais facilmente expandido com a incorporaca de novos processadores, ou substituigro de alguns deles, permitindo uma evoluço gradual do sistema.

Ambas as solucies apresentam dificuldades para a sua realizaço, e durante muito tempo as dificuldades de um sistema distribuldo influiram para que a tendencia de evoluça de sistemas fosse na dirégro do aumento do porte de isistemas centralizados. No entanto, atualmente tem sido raalizado um grande volume de pesquisas sobre sistemas distribuldos, viabilizando o surgimento de muitas arquitetures distribuidas.

Um dos motivos pelo qual um sistema distribuido é desejável, é que năo importando o porte dos processadores envolvidos, alguns problemas existem permanentemente em sistemas centralizados, que so podem ser eliminados com a utilizaço de vários processadores. Entre eles destacam-se os seguintes:

- o atendimento a periféricos onera a capacidade de processamento de dados da UCP; 
- Especialmente se houver terminais conectados ao sistema, a necessidade de atendimento aos caracteres digitados representa uma sobrecarga crepresentada pelas constantes interrupgoses geradas pelo terminal) que ngo bem absorvida pela grande maioria de processadores de grande porte, destinados a processamento de grande volume de calculo;

- Em sistemas centralizados, se houver muita demanda de memória entre os processos que estgo em execucao, há um volume muito grande de transferencia de informaçes entre membria e disco, devido aos mecanismos de paginacao. En sistemas distribuldọs a memoria associada cada processador pode ser meltior ajustada à necessidade dos processos.

Esta dissertaço apresenta a construça de um sistema operacional para um ambiente multiusubrio. Tal sistema foi desenvolvido: no Laboratorio de Instrumentaça Eletronica do Instituto de Fisica e Duimica de 5a Carlos - USP. Ao se pensar em construir tal sistema operacional, optou-se por construl-lo de tal forma que se pudesse aproveitar software.ja pronto.

Um sistema operacional bastante divulgado para microcomputadores o sistema operacional CP/M, e dessa forma ja possui un grande numero de software pronto disporivel. Mas como o sistema operacional CP/M e monousuário e que se desejava era um sistema multiusuario que apresentasse as mesmas caracteristicas do sistema operacional CPIM, decidiu-se implementar um sistema 
operacional totalmente compativel com o CP/M monousuario e depois expand-lo para um ambiente multiustario, com as caracteristicas de ser um sistema operacional muttiusubrio; como foi pretendido desde o intcio. A construcro do sistema operacionat monousuario compativel com o CPIM foi muito importante do ponto de vista de se conseguir um bom conhecimento do funcionamento interno do sistema CPIM, pois acumentacro de tal sistema a nivel de referencia nao fornece todos os dados necessarios ao pleno conhecimento interno do sistema nem tampouco permite a avaliaço correta do grau de complexidade do sistema.

\section{2 - Apresentaço}

No capitulo 2, şo apresentados conceitos de sistemas de processamento de dados distribuldos segundo vários autores e feita uma comparaço entre aqueles varios conceitos. Alem disso., e apresentada a arquitetura do sistema utilizada para o desenvolvimento deste trabalho.

No capitulo 3, e analisado: o problema de identificaço e acesso a um arquivo em ambiente multiusuario. Ds conceitos e problemas associados sa analisados, e sa apresentados os esquemas de alocação e proteção de arquivos adotados por varios sistemas comerciais existentes. Dois desses sistemas apresentados apesar de monousuarios, tambem foram avaliados por serem sistemas com capacteristicas muito proximas às do sistema desenvolvido neste trabalho.

No capitulo 4, e apresentado o concefto de membria 
cache utilizado para acelerar a acesso a informaças. Ésse conceito discutido no contexto do uso de membria cache para acelerar o acesso a instruçoses pelo processador central, e a seguir expandido para envolver o acesso a informacóges armazenadas e os dispositivos periféricos. Mostra-se também a soluço que foi dada para o.gerenciamento de memória cache na arquitetura utilizada.

No capitulo 5, detalha-se a implementacgo do sistema operacional realizada. Esse sistema foi desenvalvido para ser compativel com o sistema operacional CP/M e, portanto, algumas caracteristicas nădocumentadas deste sistema tiveram que ser obtidas experimentalmente. Mostra-se assim o resultado dessa experimentafơo e também os detalhes da nova implementagyo do CP/M realizada. A expanszo que foi feita a esse sistema operacional para torna-lo multiusuário tambem apresentada.

Finalmente, no capitulo 6 so apresentadas: as conclusies gerais deste trabalho e sugerem-se novas linhas de pesquisa e desenvolvimento que lhe podem dar continuidade. 


\section{A. P I T U L 0 I I}

\section{UM SISTEMA DE PROCESSAMENTO DE DADOS DISTRIBUIDO}

\section{1 - Introduço}

Sistemas computacionais envolvendo mais de uma unidade central de processamento (UCP) podem constituir uma solwcro quando ha necessidade de um desempenho mais elevado, suporte para aplicaçes mais complexas ou quando se pretende um uso mais eficiente de dispositivos de alto custo.

No entanto, apesar da importgncia e da grande quantidade de trabalhos realizados sobre sistem processadores, ngo existe uma terminglogia universalmente adotada para os varios sistemas existentes e nem uma definicyo consagrada para os termos geralmente empregados. Devido a isso, neste trabalho, sergo usados os termosicom os respectivos significados a seguir, sempre que ngo houver referencia a um termo com um trabalho em particular.

Ststeme de Multiprogramefro, - sistema computacional que pode ter em execucgo mais de um programa ao mesmo tempo. 0 termo: ngo faz alusgo ao número de processadores no sistema. 
Sisteme do Multiprocessumento - sistema computacional que utiliza varios processadores para executar um ou mais processos, usualmente ao mesmo tempo $\left[K R_{-} 85\right]$.

Silstens...... de Processamento Porolelo - sistema computacional constituldo de varios processadores geralmente independentes que trabalham juntos. Em geral, sao usados para executar apenas um programa de cada vez, mas o programa decomposto em vários processos, sendo que a cada processo atribuido um enico processador que o executa.

Sistema Multilusubrio - um sistema computacional que permite o acesso simultaneo de varios usuários. Se - atendimento for nivel de sistema operacional, : diz-se que o sistema também de multiprogramaço; se o atendimento aos varios usuarios é feito a nivel de aplicafyo entyo o sistema somente multiusuário.

5istomo Descentralizodo - Um sistema computacional que é constituldo por uma coleça de computadores autonomos, que se comunicam entre si para executar tarefas comuns a ambos [GY_86]. 


\section{2 - Conceituacro de Sistemas de Processamento de Dados Distribuido}

Como foi visto na secro anterior, apesar de atualmente se astar estudando bastante sistemas de processamento de dados muttiusuario, dentre os quais sistemas distribuldos, ainda há bastante diversificaço no enfoque dado por cada autor a conceituacro de tais sistemas. Assim, nas proximas sub-seços, será apresentada a maneira como varios autores tratam o assunto para, entyo, discutl-las.

2.2.1 - Conceituaço de Sistema de Processamento de Dados Distribuldo segundo Enslow

Ensfọ, em [EN_78], apresenta uma definic\%o para sistemas de processamento de dados distribuldo constitulda por cinco componentes:

a) Multiplicidade de componerites de propbsito geral, incluindo recursos fisicos e logicos, os quais podem ser associados a tarefas especificas de uma maneira dinamica. A homogeneidade de recursos flsicos ngo é essencial.

b) Distribuicgo flsica desses componentes lógicos e fisicos, os quais interagirao atraves de comunicaço por rede ("network"). 
c) Um sistema operacional de alto nlvel que unifiqueae integre o controle dos componentes distribuidios. Cada processador tem o seu proprio sistean operacional local, e eles podem ser diferentes.

d) Transparencia do sistema, isto e, os recursos sta solicitados apenas pelo seu nome.

e) Autonomia cooperativa, caracterizando a integraços operacgo dos recursos fisicos e logicos.

Deve-se ressaltar que, conforme Enslow, somente a combinaço do todos os Itens acima define um sistema de processamento de dados distribuldo.

Enfocando mais a implementaço do sistema, tries "dimensies" podem ser usadas para caracterizar o grau de descentralizą̧a do męsmo, a saber [EN_78]:

- a) Descentralizaça do hardwara;

b) Descentralizaço do controle;

c) Descentralizaço da base de dados.

Assim, pode-se classificar os sistemas segundo o grau de distribuifaro associado a cada dimensgo, estabelecendo uma escala de descentralizaça do sistema que vai desde os totalmente centralizados até os totalmente distribuldos.

Sistema operacional de alto nivel é um componente muito importante em sistemas de processamento distribuido ja que a 
integraca entre os módulos do sistema é gerenciada por ele e tambim a protecao às chamadas regibes criticas, onde os dados precisam ser protegidos contra acesso simultaneo de mais de um processador (ver segă 3.5 ).

Alem disso, a estrutura do sistema de processamento distribuldo deve ser tal que o usuario năo perceba que o processamento ná é centralizado, a năo ser talvez pela sua eficiencia.

Com o desenvolvimento da tecnologia de microprocessadores e a diminuicaro de seu custo, encorajou-se o uso de vários microprocessadores em lugar de um computador de grande porte, onde o custo bem mais elevado. Assim, os sistemas de processamento de dados distribuldos utilizando microprocessadores, adquiriram uma importancia ainda maior. E' o que veremos na secro à seguir.

2.2 .2 - Conceituaça de Sistema de Processamento de Dados Distribuido segundo Fathi e Krieger

Em [FA_B3], Fathi e Krieger apresentam o estudo de sistemas de processamento de dados distribuldo, voltados especificamente para sistemas utilizando microcomputadores.

Em um sistema de processamento distribuldo, a carga de trabalho e particionada em tarefas relativamente independentes, as quais podem entgo ser associadas a varios elementos do 
sistema. Tal sistema possui as seguintes caracteristicas principais [FR_B3]:

a) Autonomia dos elementos. Cada elemento individual geralmente consiste de uma ULP, programa local, memoria de dados e pode usar ou controlar periféricos adicionais.

b) Processadores dedicados a uma tarefa. Idealmente, cada elemento dedicado a uma tarefa especifica que determina sua relativa complexidade.

c) Processadores com complexidade variada. A configuracgo do sistema nao necessariamente homogenea, desde que seus elementos variam em - complexidade.

d) Otimizacgo de hardware e software. Cada elemento do hardware ou do software é projetado para executar una tarefa especifica.

e) Comunicacro ao nivel de dados.

f) Processadores de comunicaça e aplicaço separados. En geral, cada elemento manuseia a comunicaço do sistema e controla a entradalsalda (E/S). No caso de uma grande ațividade de comunicacă, uma dessas funçles pode ser delegada a outro processador. 
g) Partilha de carga estatica, porque em processadores dedicados um sistema minimal nă suporta partilha de carga dingmica; assim um balanco de carga aproprlada deveria ser feito durante a fase de projeto do sistema. Entretanto, algum compartilhamento pode ser introduzido, incluindo unidades adicionais.

Depois, de várias consideraçôes em [FA_B3], Fathi e Krieger chegam a conclusa de que deve-se usar um sistema de multiprocessador quando há:

a) Aplicafónes elaboradas de controle de procesşos, cam diversificada demanda computacional e restricóses de tempo-real. Para muitas dessas aplicaçes, grandes necessidades de processamento excedem as capacidades de un sistema baseado em um ánico microprocessador:

b) Aplicacores com grande processamento de Els. A recessidade de relacionar-se com uma grande variedade de processos de E/S geralmente impore uña sobrecarga de controle inaceitavel sobre um unico microprocessador causa severa degradaço na resposta do sistema.

c) Aplicaçes que demandam alta confiabilidade, mas que devido a restriçoses financeiras elou de espaço năo suportam muita redundancia.

Por outro lado, também conclui-se que deve-se evitar o 
uso de sistemas de multiprocessador quando existe uma das seguintes condiç8es:

a) Hb necessidade de maior potencia de processamento. Nesse caso, mais conveniente colocar um processador mais poderoso.

b) A tarefa a ser executada ngo pode ser particionada em tarefas relativamente independentes.

2.2.3 - Conceituagro de Sistema de Processamento de Dados Distribuldo segurido Tanenbaum e Van Renesse

Segundo Tarienbaum e Van Renesse [TA_85], um sistema de processamento de dados distribuldo, e"um sistema que é visto por seus usuarios como un sistema de processamento de dados centralizado, mas que executa seus programas en maltiplas e independentes unidades centrais de processamento (uĆps).

Aqui o conceito chave o de transparencia. Em outras palauras, o uso de maltiplos processadores deveria ser invisivel (transparente) para os usuarios., Uma outra maneira de dizer a mesma coisa, que os usuarios deveriam ver o sistema como se fosse um "processador virtual", e năo uma coleço de processadores.

Mas năo ofato de que o sistema seja constituldo por vários processadores independentes que o torna um sistema 
distribuido, pois poderia ser um sistems de processamenta de dodos am rade ("network").

Em um sistema de processamento de dados em rede a transparencia no sistema na levada em conta, pois o proprio usuário precisa especificar onde esta o recurso por ele solicitado. Por exemplo, se o usuario quiser acessar um arquivo que năo está em seu processador da rede precisa antes copia-lo em seu processador para depois entgo acessa-lo. No caso de sistemas distribuldos essa tarefa é realizada pelo sistema operacional e é transparente ao usuário.

Logo, Tanenbaum e Van Renesse argumentam que o que determina se um sistema descentralizado é distribuido ou na, é - software e nao o hardware.

Pode-se contrastar mais fortemente um sistema de processamento de dados distribuido com um sistema de processamento de dados em rede. Uma configuraço tipica de um sistema em rede pode ser: uma coleço de computadores pessoais ligados a uma impressora e um servidor de arquivos, todos unidos atraves de uma rede local. Tal sistema teria ainda outras caracteristicas que o distinguiriam de um sistema distribuldo:

a) Cada computador tem seu proprio sistema operacional. privativo, em vez de executar parte do sistema operacional global (que é c caso de sistemas distribuidos).

b) 0 sistema operacional nơ aloca dinamicamente processos às UCPs. Cada usuario normalmente trabalha em sua propria máquina e, quando necessita de algum 
recurso que năo possua, precisa fazer uma solicitaço direta de tal recurso.

c) Os usuarios precisam ficar atentos a seus arquivos, guardando transferindo arquivos entre máquinas com comandos explicitos de "transferencia de arquivos", em vez de ter o gerenciamento de alocacão de arquivos feito diretamente pelo sistema operacional.

d) 0 sistema em rede tem menor, ou nơo tem procedimentos de tolerancia a faltias, isto e, se $10 \%$ dos computadores sofrem pane, $10 \%$ dos usuarios estao fora do sistema, em vez de todos simplesmente poderem continuar seu trabalho normal, embora com $10 \%$ de chances de perder a execuço.

2.2.4 - Comparaço entre as Conceituaçôs Apresentadas

Ao comparar-se a conceituago de sistemas de processamento de dados distribuldo de Enslow e a de Fathi e Krieger, observou-se que sistemas considerados como distribuldos em [FA_83] ngo satisfazem os criterios apresentados por Enslow em [EN_78], pois a conceituafro de Enslow é bem mais rigida do que a de Fathi e Krieger. Mas a conceituacao apresentada por Fathi e Krieger e bem mais clara e talvez mais realista do que a apresentada por Enslow. D proprio Enslow declara a dificuldade de construgro de sistemas distribuldos segundo a sua definifao. 
Ja en.[TA_85], pode-se perceber que a conceituaça de sistemas distribuidos é muito mais simples do que as conceituagres apresentadas por Enslow e Fathi e Krieger.

Assim; pode-se perceber que atraves de anos de estudo (Enslow-78, Fathi e Krieger-83, Tanenbaum e Van Renesse-85), a conceituaço a distinço entre sistemas distribuldos $e$ os demais sistemas foram cada vez mais delimitadas. Deve-se ressaltar que para Enslow na havia ainda uma diferenca nitida entre sistemas distribuldos e sistemas de rede, o que para Tanenbaum Uan Renesse fundamental.

Alem disso, apesar de uma rigidez progressivamente menor na definic8o. dos conceitos; houve uma adequagăo progressivamente maior dos conceitos aos sistemas reais existentes e uma maior facilidade para a distinço entre os varios tipos de sistemas.

2.3. - A Arquitetura Distribulda Utilizada.

No Instituto de Fisica eutmica de Sa Carlos, da Universidade de 5ro Paulo, o Grupo de Instrumentaço Eletronica desenvolveu um sistema de Multi-Processadores baseado no microprocessador Z80 da Zilog, utilizado como processador central, ao qual estao ligadas as unidades de disco e impressara, e um conjunto de até quatro processadores, denominados Estaços de Trabaltio, que estgo cada um ligado a um terminal de video, podendo além disso ser cada um ligado a unidades de disquetes e impressoras locais. A figura 2.1 ilustra essa arquitetura. 
Centralizando as unidades de disco e impressoras, consegue-se um maior aproveitamento desses periféricos que, em um sistema de micro-processadores, sgo as unidades mais caras do sistema. Por outro lado, o desenvolvimento de um sistema com caracteristicas totalmente novas implica na necessidade de se desenvolver todo o software necessbrio especificamente para esse sistema. Para ser possluel aproveitar software ja existente, optou-se por desenvolver um sistema que pudesse suportar a execuço do sistema CP/M. Esse sistema, alem de dispor de uma quantidade muito grande de software jb pronto, foi concebido para poder ser adaptado para execugro em muitas arquiteturas que usassem os microprocessadores 8080,8085 ou 280 .

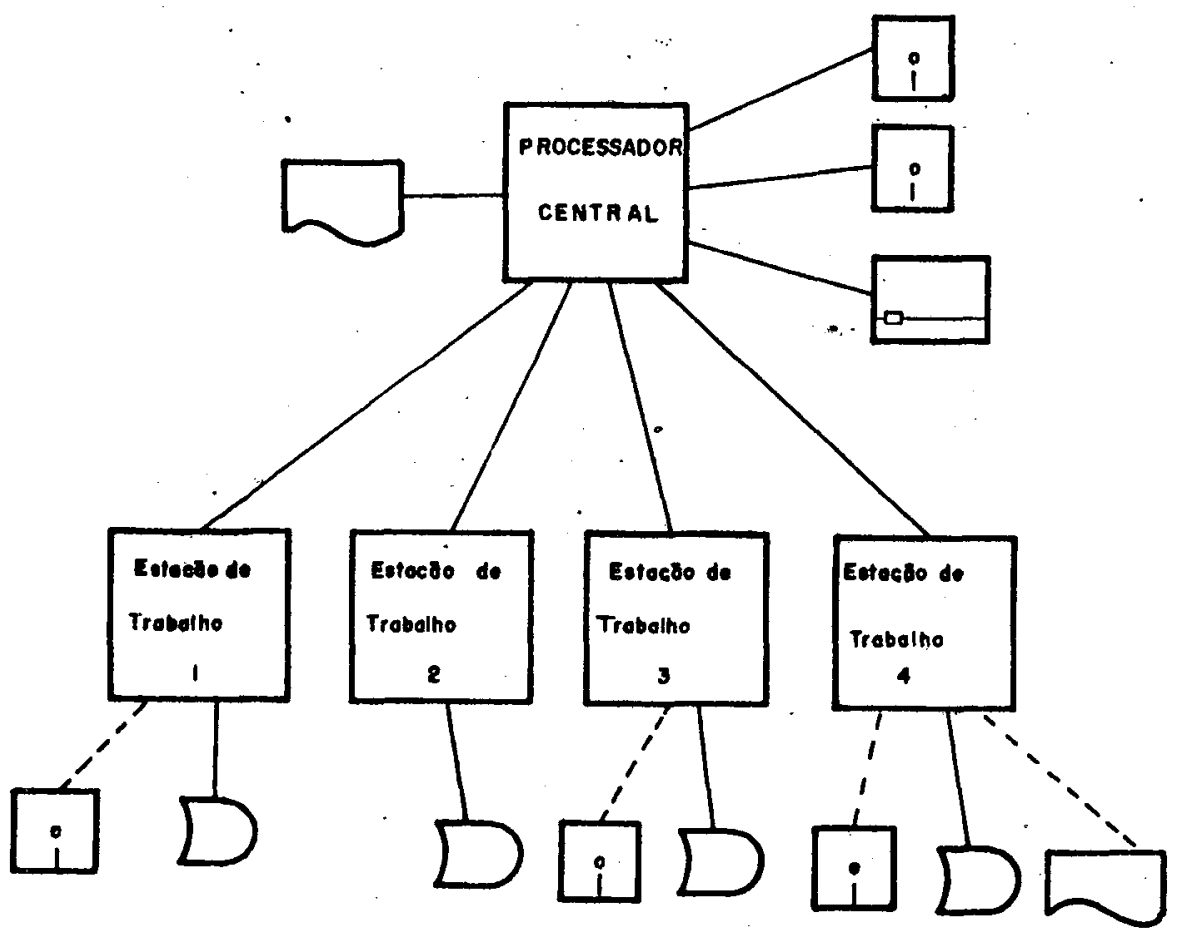

Figura 2.1 - Arquitetura do sistema distribuldo utilizado. 
Assim, a arquiteturo distribulda foi implementada de forma que cada estafa de trabalho pudesse apresentar um ambiente proplicio para a execucgo do sistema operacional CPIM, sendo que o controle de acesso ao sistema de arquivos en disquete, $e$ a impressa dos mesmos na impressora central fol desenvolvido para que pudesse ser controlado pelo processador central. Como se trata de uma versgo multiusubrio, as caractaristicas do sistema CPIM tiveram que sofrer algumas alteraçes e, para isso, o sistema foi reescrito, tal como descrito no capitulo 5. Porém, todos os programas de aplicacgo que podem sar executados sob o sistema operacional CP/M, tal como os compiladores, editores, gerenciadores de bases de dados, etc, continuam podendo ser executados diretamente en cada uma das estacbes de trabalho dessa arquitetura. Portanto, as caracteristicas de interface do sistema operacional com os programas de aplicaço ná foram alteradas.

o controle de acesso a qualquer arquivo do sistema é efetuado pelo processador central o qual, alem disso, dispre de memóia auxiliar para executar uma armazenagem dos setores dos disquetes mais usados, gerenciando um cache para os periféricos que controla, tal como é descrito na seço 4.8.

A implementaço flsica dessa arquitetura é descrita com detalhes em [TR_B6]. Nas tres subseques seguintes é feito um resumo dessa arquitetura em termos de como éfeita a estrutura de memória dos processadores e como é realizada comunicacaro entre cada Estaço de Trabalho e o Processador Central. Na subsecao 2.3.4. faz-se uma analise da forma como essa comunicacro opera e uma avalią̧a de seu desempenho. 
2.3.1. - Memória das Estacóes de Trabalho.

Existe un banco de Memoria de Escrita le Leitura denominado RAM-0, composto por duas páginas de 32 KBytes cada uma, denominadas RAM-00 e RAM-01, mais uma página de 32 KBytes denominada ROM, composta por um bloco de 4 KBytes de Memória de Escrita e Leitura (denominada RAM-e), um bloco de 4 KBytes de Memória de Apenas Leitura (denominada ROM-p) e um bloco de 24 KBytes de Memória de Apenas Leitura (denominada ROM-0). Esse esquema de chaveamento de memoria e mostrado conceitualmente na figura 2.2 .

Para permitir que mais do que 64 KBytes de memória possam ser acessados pelo processador 280 foi implementado um esquema de chaveamento de bancos de memória [TR_86], o qual é mostrado na figura 2.3. Nessa figura o sinal "seleciona", quanda ativado, guarda em registradores especiais se o bit de enderesamento de dados ex.memória "A15" deve ser complementado ou ná (comandado pela linha "A3̣"), se o banco ROM deve ser ativado ou não (comandado pela linha "pao"), ou qual o banco de RaM que deve ser ativado (comandado pelas linhas de dados "Do" a "De"). 


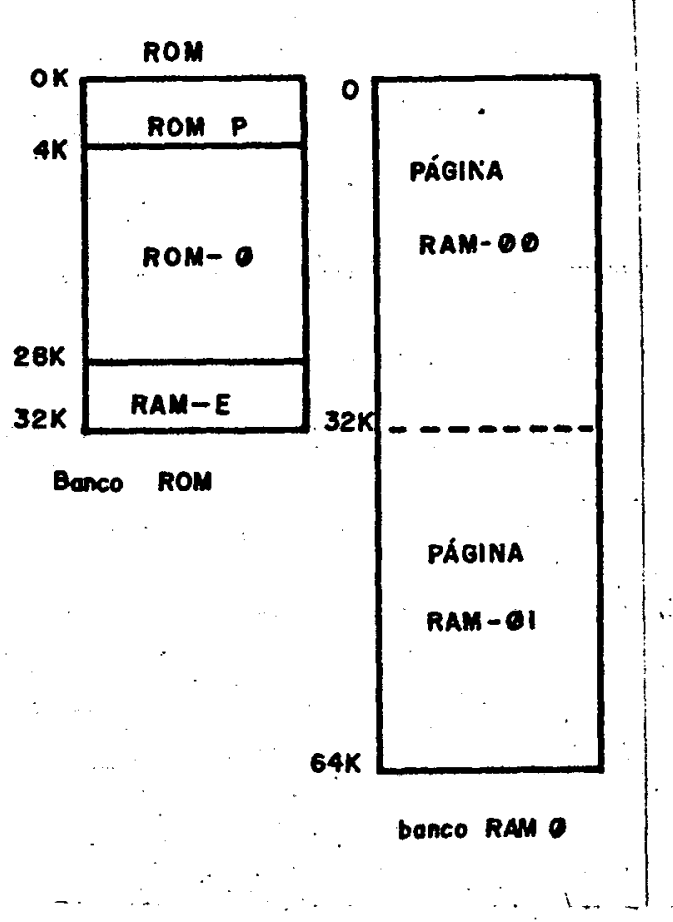

Figura 2.2 - Esquema conceitual do chaveamento dos bancos de memória.

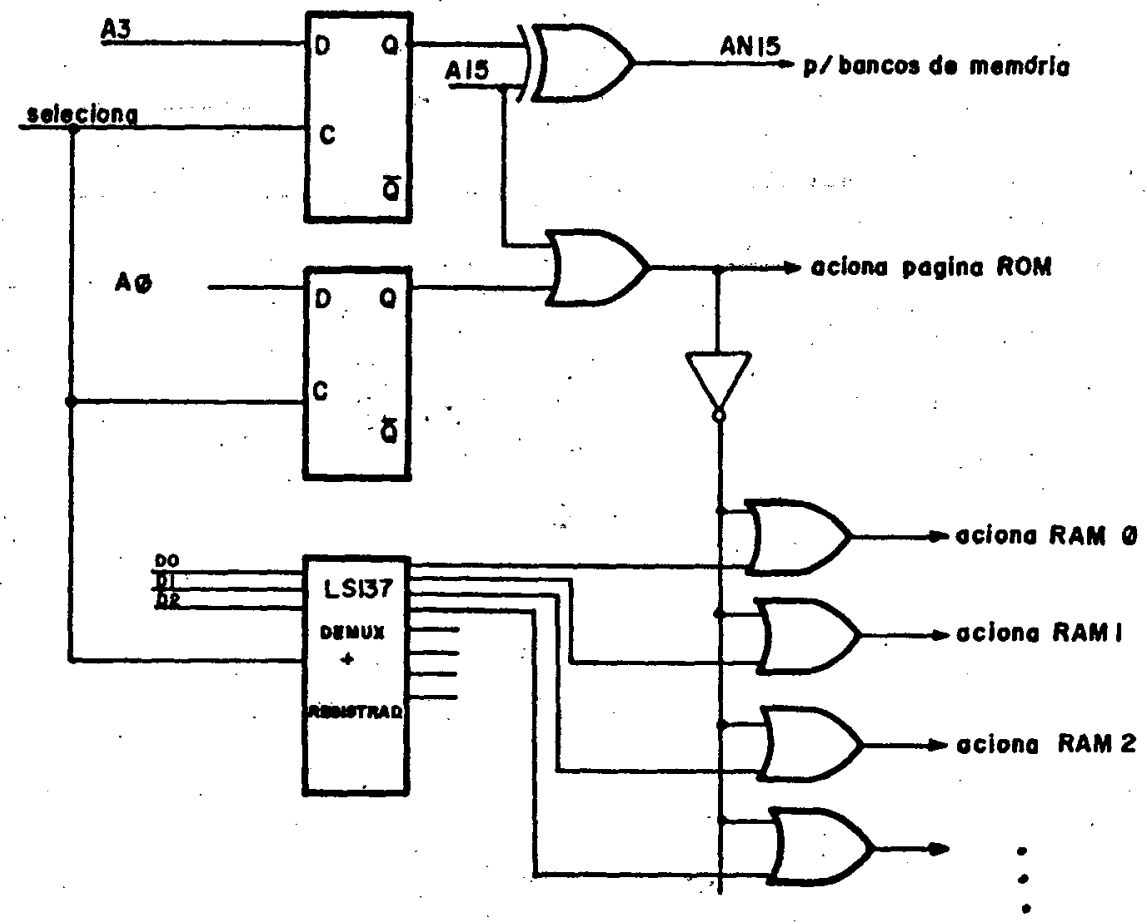

Figura 2.3 - Circuito logico do chaveamento dos bancos de memoria. 
A pagina ROM somente pode ser acessada na faixa de endereco de 0 a $32 K$, de maneira que quando essa página esta ativada, ela ocupa a primeira metade do espaco de enderecamento do processador 280 , sendo a segunda metade ocupada ou pela pagina RAM-0 ou pela pagina RAM-1. Duando a pagina ROM nag esta ativada, as paginas RAM-0 e RAM-1 ocupan cada uma delas uma metade do espaco de enderecamento do processador 280 , podendo a qualquer momento qualquer uma delas ocupar a primeira ou a segunda metade desse espaco.

A. pagina ROM tem o espaco de enderefamento de 0 a 3 KBytes ocupados pelo bloco RDM-p, o espaco de 4 a 27 KBytes pelo bloco ROM-0, e o espaço de 28 a 31 KBytes pelo bloco RAM-e. 0 Bloco ROM-p conten todas as rotinas que permitem a comunicafo com o processador central, as rotinas de acesso ao terminal de video, e se a estaço estiver conectada a unidades de disquete ou impressora locais, tambem as rotinas de acesso a esses perifericos. 0 bloco ROM-o tem armazenado toda a parte de gerenciamento de arquivos do sistema operacional CP./M, sendo incluido 1 todo o CCP e BDOS (vide seggo 5.2.). D bloco RAM-e é usado" como a memória de trabalho das rotinas gravadas nos blocos ROM-p e ROM-O. 
2.3.2 - Memoria do Processador Central.

A memoria do Processador Central segue um esquema semelhante a de uma Estaço de Trabalho com a diferenca principal que podem existir ate 8 bancos de Membria de Escrita e Leitura de 64 KBytes cada um. Cạda um desses bancos é constituldo ta duas paginas de 32 KBytes cada uma, sendo possivel que se acssse qualquer um dos 8 bancos qualquer instante, porem somente um deles de cada vez. duando um determinado banco esta ativo, qualquer uma de suas duas paginas pode estar ocupando a primeira ou a segunda metade do espaco de enderecamento do processador 280 , porem năo possivel ativar paginas de dois bancos diferentes simultaneamente. Damesma forma que em uma Estacro de Trabatho a página ROM pode substituir a página que esti ocupando a primeira metade do espaco de enderecamento do processador. Esse : squema conceitual pode ser visto na. figura 2.4 .

Dessa forma, as rotinas gravadas na pagina ROM, podem acessar qualquer pagina de qualquer banco, pois quando a página ROM esta ativa basta selecionar o banco que contem a pagina desejada e posicionar essa pagina para ocupar a segunda metade do espaco de enderefamento. Assim, pode-se pensar que existem na realidade 16 paginas de Memoria de Escrita e Leitura de 32 KBytes cada uma, que podem ser acessadas individualmente pelas rotinas gravadas na página ROM. 


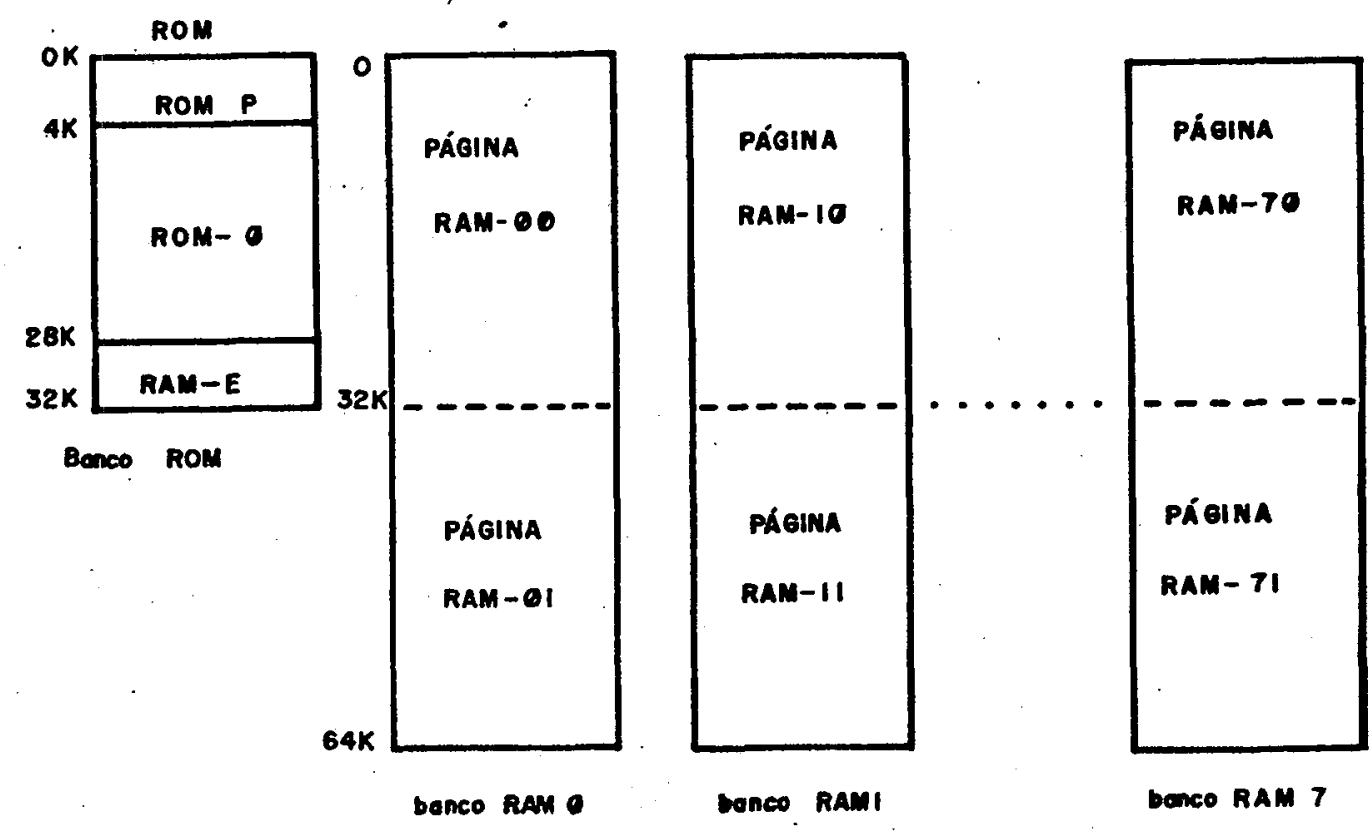

Figura 2.4 - Esquema conceitual de chaveamento de memória do Processador Central.

No bloco ROM-p da płgina ROM do Processador Central, estao gravadas as rotinas de comunicapao com as unidades de disquete e impressora e as rotinas de acesso a um porto serial auxiliar de comunicaço do sistema. No bloco RoM-0 estao gravadas as rotinas de comunicacro com as Estaçes de Trabalho, as quais operam efetuando uma varredura nas Estaçes de Trabaltio para verificar posslueis pedidos de acesso oriundos de cada Estaca de Trabalho, e também as rotinas de gerenciamento do cache descritas na seço 4.8. D bloco RAM-e é usado como a memória de trabalho das rotinas gravadas nos blocos ROM-p e ROM-0. 
2.3.3. - A Comunicaço entre as Estacŏes de Trabalho e o Processador Central

Cada Estaço de Trabalho comunica-se com o Processador Central atraves de um porto paralelo de 8 bits constituido por uma pastilha 8255 operando em modo de acesso bidirecional. D protocolo de comunicaça implementa quatro instruçós de alto nivel, sendo que todas as instruçes sempre soo originadas na Estacgo de... Trabalho, sendo entgo atendidas pelo Processador Central.

Todas as instruçes seguem uma sequencia de tros fases: 1 - Inicializaço da comunicaço. A Estaça de Trabalho envia ao Processador Central um pedido de acesso, constituldo de um Byta que indica qual a operacăo solicitada;

2 - Transferencia dos pargmetros do pedido. Uma vez que o Processador Central aceite o pedido de comunicaço, a Estacaro de Trabalho envia os pargmetros (ou dados) do acesso solicitado;

3 -. Resposta do Processador Central. Consiste na transmissgo pelo Processador Central dos dados resultantes da solicitaça pedida, e em um byte de estado final da comunicaço.

As instruçós implementadas através desse protocolo sao as seguintes:

Leitura de un registro de 128 Bytes do disco;

Escrita de um registro de 128 Bytes em disco;

Escrita de um caracter na impressora;

Informa disponibilidade de impressora. 
2.3.4 - Mecanismo de Transferencia de Dados entre as Estac8es de Trabatho e Processador Central

Para que se possa manter uma taxa de transferencia de dados elevada eritre cada Estaço de Trabalho.e o Processador Central, é usada a técnica de interrupcaso baseada na linha de interrup̧ro nao mascarável ("-NMI") do processador 280 e na geracgo de sinais de pedido de acesso a dados ("Data Request") e pedidos de finalizaço de transferencia ("Interrupt Request") desenvolvida em [MP_83]: Para que essa tecnica possa ser usada, um dos processadores que esta se comunicando gera un sinal de -Data Request" para cada Byte que ele transmite ou recebe, e executa uma instruço "HALT." Ho final de uma comunicaço, cada processador gera um sinal de "Interrupt Request", o qual fica ativo ate que o outro pracessador solicite um estado da comunicaço. Apds gerar o sinal de "Interrupt Request" o processador fica livre, finalizando a comunicaço. Os sinais de "Data Request" e de "Interrupt Request" de um processador geram um sinal de "-NMI" (interrupcro nåo mascaravel) no outro processador sempre que aquele executar uma instrucao "HALT", dessa forma tirando aquele processador do estado parado em que a instrucgo "HALT" o havia colocado ao mesmo tempo em que sincroniza a operaço dos dois processadores. A figura 2.5 mostra como o sinal de "NMI" de cada processador egerado. Os sinais "IBF" "OBF" gerados pela pastilha 8255 indicam respectivamente se a "Buffer de Entrada" ou o "Buffer de Salda" dessa pastilha 
contém um byte de dados. A direço de entrada ou salda é vista com relaçăo antrada ou salda de dados do processador central, o qual indica a direcăo em que as transferencias devem ocorrer através da Linha "Seleciona Direcăo". Quando ativada, essa i inha usa o valor da linha "Do" para indicar a seleçáo. o valor da linha "D1" indica se e o inicio ("D1"=0) ou o fim ("D1"=1) de uma transferencia. A porta OU que gera o sinal de "NMI" garante que esse sinal somente ocorrerá se o prọcessador estiver em "HALT".

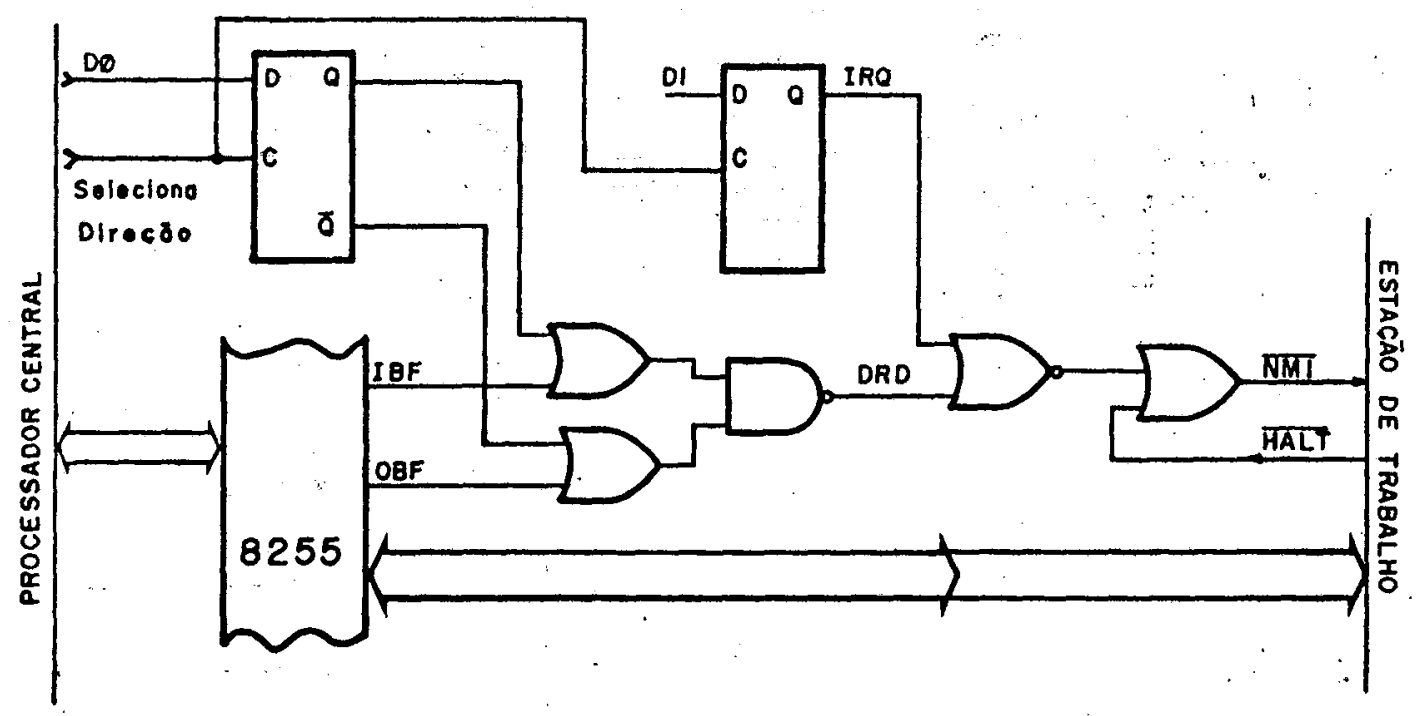

Figura 2.5 - Geraça de sinal "-NMI" em cada processador.

Dessa forma, ao iniciar uma comunicacăo uma Estaço de Trabalho envia ao Processador Central um byte que indica qual é a instrucgo de comunicacao que ela quer solicitar e entra em estado de "HALT" até que o Processadar Central leia esse byte, liberando a Estaça de Trabalho. A seguir, dependendo de qual é essa instrucaro, agora conhecida pelos dois processadores, ambos executam uma transferencia de dados sincronizada pela geraca de dados e sinais de "Data Request" até que a instruço termine, com a geracaro de sinais de "Interrupt Request". Esse ultimo sinal é 
usado com o propósito unico de impedir que um processador fique bloqueado pelo outro por ter havido algum erro na transmissa de algum byte durante o laco de comunicacaro.

Para avaliar a taxa de transferencia de dados desse esquema de comunicaço pode-se analisar, por exemplo, a instrucăo de leitura de um registro de 128 bytes de disco, solicitada por uma Estaça de Trabalho. Essa instruçăo ex executada com a Estaça de Trabalho enviando para o. Processador Central a Byte $01 \mathrm{H}$ a a seguir aguardando que a rotina de varredura do processador Central verifique que essa Estaço de Trabaliho esta solicitando a instrugro numero um. Com isso, ambos os processadores passam a executar uma rotina em conjunto, em que a Estafádo Trabalho envia para o Processador Central 1 Byte contendo o numero da unidade de disquete requisitada," 2 Bytes contendo o namero da trilha e 2 Bytes contendo o numero do setor que deve ser lido. 0 numero do setor é um namero logico indicando setores de 128 bytes, tal como é implementado pelo CP/M.: Caso o disco indicado possua setores com um numero diferente de bytes, a transformaço desse numero lógico para o setor fisico real e efetuado pelo gerenciador de memória cache, no Processador Central. Por fim, o Processador Central envia para a Estacăo de Trabalho um byte indicando o resultado da leitura $(0$ sempre indica que nă houve erro), e os 128 Bytes do setor lógico solicitado. O trecho de programa que executa essa ultima transferencia é o seguinte:

No Processador Central:

ORG $66 \mathrm{H}$

- No endereço de atendimento da 
interrupgà "-NMI",

RETN

; coloca-se a instruça para

iretornar ao programa interrompido

LD HL, ENDBUF ; Move para o registrador HL o iendereço do setor já na memória.

LD $\quad$ B , 128

; Move para o registrador B o

inúmero de Bytes a serem

itransferidos.

LD C, PORTO

- Move para o registrado $C$ o ;endereco do porto de comunicaço ;com a estaço em apręo.

A : DUT I

; Transfere o byte apontado por HL. ipara o porto indicado en $C$, ; incrementa $H L$, decrementa $B$ e ; coloca os bits da palaura de esta; do de acordo com o conteudo de $B$.

HALT - Para o processador até ocorrer iuma interrupcă "-NMI".

JP $\quad N Z, P$

; Se:o registrador B năo chegou a jzero, voltar ao endereço " $A$ ".

LD $A, \quad 0$

; Carrega o registrador A com 0 .

OUT (INTR), A

; Gera um sinal de "Interrupt

;Request " para a Estaço de iTrabalho em apreco. 
Na Estaço de Trabalho:

$\begin{array}{ll}\text { ORG 66H } & \text {; No endereco de atendimento da } \\ & \text {;interrup̧ăo "NMI", } \\ \text { RETN } & \text {; coloca-se a instrucăo para } \\ & \text {;retornar ao programa interrompido }\end{array}$

LD HL, ENDBUF ; Move para o registrador HL o ienderefo de onde o registro deve iser lido

LD B, 128

- Move para o registrador B o inumero de Bytes a serem irecebidos.

LD C, COMM ; Move para o registrador C o iendereço do porto de comunicaço ; com o Processador Central.

A: IN I

; Recebe o byte lido pelo porto ;indicado em $c$, e armazena o byte ;no endereco indicado por $\mathrm{HL}$ i incrementa $H L$, decrementa $B$ e ;coloca os bits da palaura de esta; do de acordo com o conteudo de B.

HALT - Para o processador até ocorrer iuma interrupcro "-NMI".

JP $\quad N Z, A$ ; Se o registrador B năo chegou a 


$\begin{array}{ll}\text { LD A, } 0 \quad & \text { izero, voltar ao endereco " } A " . \\ \text { OUT (INTR),A Carrega o registrador A com } 0 . & \text { i Gera um sinal de "Interrupt } \\ & \text { iRequest" para o Processador } \\ & \text { iCentral. }\end{array}$

Descontando o tempo de inicializacăo dos registradores B, $[$, eHL, verifica-se que o tempo principal gasto na execucao dessa rotina consiste na transmissă dos 128 bytes atraves das instruç8s: INI, HALT, RETN e JP NZ, A; que sao executadas uma vez para cada byte transmitido. Considerando que a sincronizacgo grasseira feita logo pela primeira instruço HaL é a respectiva espera da geraço do sinal "Data Request" pela instrufgo DUTI (OU INI) do outro processador, em cada ciclo do laco irá ocorrer um atraso de no máximo um ciclo de "clock" para o atendimento da interrupcăo. Entro o tempo maximo para a tranismissgo de um byte é seguinte:

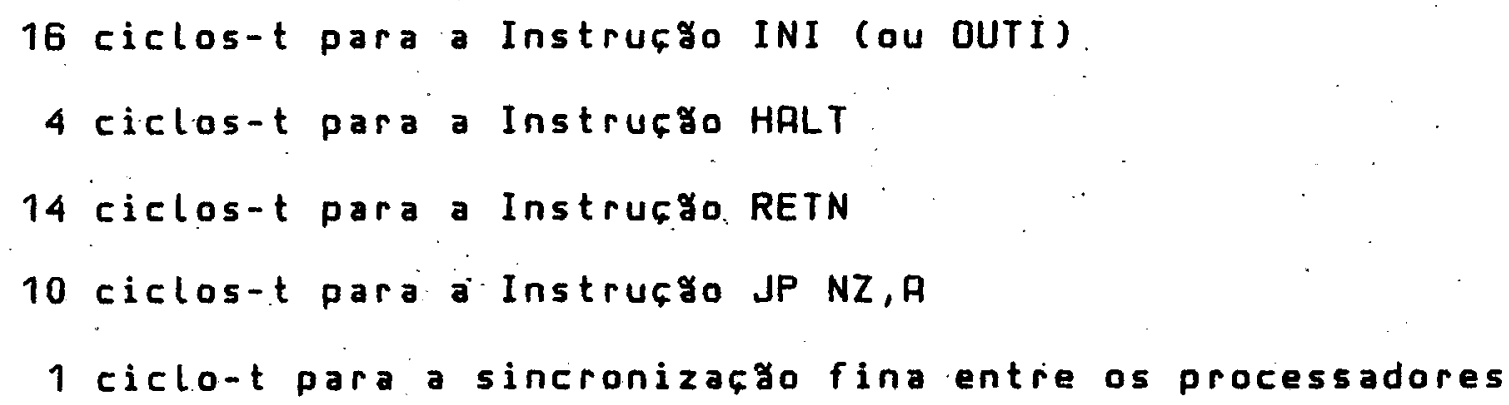

num total de 45 ciclos-t do processador Z80. Como a arquitetura implementada usa uma frequencia de "Clock" de $4 \mathrm{MHz}$, cada cicla-t tem uma durafgo de $250 \mathrm{nS}$, o que resulta em 11.250 ns para cada Byte transmitido. Isso garante uma taxa de transferencia de 88,8 
KBytes por segundo entre dois processadores, o que é uma taxa mais alta do que a mais alta transferencia de dados com unidades de disquete, a qual corresponde a 67 KBytes por segundo, quando se trata de disquetes de 8 polegadas operando em Densidade Dupla. Logicamente o atraso imposto pela rotina de varredura do Processador Central, a existencia de conflito de tempo de acesso quando um processador deve esperar a Processador Central atender a outras Estaços de Trabalho, a necessidade de leitura do disco pelo Processador Central antes que o setor possa ser

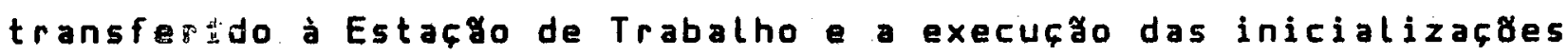
e transiarencia de parametros diminuem a taxa de transferencia efetiva. Porem, a maior velocidade de transferencia entre processadores do que a de transferencia entre um processador e disco, aliada ao fato de que existe uma memória cache bastante ampla no Processador Central fazem com que o tempo de resposta, quando o setor pedido já se encontra no cache, seja em geral methor to que o de acesso direto a unidades de disquetes locais.

2.4. - Conclusores

Com a crescente reduço de custo dos sistemas de processamento baseados em microprocessadores e o aumento da confiabilidade em sistemas descentralizados, o numero de aplicacoes que tem se aproveitado desses avancos também tem crescido muito. Essas aplicagres văo desde o acesso distribuido a recursos mais caros de um sistema de computacyo, até os recentes avancos em sistemas de quinta geraço que se aproveitam 
fortemente da associaço entre muitos microprocessadores para atingir o desampenho necessario [MU_86].

A arquitetura utilizada descrita na sefgo 2.3, tem como um dos objetivos permitir que varias aplicacoses compartithem unidades de disco e impressora.

De acordo com o estudo relatado neste capltulo, esse sistema pode ser caracterizado camo um sistema descentralizado, que pode ser multiusuario (se o sistema operacional o for) e que admite multiprocessamento. Quanto a ser ou năo um sistema distribuldo, isto deve ser analisado segundo cada uma das conceituaç̃es apresentadas. Essa classificaço envolve tambem o software (sistema operacional) que essa arquitetura esta preparada a executar.

Segundo Enslow, as caracteristicas de hardware dessa máquina permitem classifica-la coma um sistema distribuido e, tal como esta a implementaça do sistema operacional atualmente, essa classificaço permanece valida para o sistema como um todo.: No entanto, se o sistema operacional executar parte na estacro de trabatho e parte no processador central, como é sugerido no capitulo 6. (segro 6.3.3), entgo como un todo essa arquitetura segundo Enslow nă seria Classificada como um sistema distribuldo, pois Enslow exige que cada processador possa operar de maneira autonoma.

Segundo Fathi e Krieger, a arquitetura utilizada pode ser classificada como um sistema distribuido.

Ja segundo Tanenbaum e Van Renesse, a arquitetura como un todo seria classificada como um sistema em rede, uma vez que um usuario numa estacgo de trabalho so poderia acessar arquivos locais a outra estaço de trabalho através de solicitaço 
explicita, violando o conceito de transparencia exigido. Porém, se forem considerados apenas uma estacgo de trabalho e o processador central, entao essa dupla seria considerada um sistema distribuldo.

Dado o fato de que a maior partedas caracteristicas que qualquer autor apresenta para que se classifique um sistema como distribuido sa satisfeitas pelo sistema de processamento de dados en apreco, no restante deste trabalho esse sistema sera considerado como um sistema distribuldo. 


\section{ALocaÇKO E PROTEGKO DE ARQUIVOS}

\section{1. - Introduço}

Uma das mais impartantes funcres que o sistema operacional multiusuario deve executar a alocaço e protecaro de arquivos. A alocaço consiste em tomar as decisoles e fazer as operaç8es necessarias para manter em um dispositivo fisico vários arquivos e prover os meios para permitir a leitura, gravaca e modificacaro de cada arquiva. Deixadas a cargo do sistema operacional, as operactes fisicas necessarias e a escolha da estrutura dos dados real mantida no dispositivo ficam transparentes ao usuario.

A funcro de protecro de arquivos consiste em permitir que no arquivo sejam realizadas apenas operacobes que năo danifiquem o proprio arquivo e nem os demais arquivos mantidos no mesmo periferico. Alem disso, deve prevenir a acesso de usuários ngo autorizados, em sistemas que tenham essa necessidade. Deve-se notar que ambas: as funcốes săo necessărias qualquer tipo de sistema, seja ele monousuário ou multiusuario. 
3.2 - O Problema da Identificaço de Usubrio

Uma pessoa que desejar usar o sistema deve ser identificada como usuario qualificado ou nao. Se o usuario é qualificado, deve ser identificado como tal e ter seu acesso ao sistema garantido. Se nao o for, tal pessoa nao podera ter acesso ao sistema.

Uma técica amplamente adotada para identificar o usuário é solicitar-lhe logo de intcio a sua "identificaca de usubrio" ("user identification"). Para uma maior protecăo do sistema, garantindo a veracidade da identificacáo fornecida pelo usubrio, é usada a técnica de sanha ("password"), juntamente com a sua "identificaço de usuário". Assim, um procedimento comum pode ser exemplificado pelo sistema RSX-11M da Digital, onde o seguinte dilólogo pode ocorrer:

\section{User Name? none \\ Password? senhy}

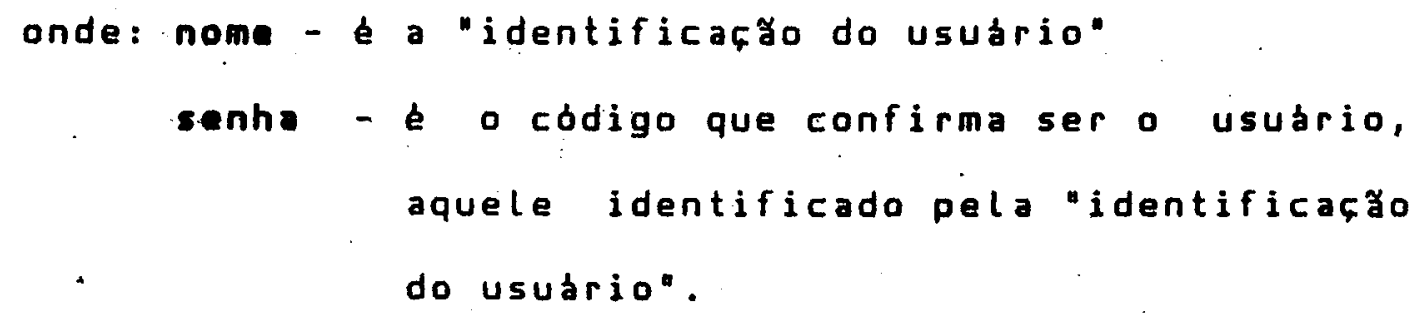

O codigo usado na "senha" năo ecoado no terminal para evitar que outras pessoas possam ve-lo, tornando-se conhecedoras de um código que deve ser conhecido apenas do usuario de direito. 


\title{
3.3 - Formas de Acesso a Arquivos
}

Um ponto importante é identificar o que o usuario deseja fazer com um arquiva, que tipicamente pode ser uma das seguintes coisas:

\author{
Executar um programa; \\ Ler un arquivo; \\ Escrevar ou Atuallzar um arquivo; \\ Eriar um novo arquivo; \\ Apagar um arquivo; \\ Alterar o privilegio de acesso a determinado arquivo.
}

Cada um desses tipos de acesso, pode ser potencialmente perigoso, dependendo do tipo do sistema. Por exemplo, em um sistema financeiro, năo poderia ser permitido a qualquer usuario executar um programa que imprima.cheques de pagamento ou cartas de crédito. Similarmente, ha inameras situacôes em que e indesajácl que usuarios possam indiscriminadamente ler ou escrever. registros ou arquivos. Apagar arquivos é anda mais crltico e deveria ser permitido a um numero ainda menor de usubrios; e finalmente, a capacidade de alterar o privilégio de acesso associado a um arquivo deveria ser outorgada apenas ao gerente do sistema. Assim deveria(m) ser restringido(s) o(s) modo(s) de acesso permitido(s) a cada usuario, dependendo do grupo de trabalho a que pertence co que pode ser obtido pelo seu numero de usuario), e de sua tarefa especifica (que pode ser-lhe 
atribuldo atraves de privilégio de acesso a arquivos).

D próximo passo seria o de associar esses tipos de acesso aos usuarios do sistema; mais genericamente, pode-se associar os modos a:

um terminal,

um programa de aplicą̧̃o,

um usuário individual,

um grupo de usuarios,

alguma combinaço dos acima.

Yourdan, em [YO_72] apresenta um metodo simples de implementar esta forma de protecăo de arquivos, denominada Acesso por Choves. Esse método utiliza-se de bits, nos quais é armazenado $1(5 \mathrm{im})$ ou 0 (năo) como resposta a determinada combinacgo do tipo de usuario e tipo de acesso (ver figura $\hat{3} .1$ ). 


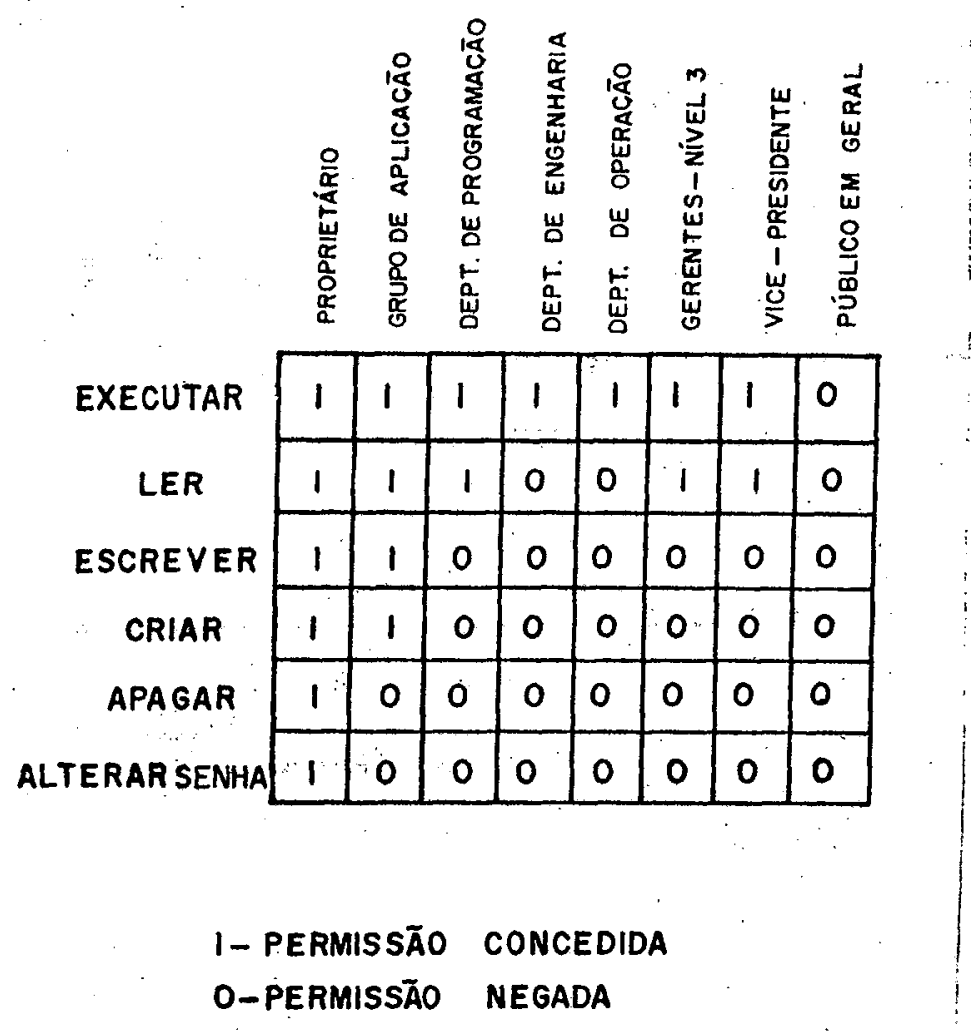

Figura 3.1 - Metodo de acesso por chaves para protecăo de arquivo

Desde que os usubrios sa farfados a identificar-se quando desejam usar o computador, o sistema operacional sabe quem ele é, que terminal está usando a que grupo de usuarios ele pertence. Duando o usuario emite algum comando a partir de seu terminal, um programa de aplicacao processa o comando e tenta acessar arquivos. Antes de ser permitido o acesso a um arquivo, o sistema operacional deve ser informado de como o usuario tenciona usar o arquivo. Agora o sistema operacional deve verificar o acesso por chaves e comprovar que o acesso está permitido. Conforme [YO_ 72$]$, esse acesso e usualmente verificado quando o 
arquivo é aberto pela primeira vez pois, a partir de entao, o sistema operacional possui informacgo suficiente para saber se as futuras solicitaças de leitura, escrita, criaço, ou destruicăo de um arquivo sqo licitas.

Ha ainda o problema de protecao a chamadas de determinadas instrucốs de maquina; pois dessa forma, un usuario nă qualificado poderia acessar blocos flsicos de dados, alterando seu grau de privilégio ou a propria proteça do arquivo. Essa protecăo deve em parte ser implementada em hardware.

\section{4 - Drganizaço de Arquivos}

A gravaço e recuperaço de dados em dispositivos de armazenagem de dadas, tipo disco ou fita magnética, pelo sistema operacional, deve ser feita de forma a atender a todos os requisitos do usuario, de uma maneira eficiente e o mais transparente possivel ao usuário.

$\therefore$

Para atender a todas as necessidades, alem dos dados do usuario, possivelmente espalhados em varios arquivos, o sistema operacional mantém também dados que permitem o mapeamento dos arquivos lógicos nos arquivos flsicos, caracterizando a organizacaro da estrutura de arquivos, que normalmente é chamada de estrutura de diretario de un dispositiva.

A seguir algumas técnicas mais usuais apresentadas em [YO_72], sergo discutidas, procurando ressaltar sua situaço frente aos seguintes critérios: 
a) Minimizar os acessos ao dispositivo - 0 sistema operacional deve atingir o dado requisitado com o minimo de acessos à estrutura.

b) Minimizar o espaco requerido pelo arquivo - além dos dados do usuario o espaco requerido para um arquivo deve conter poucas informaçoses do sistema e, ao mesmo tempo, alocar apenas o espaco necessario.

c) Vulnerabilidade do sistema a falhas - capacidade de evitar perdas totais no caso da estrutura de diretorios ficar danificada ou parte do meio fisico armazenador ficar inacessivel.

d) Facilitar alteraços em arquivos jä existentes - a extensăo de um arquiva já criado deve ser possivel sem. gastos excessivos de tempo espaço, bem como deve ser possivel a recuperaço do espaco deixado por um arquivo apagado ou encurtado.

\subsection{1 - Estrutura de Diretório}

D sistema operacional mantém uma estrutura que armazena informaços sobre cada arquivo contido no dispositiva, informacõos essas que podem ser:

nome do arquivo, 


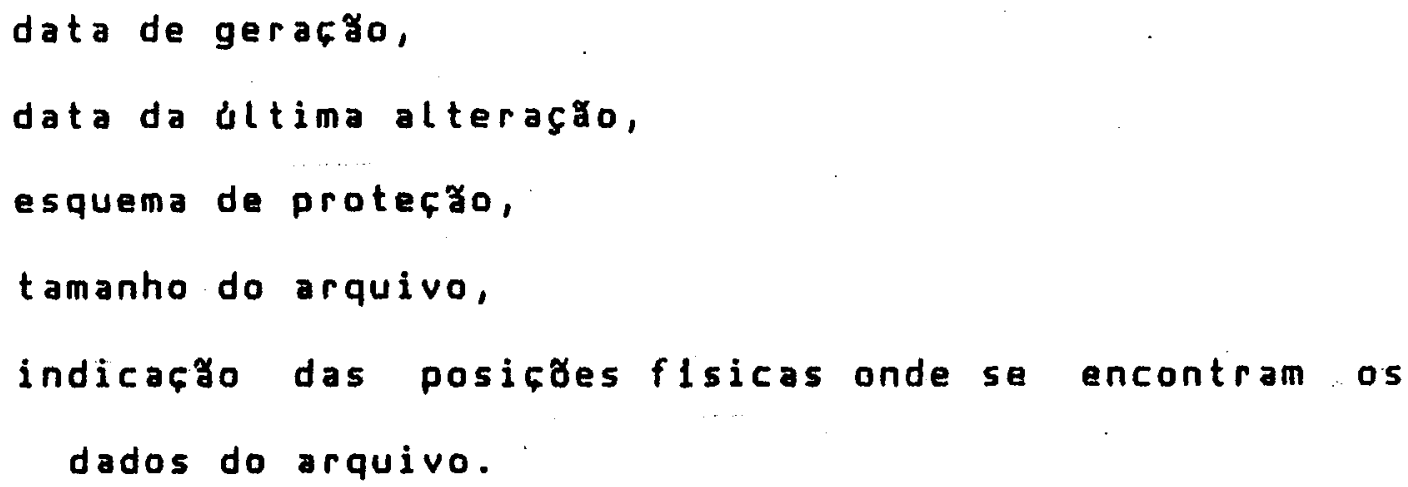

A estrutura de diretorio altera-se principalmente na maneira en que as informaçóes s\%o estruturadas para acesso e na forma como um arquivo pode ser identificado pelo usuario.

Uma maneira de se implementar uma estrutura de diretorio a através de árvore, onde cada nóda arvore é um diretorio (arquivo) e cada ramo é uma entrada de diretorio que aponta para outro diretório ou para um arquivo de dados. A raiz da árvore é chamada de diretorio principal [5H_74].

\subsection{2 - Armazenagem de Arquivos Através de Listas}

Entre as informaços de um arquivo armazenadas no diretorio, encontra-se os ponteiros para os blocos de dados do arquivo. Esses ponteiros săo armazenados em campos especificos do diretorio sendo, portanto, de numero limitado. Para minimizar a alocaço de espaço que ngo será usado a área abrangida por cada ponteiro năo deve ser grande, o que leva à existencia de um grande numero de ponteiros.

A técnica de armazenagem atraves de listas consiste em manter-se no diretorio um pequeno numero de ponteiros para blocos 
de dados, e um ponteiro para uma celula que contenta mais ponteiros para blocos de dados mantendo uma estrutura semelhante a da celula original no diratorio (ver figura 3.2). Dessa forma, - arquivo pode ser estendido indefinidamente [YG_85]. Em. geral todos os blocos de dados so estruturalmente semelhantes e repetem as informaçóes do arquivo contidas no diretório.

Essa técnica nao impore restriç̋es às operaçes de leitura ou escrita nem a extensa ou tamanho maximo do arquivo. Alem disso, por manterem todos os blocos de dados, a identificaço do arquivo permite uma facil recuperacăo do arquivo em caso de pane do sistema ou perda do diretorio.

A grande desvantagem desse método reside no fato de que - namero de acessos a disco para recuperar um dado no inicio ou no final do arquivo năo a mesmo, pois o numero de acessos a disco aumenta conforme mais celulas vao sendo encadeadas a lista. Esse problema, no entanto, pode ser minimizado se o sistema operacional dispuser de espaco de memoria ("buffer pool"), que possa armazenar um namero razodvel dessas celulas.

Dutra desvantagem é o espaço em disco perdido, já que há grande quantidade de informacaro repetida. Tambem quando é necessario fazer-se alguma alteraço no diretório ha uma demanda maior de tempo, pois todas as celulas da lista precisam ser alteradas. 


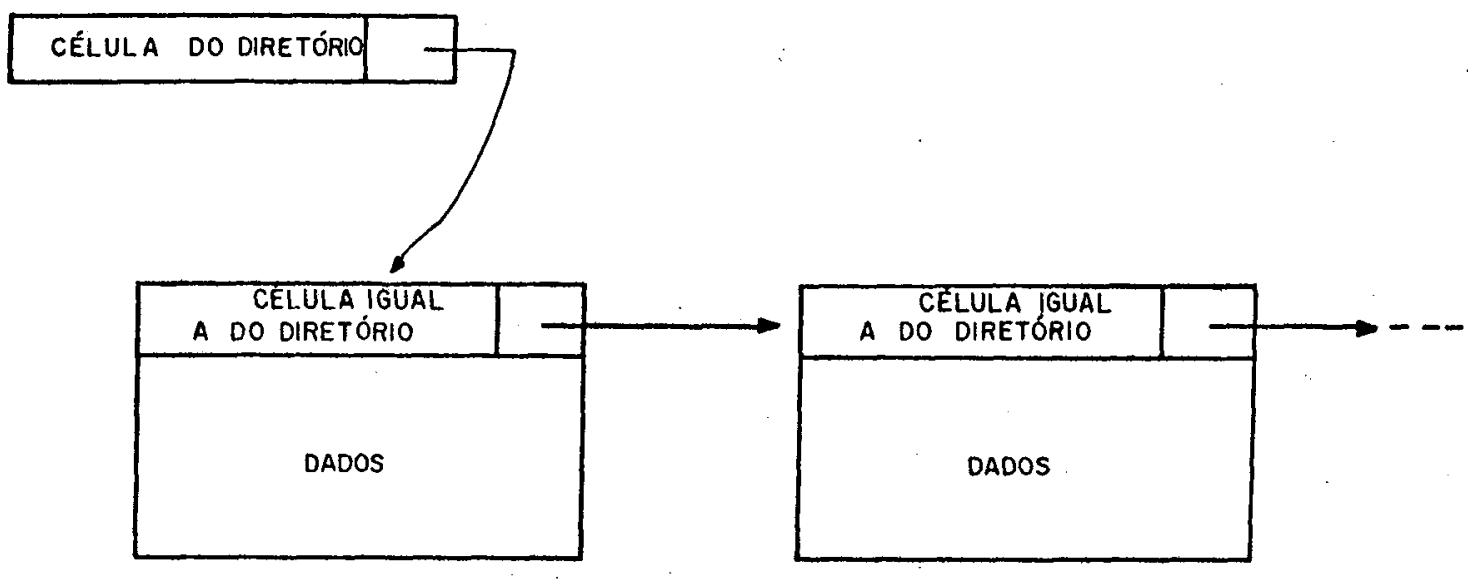

Figura 3.2 - Estrutura de armazenagem de arquivos atraves de listas.

\subsection{3 - Armazenagem por Pre-Alocaço de Arqúivos}

As operaçes basicas que o sistema operacional oferece sáo criar ou apagar um arquivo, e ler ou escrever qualquer de seus registros. Considerando apenas essas operacốs, ao criar-se um arquivo, devem ser fornecidas todas as informaçes sobre ele, tais como: seu tamanho, metodos de acesso, etc. A alocacaro efetiva do espaco necessário a um arquivo pode ser feita na operaca de abertura ou conforme o arquivo seja preanchido com operaços de escrita; neste ultimo caso, náó necessário o conhecimento prévio do seu tamanho na operaço de abertura.

Na técnica de pré-alocacaro de arquivos, o espaco fisico necessario a un arquivo alocado na operacgo de abertura e esse espaco deve ser continuo. A previsao do tamanho do arquivo deve 
ser maximizada de modo a comportar alteracobes feitas sobre o mesmo.

Essa técnica apresenta varias vantagens, a principal das quais a eficiencia de acesso. Presta-se bem a armazenagen de arquivos sequenciais. Para arquivos de acesso aleatorio com registros de tamanho fixo, esta a melhor técnica a ser utilizada, pois ngo há necessidadade leitura de registros intermediarios para recuperaço de ponteiros que indiquem a posifăo do registro, porque essa posicgo pode ser obtida diretamente atraves da posiço do inlcio do arquivo e do tamanho do registro.

No entanto, a técnica de pré-alocacăo de arquivos apresenta alguns problemas sérios caso o tamanho do arquivo na. seja seguramente conhecido a priori. En primeiro lugar o desconhecimento do tamanho exato leva a um desperdicio de espaco ao tentar-se maximizar o espaco solicitado injcialmente. Tambem é comum ra se poder automatizar essa operaca. Outro problema. surge na tentativa de estender-se um arquivo ja existente, quando pode ser necessaria a relocaca do proprio arquivo ou de um conjunto de outros arquivos. 0 mesmo problema ocorre quando da criacão de un novo arquivo para o qual ainda há espaca, mas nenhum espaca continuo que o contenta. 
0 disco magnetico é dividido em setores de tamanto fixo, nos. quais arquivos syo armazenados. A tecnica de mapa de bits assinala quais os setores que estro sendo usados. A maneira usual de implementa-lo é alocar um numero de bits, igual ao numero de setores no disco ligar o bit associado ao setor quando ele a alocado; e destigar o bit, quando o setor é Liberado.

Esta técnica apresenta diversos resultados importantes:

a) 0 espaco em disco é eficientemente usado. Há sistemas que exigem que o tamanho do arquivo seja especificado de antemaro, isto e, o tamanho do arquivo definido quando ele e aberto pela primeira vez, maximizando-o para que nao ocorra falta de espaco, o arquivo necessite ser retécado com o novo tamanho; mas tal procedimento faz com que geralmente sobrem pequenos espacos, que dificilmente seriam usados por outros. arquivos. D mapa de bits permite recuperar esse espaço perdido.

b) D menor espaco utilizado por um arquivo (mesmo vaziol é o de um setor.

c) Quando o sistema operacional faz uma solicitacăo de escrita sao alocados os primeiros setores vazios encontrados; ou é utilizado algum algorltmo de alocacgo mais adequado que na permita fragmentacgo 
demasiada do disco.

d) Uma requisiço de escrita sempre será atendida até que o disco esteja completamente cheio.

3.5 - Acesso 5 imultaneo a um Arquivo

Em sistemas que possuem processamento paralelo pode ocorrer que mais de um processo altere o contedua de uma drea, de dados comum peritencente a um arquivo, gerando um grave problema, - da incompatibilidade de informacao. Dessa forma, é necessario proteger o dado contra acessos simultaneos. A essas areas de dados, denominamos de Segro Critica ou Reglyo Critica.

Nas proximas secóes, apresentaremos duas soluçes para a proteço da seço critica.

\subsection{1 - Semáforo}

Un semáfora consiste em uma varibuel " 5 ", que indica se - acesso a uma secaro critica está permitido ou bloqueado em um dado instante, e um conjunto de duas operacŏes sobre ela [SH_74]:

Uma operacaro denotada por "p(5)": que permite a um processo o acesso a seço critica controlada por " 5 " e a bloqueia para outros processos; e una operafao 


denotada por " $v(5)$ ", que libera o acesso à secao
critica.

Quando um processo solicita acesso pela operaço p(S), esta solicitaço sera atendida se nao houver outro processo na seço critica. Neste caso, o semaforo o indicará e o processo ficará em espera até que a seço critica esteja livre.

A variável " 5 " tambem é um dado que pode ser acessado por varios processos; logo tambem éma regigo critica. Dessa forma, as operacócs $p(5)$ e $v(5)$ deven ser feitas de tal forma, que sejam indivisiveis, ininterruptiveis. Assim, nunca havera inconsistencia devido a varibuel " 5 ".

\subsection{2 - Monitor}

A técnica de semaforo étil quando as operacoses p(5) e $v(5)$ poden ser ininterruptiveis e nao passiveis de erro. Em sistemas que nao possam atender a alguma dessas caracteristicas, outra tecnica deve ser usada. Esse é o caso de sistemas distribuldos onde a comunicacgo entre processos é passivel de erros, e sistemas de multiprocessamento com memória compartilhada, onde uma simples operaca de troca de conteddo de um registrador com uma posifgo de memória, apesar de ser uma ánica instruça de máquina de um processador (ininterruptivel), é vista pela membria como um acesso de leitura um de escrita independentes e, portanto, interruptiveis.

Nesses casos, a soluforo é permitir que apenas um 
processo possa acessar as variácis que se pretende proteger. [GU_BO]. Quando mais de uma tarefa necessitar de dados compartilhados, cria-se uma outra tarefa que desempenha sobre esses dados qualquer operacgo que as tarefas originais necessitem. Dessa forma, quando uma das tarefas originais necessita operar na seça critica, ela ofaz solicitando à nova tarefa que o faca por ela. Cria-se, assim, uma proteço em torno da secao critica, permitindo-se que apenas uma tarefa tenha acesso a ela. Essa tarefa e conjunto de dados que ela protege é denominada Monitor.

Deve-se notar que o monitor consiste en essencia do conjunto de todas as funçres sobre um conjunto de dados, além dos proprios dados.

3.6 - Exemplos em Alguns Sistemas Existentes

$3.6 .1-C P / M$

O sistema operacional CP/M (Control Program for Micros) foi desenvolvido para gerenciar as operaçes de entradalsalda de varios tipos de máquinas. Dessa forma, e constituldo de duas partes principais, a saber:

BDos (Basic Disk Dperating System): que mantém a estrutura de diretorio e supervisiona a alocacao de espaco em disco; 
BIOS (Basic Input/Dutput 5ystem): que efetua as transferencias de entrada/salda ao nlvel de maquina.

0 BDOS e sempre o mesmo para qualquer maquina onde o EPIM seja implantado. Ja o BIOS é desenvolvido especificamente para cada máquina pelo seu fabricante.

No BIOS estyo definidos parametros que especificam o acesso a disco para cada maquina especificamente, tais como:

area de disco utilizada para sistema;

capacidade maxima de cada arquivo;

tamanho minimo do bloco alocado de cada vez;

numero maximo de arquivos por diretorio, ete.

0 BDOS mantém astrutura basica de arquivos, seguindo - seguinte padra:

\footnotetext{
uso do mapa de bits para alocacgo de espaco livre em disco;

cada arquivo mantém no diretorio uma estrutura contendo identificaça do arquivo e um conjunto de até 16 ponteiros para blocos de dados usados pelo arquivo.
}

o CP/M, a partir de sua versao 2.0 , permite a identificafaro do usuario dono de um arquivo, admitindo a extensaro para sistemas multiusuário (MP/M - Multicontrol Program for Micros).

A estrutura de diretorio do CP/M nas permite subdiretorios; no entanto, fornece condicoes para especificar se - arquivo do sistema ou nao permite proteger um arquivo contra modificacro e apagamento. 
No capitulo 5 é apresentada uma descriczo mais detaltada sobre as estruturas internas do CP/M.

3.6.2. - coos da Cromemco

0 Sistema Operacional coos C Cromemco Disk Operating System] [CR_81] tem seu sistema de diretorio compativel ao do sistema operacional CPIM versgo 1.3. Em cada entrada para o diretorio já especificado se orquivo está protegido contra escrita, leitura ou eliminaço; e os outros blocos de dados que comprem o arquivo.

Utiliza-se também da tecnica de mapa de bits para especificar quais setores do disco estao sendo usados.

D CDOS năo prove recursos para proteço de arquivos de vários usuários.

0 CDOS consiste basicamente de uma extensao do sistema operacional LP/M versao 2.2, onde foram adicionadas, entre as mais importantes, as seguintes caracterlsticas:

a) maior facilidade para gerenciamento de arquivos extensos em disco rigido;

b) maior capacidade de protecăo a arquivos;

c) configuraça dos parametros de disco pelo usuario (tamanho de bloco, numero de entradas en um diretbrioj. 
3.6.3. - UNIX

- sistema operacional UNIX tem o seu sistema de diretório implementado atraves da estrutura de arvore [RI_78b]. 0 acesso e feito a partir de un diretorio central, chamado de "raiz" (root), atraves do qual sgo encontrados todos os demais nós e arquivos. Um diretório visto tambem como um arquivo e, portanto, pode pertencer a outro diretorio.

Cada usuário possui um diratorio de seus arquivos, podendo também criar subdiretorios que contentam arquivos que, a criterio do usuário, seja conveniente mantelos juntos.

Quando um arquivo e criado, ele marcado com a "identificacgo do usuario" que o criou. Tambem associado ao arquivo um conjunto de dez bits que autorizam, independentemente, a dono do arquivo, a membros de seu grupo ou as demais usuários: a ler, escrever ou executar o arquivo.

5e o décimo bit de um arquivo contendo um programa que deve ser executado está ligada, o sistema considera para executálo a "identificacaro do usuario" que criou o arquivo. Essa mudanca da "identificacgo do usuario" éfetiva somente durante a execucăo do programa. Com esse recurso, é possluel que programas privilegiados possam acessar arquivos de outra forma inacessiveis aos usuarios que os executam [RI_78a].

Para o. UNIX, as arquivos sao tratados apenas como uma sequencia unidimensional de bytes e nă como um conjunto de registros. Nenhuma outra estrutura de arquivos é reconhecida pelo sistema. Os arquivos sao ligados em qualquer lugar laté de forma mútipla na hierarquia de diretorios. Diretorios sao simplesmente arquivos nos quais o usuario somente pode escrever 
atraves de programas que mantem a estrutura do proprio diretorio $\left[T H \_78\right]$.

D espaco livre de um disco mantido por uma lista ligada indicando os blocos livres e năo por mapa de bits. Cadabloco na lista aponta para até 50 blocos lives e para opobrio bloco. Mantendo em cada bloco ponteiros para ate 50 outros blocos livres, minimiza-se o acesso a disco en relaço ao uso de listas simplesmente ligadas.

3.6.4. - R5X-11M da Digital Equipment Corporation

0 sistema RSX-11M usa paradisco uma estrutura de arquivo denominada "Files-11" que organiza o disco mantendo nele fundamentalmente os seguintes arquivos [RX_79b]:

1. Arquivo de "checkpoint";

2. Arquivo de Indices;

3. Arquivo de alocaço de armazenamento;

4. Arquivo de blocos defeituosos;

5. Arquivo de diretório principal.

A estrutura do arquivo é definida pelo arquivo de Indices e pelo arquivo de diretorio principal que passaremos a descrever.

- numero de arquivos de diretório em um disco depende do numero de usubrios desse disco. D "Files-11" distingue discos 
para um unico usuário e para varios usuarios. Para discos de um Unico usuario existe apenas o arquivo de diretbrio principal (Master File Directory - MFD), que aponta para cada arquivo do usuario. Para discos de varios usuarios existe um MFD e um arquivo de diretorio do Usubrio (User File Directory - UFD) para cada usubrio. D MFD aponta para todos os UFD e cada UFD para os arquivos de un usuário (Ver Figura 3.3).

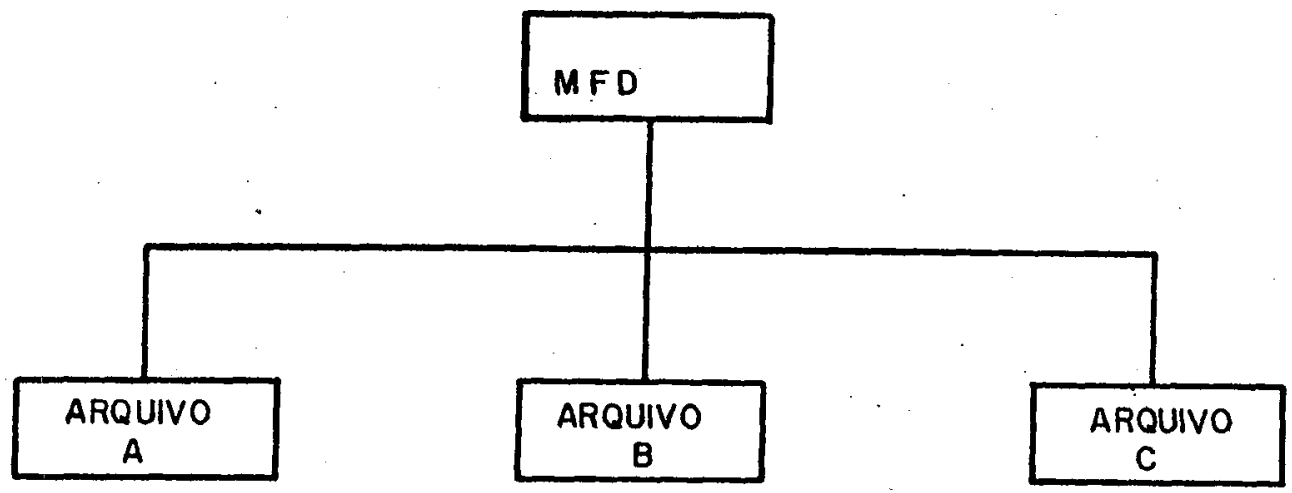

Figura 3.3a - Estrutura de diretorio para discos de un tunico usuário

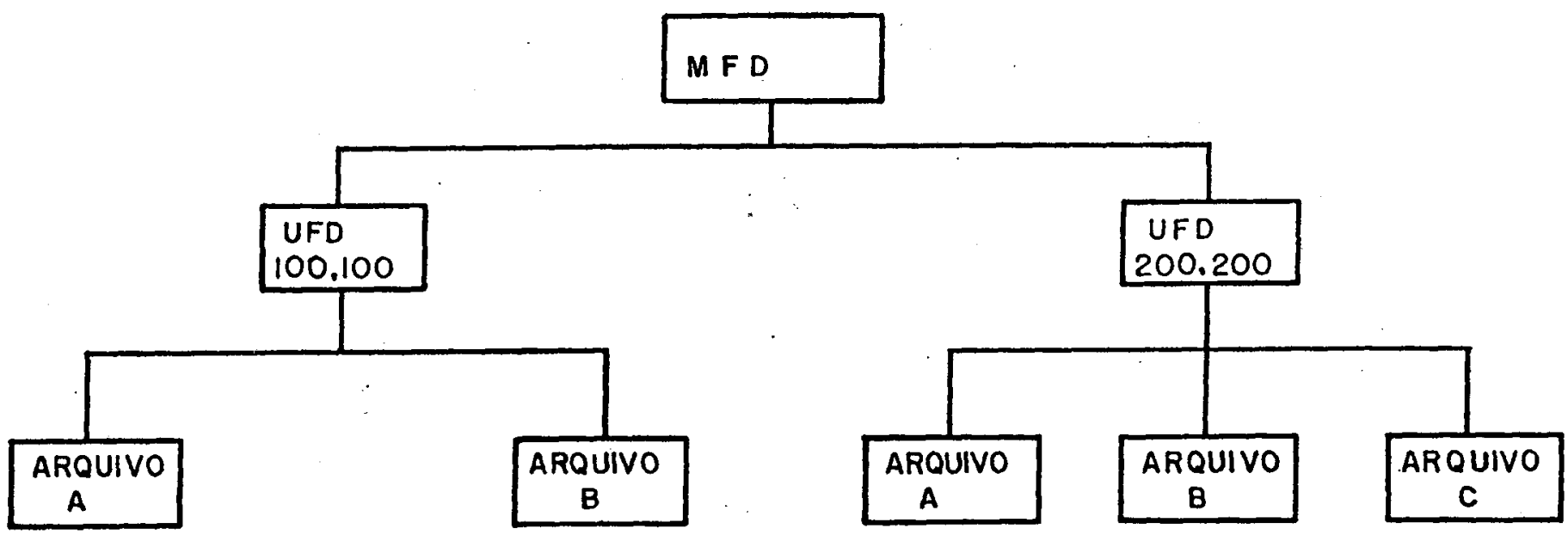

Figura 3.3b - Estrutura de diretório para discos de varios usubrios 
Un arquivo de diretorio e constituldo de entradas de diretorio consistindo da identificafgo do arquivo, numero do arquivo e numero de sequencia.

0 arquivo de indices contem informaço sobre o disco como um todo e informacyo sobre cada arquivo de usuario. Como informaço geral do disco esta armazenado o bloco de inicializacoo do sistema cque pode ser usado para carregar o sistema), o bloco de informaçes do disco (nome do disco, dono do disco, numero maximo de arquivos aceitos, etc), os blocos do mapa de bits do disco, e os cabecalhos: de todos os arquivos contidos no disco.

Os cabecalhos contem todas as informaçes necessárias a cada arquivo: estas informacóes que no trabalho que esta sendo apresentado, constituem o que chamado normalmente de diretario.

Cada cabecalho contém tres áreas:

trea da cabecalho-que repete a informaço do arquivo de diretorio.

tras de Identifleacto - que contém todos os dados relativos ao arquivo, tais como: nome, data de criacyo, versă, proteço, dono do arquivo, etc.

trea de mapeamento - contém as informacốs para acesso aos blocas de dados do arquivo. 
A protecaso do arquivo é feita para quatro classes de usuarios:

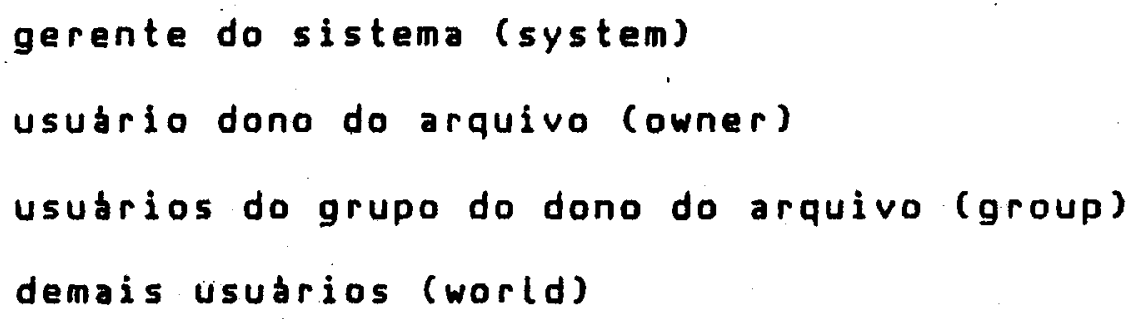

Para cada classe de usuario, o arquivo é protegida contra escrita, leitura, extensao e apagamento [RX_79a].

Um usuário e identificado através de um numero de identificaço do usuario (user identification code - UIC) que é constituldo de um namero de grupo e um namero de usuario dentro do grupo. O acesso de um usuario ao sistema feito atraves de seu UIC e de uma senha de confirmaça.

\section{7 - Canclus 8es}

Nesse capitulo foram vistas algumas formas de identificaço e proteço de arquivos bem como a importancia de tais mecanismos.

Das técnicas mais usuais de alocacaro de arquivos, a mais usada é a alocaço por Mapa de Bits. Isso deve-se ao fato de que tal técnica permite um aproveitamento melhor do espaco em disco, utilizando ao maximo a fragmentacão deste espaco. Essa técnica utilizada nos sistemas CP/M, CDDS, R5X-11M.

$$
\text { Já o sistema UNIX usa a técnica de listas-ligadas para }
$$

indicar o espaco livre em disco. Apesar de que nessa técnica o 
tempo de acesso a um arquivo depende grandemente do tamanho do arquivo e da posiço em que se encontra na lista.

A técnica de armazenagem por pre-alocaço de arquivos, é bastante recomendada quando se trata de recuperar arquivos sequenciais pais. o acesso é imediato. Mas tambem possui uma grande desvantagem, que é desperdicio e fragmentaça de espaco em disco.

E' claro que cada tecnica oferece vantagens e desvantagens devendo-se em cada caso avalia-las antes da implementaço do sistema de alocaço de arquivos.

Os mecanismos de proteça a arquivos dos sistemas CP/M, cDOS e UNIX sgo bastante parecidos, sendo que o CP/M e o CDOS possuem proteça apenas contra escrita. Ja no UNIX, quando um arquivo é criado, é associado ao arquivo um conjunto de dez bits para protecaro do arquivo.

Já o sistema RSX-11M, por ser um sistema multiusuário, possui um sistema de protefro mais sofisticado, separando a protecăo do arquiva da protecaro de acesso a sistema de computacto. Dessa forma; pode-se perceber claramente o pulo que se da em sistemas de proteço quando se passa de um sistema operacional monousuário ( $[P / M, C D D S)$, para um sistema operacional multiusuário (UNIX e R5X-11M). 


\section{ESTRUTURA DE CACHE}

\section{1 - Conceito Geral}

0 desempenho dos computadores estó grandemente relacionado ao tempo de acesso à memória. Assim, uma maneira de melhorar tal desempenho e diminuir ao maximo o tempo de acesso à membria. Mas, memórias mais rápidas sao tambem mais caras e o custo da reducro do tempo de acesso à membria nem sempre é compens ador.

Dessa maneira, torna-se atraente a construcaro de uma memória bastante rapida, pequena, mas de alto custo, usada como intermediaria entre a Unidade Central de Processamento (UCP). e a memoria principal [GR_85]. Nessa memoria seriam armazenadas temporariamente as informacốs da memoria principal mais utilizadas (ou que pelo menos acredita-se que sejam) pelo computador. Esta memória é denominada Coche.

O cache, sendo pequeno, tem custo pouco elevado. Assim, comparado ao tamanho da memória principal, a relaço custoldesempenho éminimizada, pois se a memória cache for bem utilizada, o tempo de acesso à memória é bastante reduzido.

Para uma comparaço entre esses tempos, cita-se o exemplo dado em [SM_82], no qual encontram-se os valores de 300 a 600 nanosegundas para acesso à memória principal em computadores 
de alta velocidade, tais como Andahl 470 V/7 e 0 IBM 3033, e de 50 a 100 nanosegundos se é usada a membria cache.

Uma caracteristica importante da memoria cache que ela é constituida por blocos de tamanho fixo que espelham blocos de igual tamanho da memória principal. Todo o acesso a alguma posica de memória que esta também armazenada no cache, feito posicro de memória no cache, sendo por isso feito na velocidade da memória cache [RE_84]. [aso um acesso seja feito a uma posiço que năo está na memoria cache, a memoria principal é acessadaj diz-se entăo que ocorre uma falha de acesso ao cache. Para maximizar o uso do cache deve-se procurar manter no cache a maior quantidade possivel das informacous que seră a curto prazo necessarias, e para isso deve-sa buscar ao mesmo tempo um valor otimo tanto do tamanho do bloco de transferancia do cache, quanto do namero de blocos; a tambem encontrar um algoritmo de troca dingmica das informaçoses do cache, para mante-lo a cada instante com as informaços realmente necessarias imediatamente.

Quando é necessario armazenar dados na membria principal, pode-se adotar duas tecnicas [YE_83], [ZU_76], ERE_84]:

a) escrita-simultanea (write-through);

b) escrita-posterior (write-back).

Na tecnica de escrita-simultanea todas as escritas s\%o feitas diretamente na memoria principal; caso o dado encontre-se também no cache, será também atualizado ali. Nessa condicăo garante-se que a memoria principal nunca contem dados obsoletas. Na tecnica de escrita-posterior cada operacao de 
escrita solicitada pelo programa feita apenas no cache. auando e feita a substituiço de un bloco no cache, caso o bloco a ser substituido tenha sido modificado, este tambem deve ser reescrito na memória principal.

\section{2 - Tamanho da Memória Cache}

- tamanho da membria cache geralmente ditado por dois fatores: o custo do cache e o desempenho esperado da maquina. 0 cache nao deveria ser tao grande que representasse un custo fora de proporgago para o aumento do desempenho nem deveria chegar ao outro extremo deser tao pequeno que năo resultasse em um ganho significativo.

Dessa forma, pode-se geralmente assumir, que levando-se em conta apenas a taxa de falha (miss ratio) - que é o quociente entre o número de falhas de acesso ao cache pelo numero total de acessos ao cache - quanto maior for o tamanho da memória cache menor sera a taxa de falha e melhor o desempenho da máquina. Isto leva necessidade de se especificar uma relacăo entre o tamanho do cache a taxa de acerto (hit ratio)-que é quociente entre - numero de acessos bem sucedidos ao cache pelo namero total de acessos ao cache. Mas este um problema bastante delicado, desde que a taxa de acerto varia com a carga e tipo de trabalho, e a arquitetura da maquina. Segundo Smith, em [SM_82], um cache que poderia produzir uma taxa de acerto de 99.8 porcento sob um programa em um PDP-11, chegaria a produzir uma taxa de acerta de noventa porcento ou menos em um IBM sob o sistema operacional 
MUS.

Este problema nao pode ser usualmente estudado usando simulacgo dirigida por rastreio porque a taxa de falhas varia tremendamente de programa para programa e somente um pequeno numero de rastreios pode ser analisados.

D tamanho de un cache varia muito como podemos ver pelos exemplos a seguir: PDP-11/70 (1 Kbyte); VAX $11 / 750$ e IBM 4331 (4 Kbytes); Andahl 470V/6, IBM 4341 a DEC VAX 11/780 (6 Kbytes); IBM 3033 e Amdahl 470/8 (64 Kbytes), NEC ACDS 9000 (128 Kbytes).

4.2.1 - Tamanho de Bloco de uma Memória Cache

A unidade de transferencia de informaça entre o cache e memória principal, a qual possui tamanhofixo, é denominada bloco ou linha [SM_82], [RE_84]. O bloco corresponde ao conceito de pagina, a qual a unidade de transferencia entra a memória principal e a memória secundbria em um sistema de memória virtual.

Como os blocos podem ser pequenos ou grandes, discutiremos suas vantagens e desvantagens a seguir:

Vantagens de blocos de tamanho pequeno:

a) 0 tempo de transmissao de um bloco pequeno entre a memória principal e o cache é menor;

b) Se a máquina precisa esperar um tempo de transmissao 
completo, blocos menores săo mais adequados;

c) Um bloco pequeno contem um menor numero de informaçâes năo necessàrias.

d) Em cada transferencia, a chance de transferir para o cache informactes desnecessarias é menor.

Vantagens de blocos de tamanho grande:

a) 5 um numero maior de informaços será realmente utilizada, a busca em uma unica vez mais eficiente;

b) 0 namero de blocos no cache e menor, sendo mais facil gerenciar o conjunto de informaços sobre cada bloco (rotulos, estado de reposicgo, etc.);

c) Blocos grandes permitem poucos elementos por conjunto no cache, o que minimiza a pesquisa associativa;

d) Minimizam a frequencia de blocos cruzados, isto e, a ocorrencia de informaço espathada em mais de um blaco, mas que logicamente deveriam estar em um só.

Note que as vantagens citadas acima para blocos pequenos tornam-se desvantagens para blocos grandes e vice-versa. Para se escolher o tamanho do bloco émuto importante 
avaliar o seu efeito sobre a taxa de falhas. Mas o tamanho do bloco e apenas um dos fatores que atuam sobre a taxa de falhas. Dutros fatores sao a maneira como a informaço e utilizada qual a máquina considerada.

A variacao no tamanho dos blocos é bastante grande. Citamos por exemplo, que o PDP 11170 usa 4 bytes; o VAX 11/780 usa 8 bytes; O IBM usa 64 bytes e 0 IBM 3081 usa 128 bytes.

\section{3 - Algoritmos de Busca}

O algorttmo de busca é usado para decidir quando trazer uma informaço para o cache.

Em [5M_82] săo apresentadas duas alternativas:

a) Busca sob demanda: traz a informacaro quando ela é solicitada;

b) pré-busca: traz a informacao antes que ela seja necessária. Os algorltmos de pré-busca tentam prever qual informacăo sera necessária em breve, adiantando-se assim à solicitaço da informaço.

Resultados de simulaçoses com os algorltimos de busca sob demanda e pré-busca indicam que a pré-busca leva a uma diminuiça na taxa de falthas (miss ratio).

Para o algaritmo de pré-busca há tres problemas a serem Levados em conta:

a) quando iniciar a pré-busca; 
b) quais blocos serao trazidos;

c) qual o estado dos blocos trazidos por busca, com relaço a quando sergo substituldos.

Além disso, hà o pisco de poluiço docache, isto é, quando uma instrucaro de pré-busca traz grandes quantidades de informacgo que ngo să usadas tgo cedo quanto se esperava ou ngo săo usadas nunca. Nesse caso, há necessidade,de técricas de avaliaço mais sofisticadas.

Consideremos os tres tipos basicos de pre-busca:

a) pré-busca sempre: onde en toda referencia à memória, um acesso ao bloco i (para todo i) implica uma prébusca ao bloco $i+1$.

b) pre-busca sob falha: implica que a referencia a um bloco i causa uma pré-busca oo bloco $i+1$, se a referencia ao bloco i foi uma falha.

c) prébusca rotulada: a cada bloco j essociado um bit, chamado de robtulo, que é inicialmente zero. Quando o bloco ecessado por algum programa, esse bit recebe o valor um. Se o bloco é removido do cache, recebe o valar zero. Sempre que o rótulo de um bloco i passa de zero para um, havera uma prébusca do bloco i+1.

5mith, em [5M_82], compara os tres tipos de pré-busca citados acima e conclui que a pré-busca sempre e a pré-busca 
rotulada foram ambas bem sucedidas quanto à reducgo da taxa de falhas. A pré-busca rotulada tem ainda a vantagem adicional de requerer somente un pequeno aumento do número de acessos à memória para transferencia de blocos sobre a prebusca sob demanda. A taxa de transferencia equivalente para prébusca rotulada éprébusca sempre. Alem disso, a pré-busca sempre a rotulada reduzem a taxa de falhas em 50 a 90 porcento, em relaço a năo se utilizar a pré-busca.

No caso da pre-busca sob falhas o efeito bem menor, sendo que a reduço da taxa de falha menos da metade que a dos casos de prébusca sempre ou rotulada. Esse efeito era de se esperar, uma vez que a pre-busca sob. falha nada mais do que uma busca sob demanda, com o tamanho do bloco dobrado.

\section{4 - Algorltmos de Localizacgo}

Para a localizaça de um dado na memória cache, é necessária a comparacaro do endereco solicitado com os enderecos dos dados que estă no cache, necessitando-se entă, de uma busca associativa para localizar o bloco que contem o dado solicitado, se houver um encontro. Como memórias associativas grandes săo usuatmente muito caras e tendem a ficar lentas, o cache é geralmente organizado como um agrupamento de pequenas memorias associativas, cada agrupamento controlando un conjunto de blocos. Assim, somente uma das memórias associativas deve ser pesquisada para se determinar se a informaço esta presente no cache. Cada uma dessas memórias denominada conjunto e o numero de blocos 
por ela controlados é o tamanho do conjunto.

- algoritmo de localizacgo é usado para se determinar em que conjunto esta a informacao procurada.

D cache por si sob năo é uma memória endereçavel pelo usuario mas funciona como um "buffer" para a memória principal. Assim, para localizar um elementa no cache el...necessaria uma funço que mapeie na memória principal os enderecos do cache ou que pesquise o cache associativamente ou ainda uma combinacro das duas. D algoritmo de localizaço determina a funcăo de mapeamento dos enderecos da membria principal para a localizacaro no cache.

D algorltmo de localizaço mais usado é chamado mapeamento do conjunto associativo. Envolve a organizacăo do cache em conjuntos 5 de E elementos por conjunto (ver figura 4.11.
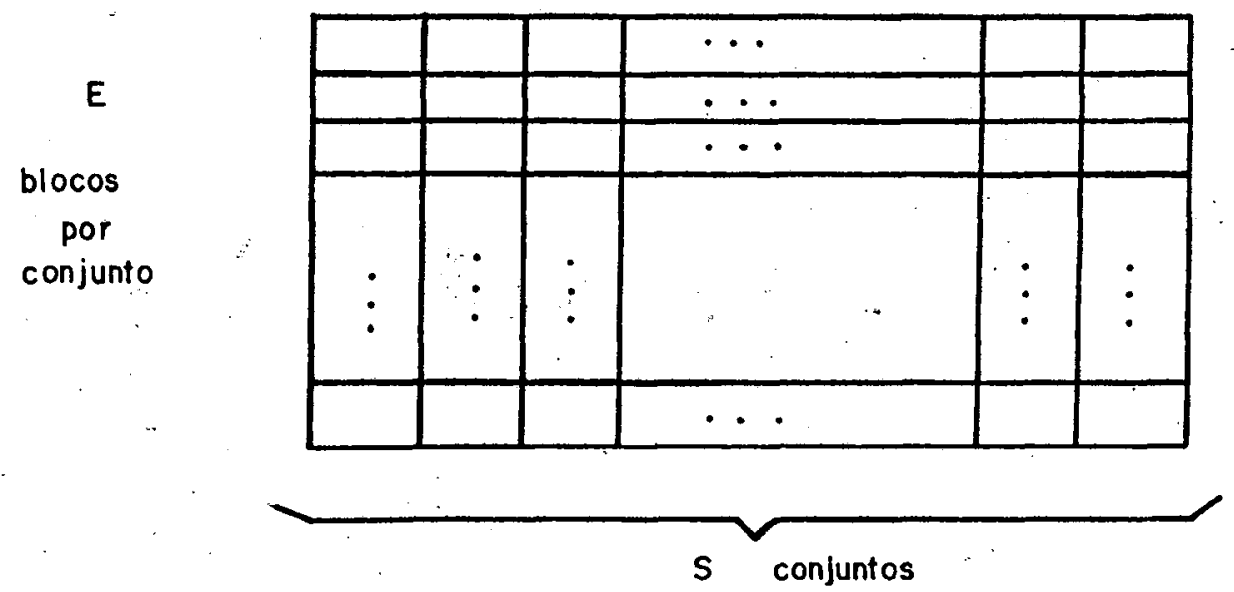

Figura 4.1 - Organizacăo do cache para o algoritmo de mapeamento do conjunto associativo.

Dado um endereço de membria $r(i)$, uma funço $f$ mapeia $r(i)$ no conjunto s(i) da seguinte forma: 


$$
s(i)=f(r(i))
$$

D algoritmo que utiliza a funfro de mapeamento mais simples e mais popular co conhecido como seleça de bit. o ndmero de conjuntos 5 escolhido como uma potencia de 2 (isto é, $S=2 * * k)$. Se ha $2 * * j$ bytes por bloco os j bits menos significativos selecionam o byte dentro do bloco e os bits j+1 até $j+k$ selecionam o conjunto (ver figura 4.2).

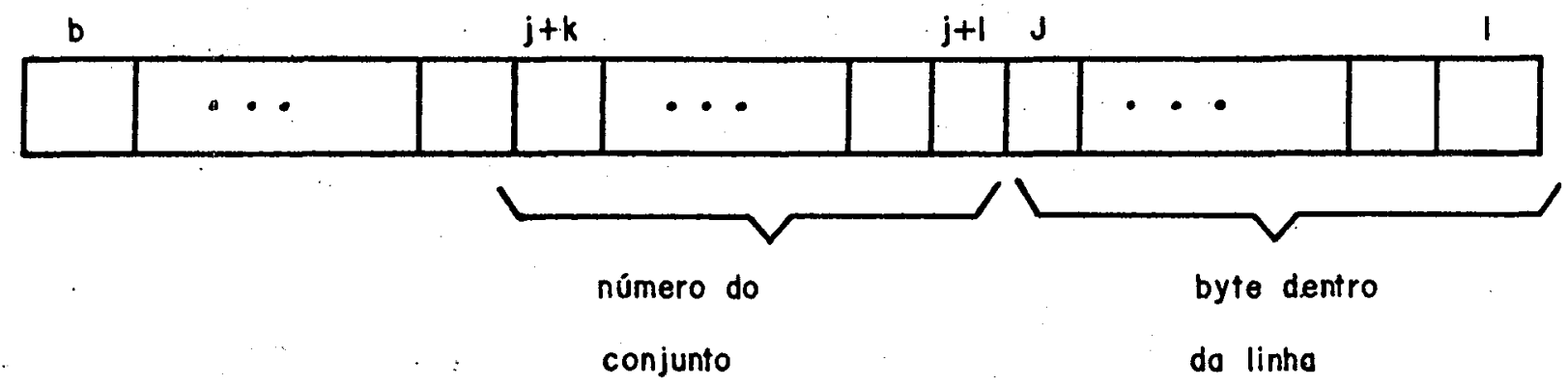

Figura 4.2 - Estrutura da palavra de endereço de memória para a funço de mapeamento por selecgo de bit.

Baseado em simulaçes realizadas, Smith sugere um número minimo de elementos por conjunto, de quatro a oito, para uma taxa de falhas aceitavel. Esse modelo faz com que a distribuifáo de blocos entre os varios conjuntos năo seja balanceada, podendo diminuir a taxa de utilizaço do cache. No entanto, como blocos de memoria consecutivos na memoria principal quase nunca estao num mesmo conjunto no cache, esse modelo 
apresenta a vantagem de permitir operacaro em paralelo de reposiço e consultas em blocos distintos para acesso de código (que normalmente sequencial), o que aumenta a eficiencia de técnicas de reposicionamento usando a pré-busca.

D algoritmo da selecao de bit e utilizado pela maior parte dos computadores atuais, ressaltando-se todos os da Amdahl e da IBM.

4.5 - Algorltmos de Reposifgo

Quando uma informaço solicitada pela UCP à memória principal, e o cache esta cheio, alguma informaço no cache deve ser substitulda.

Os algorltmos de reposicgo podem ser classificados em dois grupos:

(i) Algoritmos baseados no uso contra algoritmos ngo baseados no uso;

(II) Algoritmos de espaco-fixo contra algoritmos de espaco variável.

Algoritmos baseados no uso consideram as referencias feitas às informaças. Exemplo desse tipo de algoritmo, são o LRU CLeast Recently Used - substitui o bloco menos recentemente usado) a o LFU (Least Frequently Used - substitui o bloco menos frequentemente usado). Ja os algoritmos nă baseados no uso năo consideram as referencias feitas as informaços. Exemplos desse 
tipo de algorltmo şo o FIFO (First in, First out - primeiro entrar o primeiro a sair) e oleatorio.

Ds Algoritmos de espaco-fixo utilizam sempre unam quantidade fixa de memoria para um determinado processo. 5e algorltmo varia a quantidade de memória alocada a um determinado processo dito algorltmo de espaco variável.

o tamanho da memória cache fixo e geralmente muit to pequeno para guardar a conjunto de informaços de mais de processo. Por essa razor, acredita-se [5M_82] que algoritmos de espaço variável năo sejam convenientes para a membria cache.

Dessa forma, usam-se normalmente algoritmos de espacfofixo, cujos representantes principais sao o LRU, o FIFO $e$ o aleatorio.

Smith, en [5M_82], compara os algoritmo LRU e FIfFo. concluindo que a taxa de falhas é aproximadamente 12x maśar quando o algoritimo fIFO e utilizado. Mas é bom lembrar-se quee o algoritmo FIFO ou o. aleatório săo muito mais faceis de selres implementados que o LRU.

As maquinas da IBM usam o algoritmo LRU para reposiffro de blocos no cache [GR_85]. Assim. asseguram uma maior eficienccia de uso do cache. 
4.6. - Tipos de Implementacaa do Cache em Sistema de Multiprocessador.

\subsection{1 - Cache Privativo}

Em um sistema de multiprocessamento com cache privativo cada processador possui un cache individual que somente ele pode acessar.

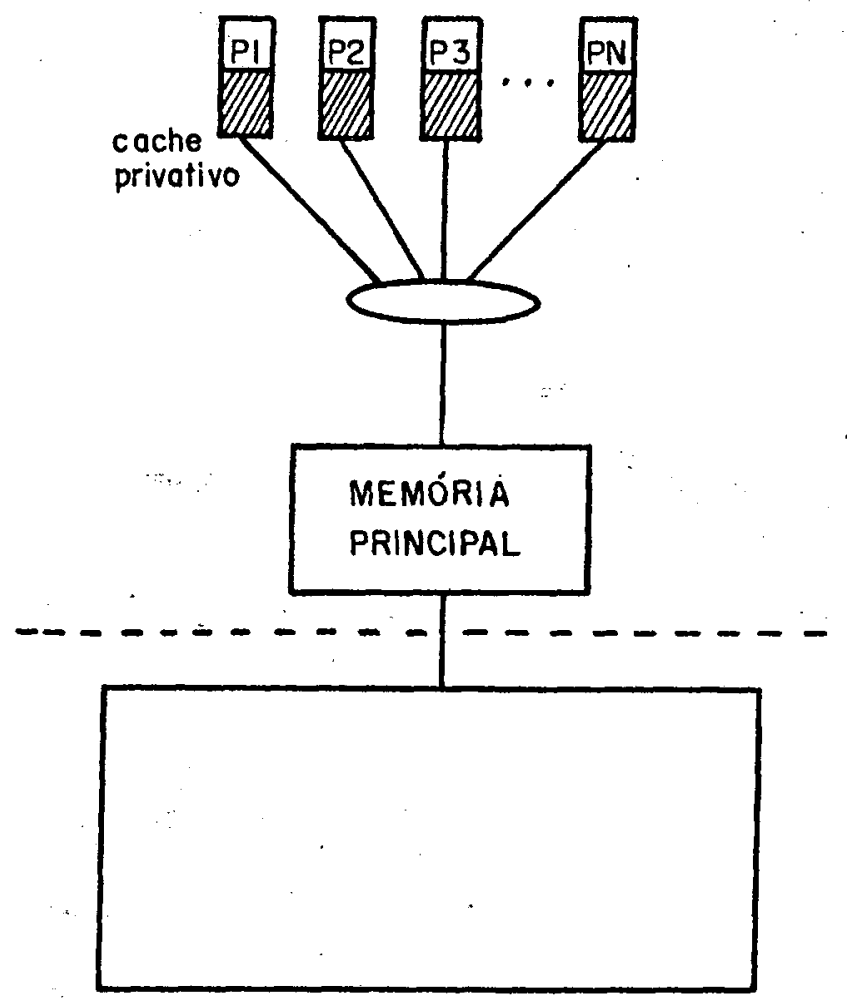

Figura 4.3 - Sistema de Multicache.

Infelizmente, o sistema de multicache mostrado na figura 4.3 causa um problema de coerencia de dados porque podem 
existir maltiplas cópias de um mesmo bloca da memoria principal em vários caches ao mesmo tempo [PA_82]. Qualquer modificacão em qualquer destas copias causaria un valor obsoleto do dado compartilhado pela memoria principal a cada un dos outros caches que contenham o mesmo bloco. Em geral, pode ocorrer um problema de coerencia sempre que um dado pode ser acessado por dois ou mais processadores.

Dutra desvantagem do cache privativo que certos recursos do sistema, tais como rotinas do sistema operacional, precisam ser copiados diversas vezes nas memorias cache quando forem solicitados por mais do que um processador [YE_83]. Assim, - tamanho efetivo total do cache diminui sua taxa de falha será maior.

4.6.2 - Cache Compartilhado

Para contornar o problema de coerencia de dados, podese restringir o modo de acesso multiplo a um dado a apenas um modo [YN_85]. Todos os processadores possuem agora un cache, que será entao compartilhado por todos (figura 4.4). 


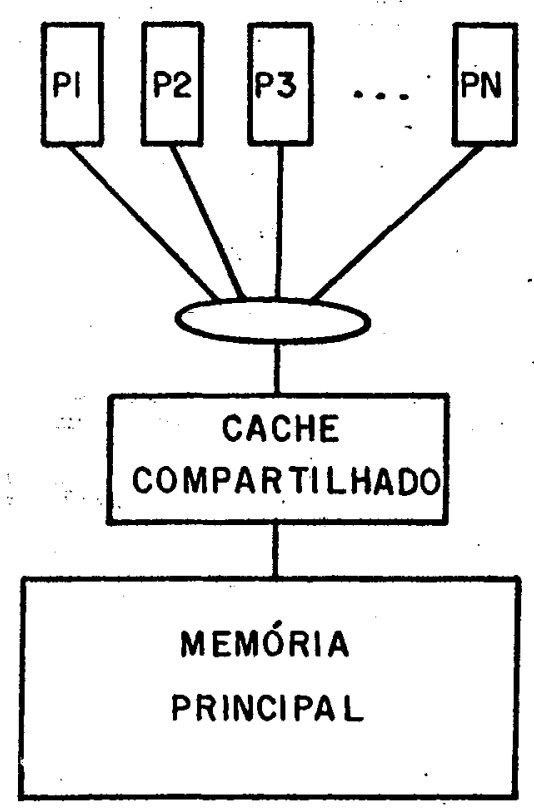

Figura 4.4 - $5 i$ stema de cache compartilhado.

0 sistema de cache compartilhado prove melhor utilizaço do cache do que o cache privativo devido ao compartilhamento dinamico de espaco e a presenca de apenas uma copia de bloco de memória no cache. Dessa forma, o tamanho efetivo total do cache compartilhado maior do que a do cache privativo e, portanto, sua taxa de falhas sera menor. A comunicaço entre os processadores é tambem facilitada pelo cache compartilhado. As desvantagens desse cache săa a dificuldade de implementaço a alta.taxa de acessos e de transferencia de dados entre o. cache e os vários processadores.

Exemplos de máquinas que usam o cache compartilhado sao as máquinas da IBM [GR_85]. 
4.7 - Cache para Dispositivos Periféricos

A mesma filosofia de cache usada para membria principal pode ser aplicada para a memoria secundaria, isto e, para as informacớes armazenadas, por exempl, o em disco, ou para outros dispositivos, como apresentado em [FU_B5] para impressoras de alta resoluço.

Em [BR_83], e destacada a necessidade de aperfeicoamento nos recursos de entradalsalda. Por exemplo: Um microcomputador acessando uma grande base de dados gasta ate 90 porcento de seu tempo esperando que transferencias em disco se completem, o que torna o sistema muito. Lento.

Uma boa técnica para melhorar o desempenho de um sistema é reduzir o tempo de espera para transferencias em disco. Tal sistema deveria incorporar técnicas como cache para setor em disco a area especial de diretorio (isto é, manter o diretório permanentemente na memória em area reservada exclusivamente para esse fims, para diminuir as atividades em disco tanto quanto possivel. O resultado final do uso de tais técnicas e que programas podem ser executados de 3 a 6 vezes mais rapidamente. D sistema operacional CP/M Plus é um exemplo tipico do uso destas técnicas [BR_83].

Todos os tópicos estudados para cache de memória, continuam validos em cache para dispositivos perifericos no entanto, cada caso deve ter um estudo particular.

A principio, pode-se dizer que o tamanho do bloco para 
- cache de dispositivos perifericos esta fortemente relacionado ao tamanho do registro flsico do periferico. Por exemplo, no caso de disco ou fita magnetica, o tamanho do bloco sera um meltiplo do tamanho do registroflsico da fita, ou do setor fisico do disco.

Un outro ponto importante que um cache de memória principal deve necessariamente ser implementado totalmente atraves de hardware dedicado, e que pode, portanto, usar algoritmos que explorem paralelismo catualizacăo de dados em um conjunto, enquanto se usa dados outros conjuntos, prébusca, ete).

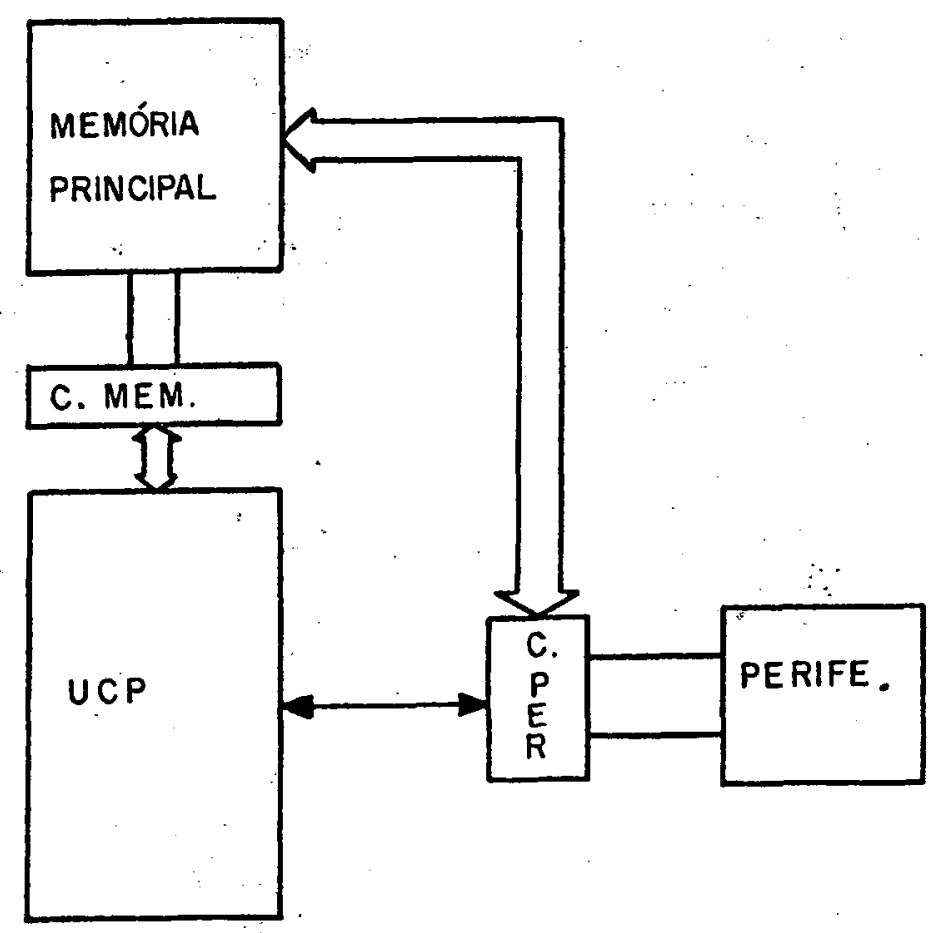

Figura 4.5 - Esquema de um sistema com cache para membria cache para perifericos. 
Ja un cache para dispositivos perifericos poderia ser implementado apenas através de software e esse a caso mais frequente. Isso se da principalmente porque os tempos de acesso envolvidos sgo muito maiores do que aqueles para o cache para memória; porem, essa implementaço obriga execucro sequencial do algoritmo implementado.

Deve-se ressaltar que mesmo em um sistema contendo cache para a memoria principal e cache para periferico, todos săo independentes entre si. Cada cache para periferico esta conectado diretamente a memória principal, normalmente nao podendo ser acessado diretamente pela UCP (ver figura 4.5). 


\subsection{1 - Consideraç8̄es Gerais}

Nas secoes anteriores foi feita uma descrica dos estudos tebricos sobre sistemas que incorporam o uso de cache a fim de se obter o conhecimento necessario à implementaço do cache adequado ao sistema em desenvolvimento pelo Laboratorio de Instrumentacgo Eletronica do Instituto de fisica e Quimica de 5\%o Carlos (LIE - IFQSC), bem como para poder escolher quais as caracteristicas que deven ser implementadas. Esse sistema deverá ser usado para gerenciar acessos disco tanto para operacoses normais de un sistema operacional, quanto para um sistema de gerenciamento de base de dados, tal camo descrito em [TR_86].

Sera apresentada a seguir a implementacro que foi realizada. Trata-se da implementaça de un cache compartilhado, pois o acesso a qualquer dispositivo de disco é gerenciado por apenas um processador, utilizando um anico conjunto de blocos para todos eles. Além do que, o modelo de cache compartilhado é mais viável por năo apresentar o chamado "problema de coerencia de dados" que ocorre no modelo de cache privativo. (ver segres 4.6 .1 e 4.6.2).

Deve-se ressaltar que nessa implementacao o tamanho do bloco do cache corresponde ao tamanho do registro fisico do disco, pois em um acesso a disco o processador consegue recuperar apenas um registro fisica, tanto para leitura como para escrita. Hssim, pode-se referir-se indistintamente a um bloco no cache ou a um registro fisico. 


\subsection{2 - Estrutura de Dados Utilizada}

As caracteristicas do sistema alvo indicam que o sistema de gerenciamento de cache deve ser implementado através de software. Aliado ao fato de que o cache usado para atender a solicitaçres provenientes de varias estacles de trabalho, isso indica que os seguintes requisitos devem ser atendidos pelo gerenciador de membria cache:

- rapido reconhecimento de que um bloco solicitado está no cache;

- rapida localizaço de un bloco que está no cache;

- a quantidade de memoria gasta para manter as estruturas a disponivel; do cache ngo deve representar uma parcela muito grande da memb

- as operacoles de manutengro do cache ngo devem causar sobrecarga significativa sobre o desempenho do sistema.

Levando-se esses requisitos em conta, chegou-se a uma estrutura que usa .o principio de particão ('hash') para a verificafgo e localizacgo de um bloco na memoria e uma lista de listas duplamente encadeadas para a manutenca dos dados sobre o cache. Assim, as estruturas de dados que gerenciam o cache podem ser divididas em duas partes:

a) Estrutura que armazena o estado de acesso da memória cache;

b) Estruturas que indicam a posiforo onde se encontram os blocos no cache. 
A estrutura de estado de acesso do cache ("Estcacha") e constituida basicamente por uma estrutura logica, constituida. por tres vetores, cada um com "nb" posic8es, onde "nb" o numera de blocos da membria cache (ver figura 4.6A):

- D primeiro vetor dessa estrutura, denominado "nDriver", armazena o numero do driver a que se refere o bloco.

- O segundo vetor, denominado "NdoReg", armazena o namero do registro fisico que esta armazenado nesse bloco.

- O terceiro vetor, denominado "Estado", armazena o estado desse bloco na memória cache, isto e, se o bloco foi alterado ou na.

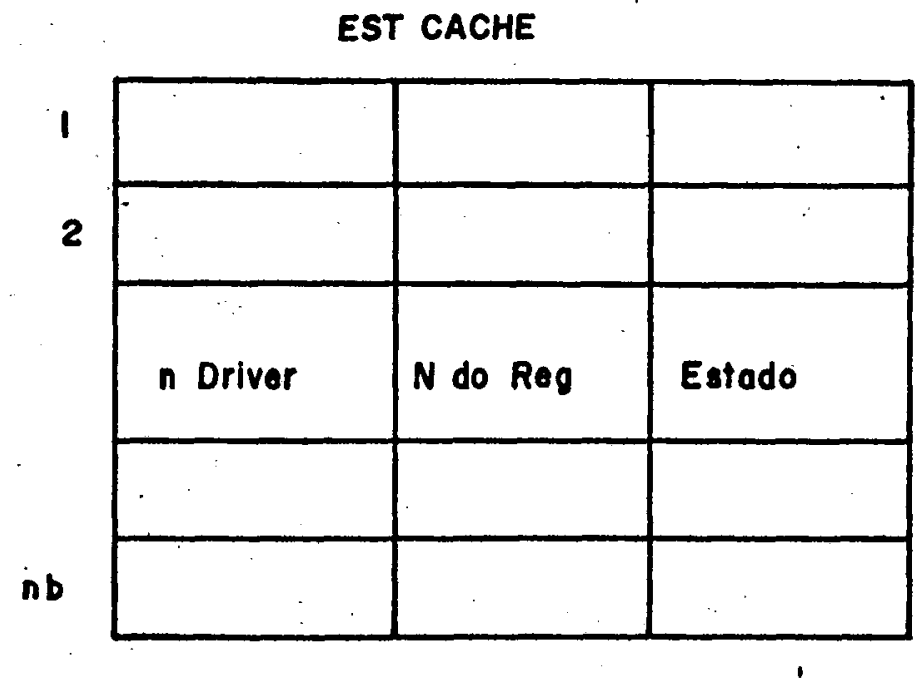

Figura 4.6A - Estrutura de Estado de Acesso - "Estcache".

As estruturas que indicam a posicao onde o bloco é armazenado no cache podem ser divididas em duas partes:

- Estruturas de recuperacaro de ponteiros para os blocos do cache, que e constitulda por dois vetores de 
ponteiros (ver figura 4.6B):

a) Vetor de ponteiros denominado "ApontBlocMem" para indicar se um conjunto de ate 16 blocos está no cache.

b) Vetor de ponteiros denominado "BLocMemor", que armazena o endereço no cache dos blocos, dentre os dezesseis blocos da estrutura anterior, que estáo no cache.
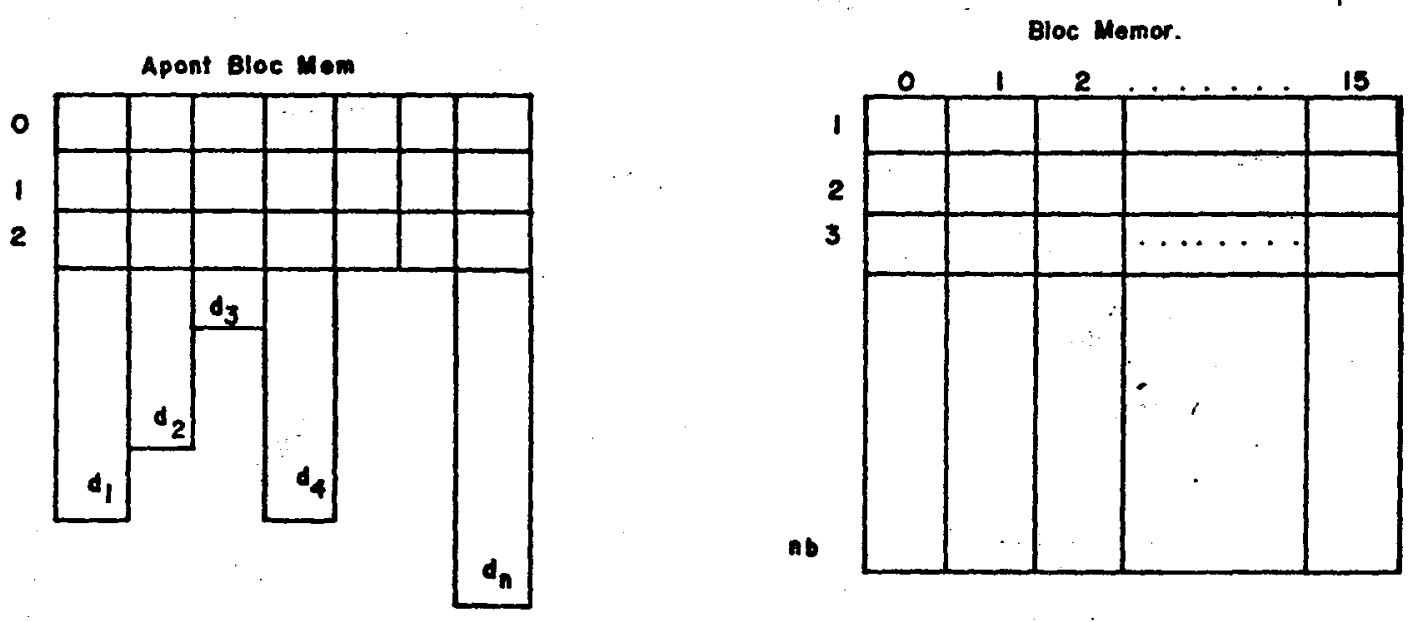

Figura 4.68 - Estruturas de Recuperacgo de Ponteiros para os Blocos do Cache.

- Estrutura de atualizaça de acesso a blocos no cache, que é constituida por uma lista bidirecional de Listas duplamente encadeadas (ver figura 4.6D). Dividimos logicamente essa estrutura em duas listas para melhor compreensao (ver figura 4.6[):

a) Lista denominada "ListTotas", que armazena as informacóes referentes ao ndmero total de acessos a determinado bloco, incluindo nessas informacores a lista de todos os blocos com o mesmo total. 
b) Lista denominada "Llstblocos", que armazena quals sao os blocos que possuem o mesmo total num mesmo instante.
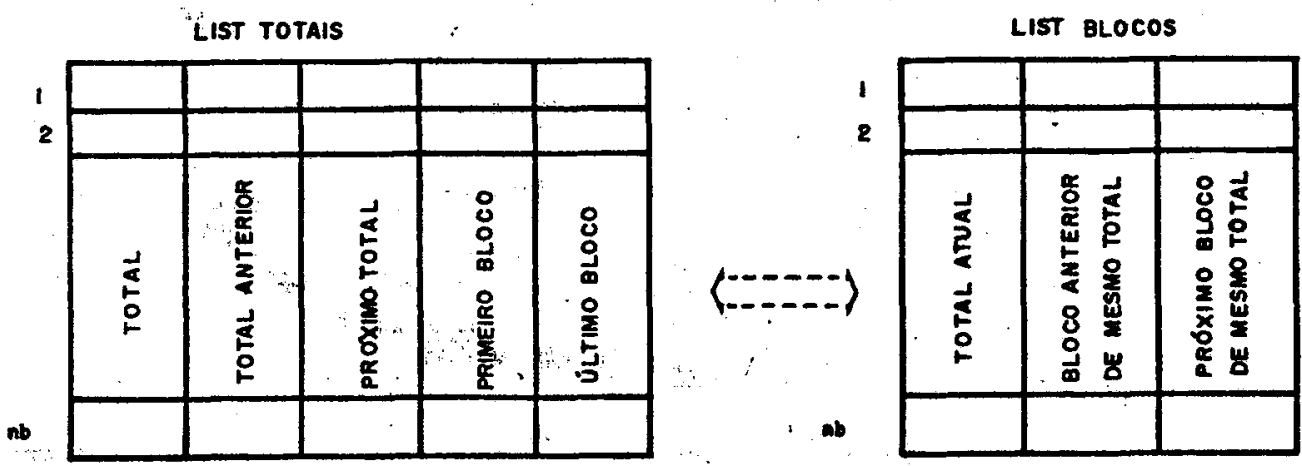

Figura 4.6[ - Estrutura de Atualizaço de Acesso a Blocos no Cache (Visao Lógica).

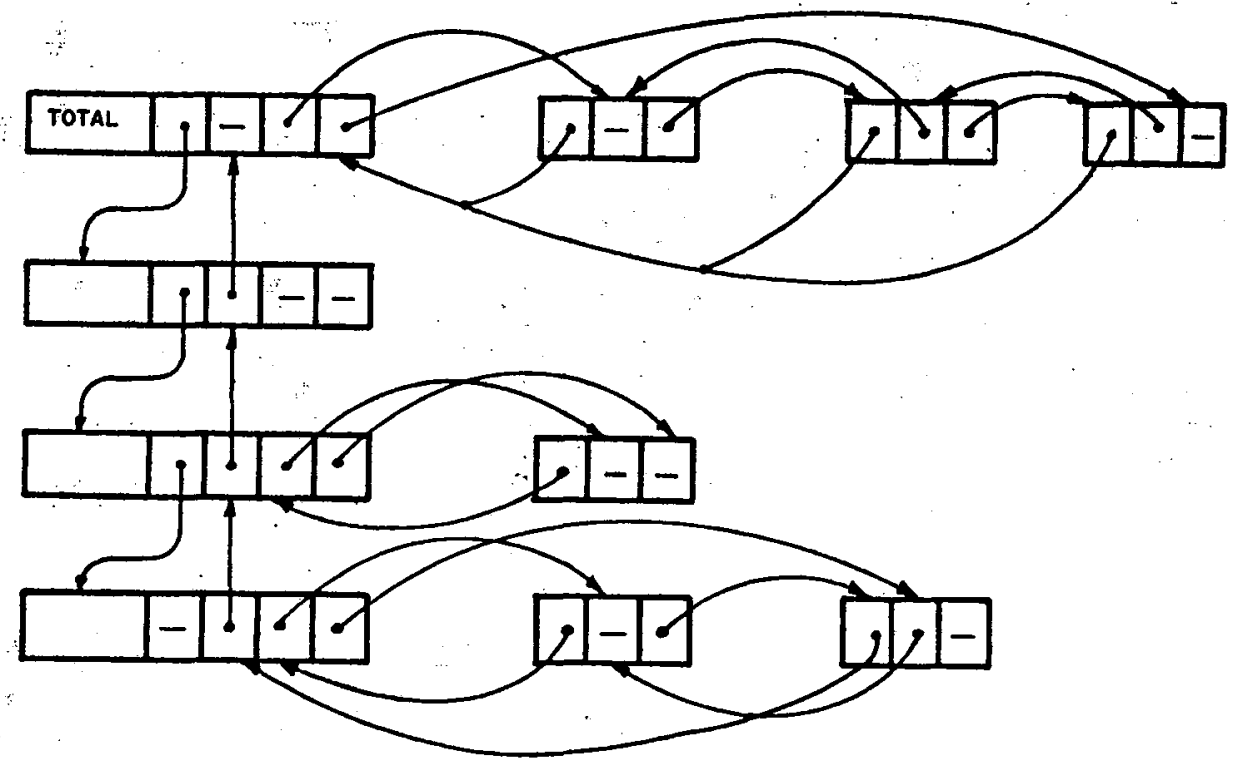

Figura 4.60 - Estrutura de Atualizaçao de acesso a blocos no cache (vista em forma de lista bidirecional de listas duplamente encadeadas). 
Antes de prosseguir a explicaço de como deve-se usar essas estruturas para acessar o cache, e preciso especificar o que cada um de seus campos contém.

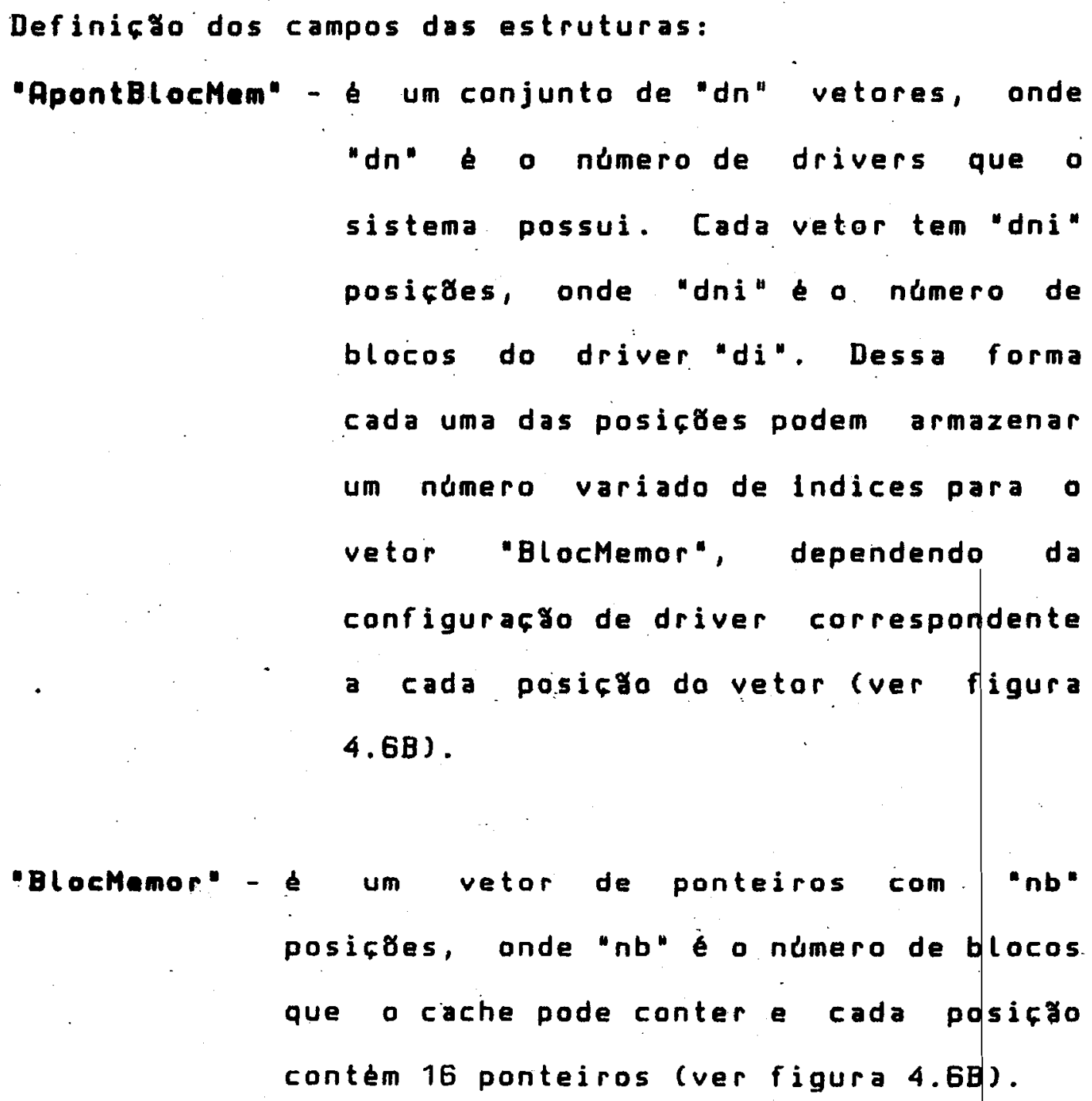

- Blocmemor" - é un vetor de ponteiros com. "nb" posicôes, onde "nb" è namero de blocos que o cache pode conter e cada posicao contem 16 ponteiros (ver figura 4.68 ).

"ListTotais" - e uma lista bidirecional duplamente encadeada, onde cada registro constituldo por 5 campos:

- D primeiro campo armazena o valor total de acessos ao bloco correspondente a esse 
registro.

- D segundo campo armazena o Indice do bloco com a valor total imediatamente inferior ao desse registro.

- O terceiro campo armazena o Indice do bloco com o valor total imediatamente superior ao desse registro

- 0 quarto campo armazena o ponteiro para o primeirobloco com esse total de acessos.

- 0 quinto campo armazena o ponteiro para o ultimo bloco com esse total de acessos.

"ListBlocos" - uma lista bidirecional duplamente encadeada, onde cada registro é constituido por 3 campos:

- D primeiro campo armazena o ponteiro para o registro da lista de totais ("ListTotais"), que indica o numero de acessos a esse bloco.

- o segundo campo armazena o ponteiro para o bloco anterior que tenha esse mesmo total.

- D terceiro campo armazena o ponteiro para o proximo bloco que tenha esse mesmo total. 
4.8.3 - Algoritmo de Gerenciamento do Cache

Agora deve ser verificado como essas estruturas sao utilizadas para gerenciar o cache. Inicialmente serb feita. a descriço do algorltmo de localizaço implementado, uma vez que a busca é efetuada apenas sob demanda.

Sempre que um acesso de leitura ou escrita é solicitado, verifica-se se o registro correspondente está no cache. Para isso usa-se inicialmente a estrutura de recuperacaro de ponteiros para os blocos do cache "ApontBlocMem". Divide-se o numero do registro solicitado por 16, sendo a parte inteira usada como Indice do vetor "Apontblocmem" correspondente ao driver solicitado. Se o valor contida nessa posicaro de "ApontblocMem" for igual a zero, temos que o bloco (registro) ngo se encontra no cache. Se o valor for diferente de zero, o bloco poderá estar no cache

e esse valor indica un registro (de 16 ponteiros) do vetor "BlocMemor".

- Indice de qual é o ponteiro a ser usado é o valor obtido como resto daquela divisao do numero do registro por 16. Verifica-se entzo o valor desse ponteiro. Se o valor for diferente de zero, esse numero o Indice da posicaro do bloco solicitado no cache , se o valor for igual a zero, significa que o bloco ngo esta no cache.

Deve-se ressaltar que a lista de totais ("ListTotais") possui um ponteiro de recuperaço, denominado "Apontltotais", que aponta para o registro que contem o menor valor total, demarcando-se dessa forma o inlcio da lista de totais.

Depois de se verificar que o bloco esta no cache, 
sempre que um acesso é solicitado a esse bloco, o numero total de acessos a esse bloco deve ser atualizado. Mas ha quatro maneiras de fazer-se essa atualizaço:

1 - ovalor total de acessos a esse bloco ja atualizado. e igual ao valor total imediatamente superior na lista de totais ("ListTotais"). Logo, esse bloco deve ser retirado da listade blocos com o valor total corrente e incorporado a lista com o total imediatamente superior.

2 - o bloco acessado o unico bloco da lista de totais com esse valor. Logo, a ter seu total acrescido e passar nova lista de blocos, o registro da lista de totais ("ListTotais") eleliminado, pois ngo há mais nenhum bloco na lista de blocos" ("Listblocos") que possua esse mesmo valor total de açessos.

3 - D valor total desse bloco já atualizado ainda "e inferior ao valor total imediatamente superior na lista de totais ("ListTotais") e esse é o unico bloco com esse total de acessos. Logo, apenas o primeiro campo (total atual de acessos) do registro correspondente a esse bloco na lista de totais será atualizado e o registro da lista de blocos ("ListBlocos") : correspondente" a esse bloco continuara onde esta:

4 - Existe mais de um bloco com o mesmo valor de total de acesso, porém nao existe nenhum bloco com o 
valor corrente mais um. Logo, o bloco deve ser retirado da lista de blocos com esse total e deve ser criado um novo registro na lista de totais com - valor do total corrente mais um, ao qual o bloco passa a ser associado.

Se o acesso ao bloco alterou algum dado contido nesse bloco (foi realizada uma operacgo de escrita), a estrutura que armazena o estado de acesso da memória cache ("Estcache") o indicará. Isto é, no registro correspondente ao bloco, o terceiro campo ("Estado") receberá o valor um, indicando que o bloco foi alterado. Assim, quando esse bloco for substituldo no cache deverb ser recopiado na memória principal.

Quando o bloco solicitado por um acesso ngo está no cache, um algoritmo de reposicao deve ser executado o qual consiste de duas operaçós: retirar um bloco que esta no cache para permitir que o bloco solicitado seja colocado e colocar esse bloco: D algoritmo implementado é baseado no uso e opera sob o princlpio de espaco fixo.

Para a escolha de qual bloco será retirado do cache, usa-se o bloco menos frequentemente usado que esta há mais tempo sem ser usado. Pode-se perceber que a atualizacgo dos blocos no cache obedece a uma aglutinaço de dois algoritmos: o LFU (pois é sempre retirado o bloco menos frequentemente acessado) e o LRU (é retirado o bloco menos recentemente acessados. Através dessa associacro utilizam-se as vantagens dos dois algoritmos, otimizando ainda mais o uso do cache neste sistema.

Essa escolha e feita no algorltmo implementado da 
seguinte maneira: usa-se a variável "Apontltotais" para se determinar o registro da lista de totais que guarda as informaços dos blocos com o menor total de acesso. Desse registro, obtem-se o blocofinal da lista de blocos desse total. Esse o bloco com o menor total de acessos e que esta há mais tempo sem ser acessado.

A colocacăo de um registro na lista de blocos ("ListBlocos") é feita no inlcio da lista e a retirada feita no final da lista, obedecendo-se assim ao algorltmo LFU. Se um bloco sai de uma lista, le eliminado do cache cfoi retirado para substituifaol ou ele passa para a lista de totais imediatamente superior (foi feito un acesso a bloco): Note-se que a colocaço de um novo bloco no cache nă necessariamente faz com que esse bloco seja colocado na listade tatais com o valor um, mas sim na lista que tem o.menor total. Isso feitopara nao ser necessário subtrair um de todos os totais existentes na lista de totais quandodeixa de existir umbloco com total de acesso igual a um. Assim o que importa năo e valor absoluto de. um total e sim o seu valor relativo ao menor total existente na lista.

Para evitar um algoritmo diferenciado para os primeiros acessos feitos ao cache na inicializaço do sistema, quando o cache nåostara ainda totalmente preenchido, na inicializaçăo preenche-se: o cache arbitrariamente com os "nb" primeiros blocos de un disco. 
- estudo teórico realizado teve o objetivo de identificar quais os pontos principais que deveriam ser levantados para a implementacaro de um cache. Do estudo estruturado que se fez, buscando as caracteristicas e alternativas em jogo em uma implementaço de cache, conseguiu-se os subsidios para a especificacao daquele que foi implementado.

Assim, foi implementado um cache para dispositivos de disco, usando como controlador um processador ZBo com acesso a ate 256 Kbytes para memória dos blocos (membria cache), dividida em oito bancos de 32 Kbytes. Ds programas de controle ficam armazenados em uma memória ROM, de 28 Kbytes, dispondo de uma memória de 4 Kbytes para as varibueis de controlé: 0 tamanho de cada bloco e de 1 Kbyte.

D algoritmo de controle implementado constitui-se em um algorltmo de busca sob demanda com reposicgo baseada no uso, alocando sempre um espaco fixo de membria. Para substituica de blocos na memoria cache; o algoritmo emprega uma combinaço do algor 1tmo LFU com o LRU. 


\section{A IMPLEMENTAGXO REALIZADA DO SISTEMA CPIM}

\section{1. - Introducgo.}

Neste capitulo săo apresentados os principais conceitos sobre o Sistema Dperacional CP/M, segundo as especificactes padrgo da Vers\%o: 2.4 , como objetivo de explicar seu funcionamento, para permitir uma compreensă de uma expansăo de suas funçes feita posteriormente. Essesistema operacional foi desenvolvido pela Digital Research paraser usado em Micro-computadores de 8 bits que utilizem o.s Micro-processadores 8080,8085 ou 280 .

0 objetivo da construcgo do sistema monousuario é certificar que a implementaca do sistema operacional efetuada é compativel com a versăo original suprida pela Digital Research. Entăo, a partir dessa versăo, foi implementada uma nova, que incorpora recursos de protecgo a arquivos entre varios usuarios, controle de acesso simultaneo a arquivos a partip de vários aplicativos e utilizaço de memória cache.

Para a implementaço de ambas as versares do sistema, foi escolhida a linguagem " $\mathrm{C}$, com a qual foi realizada quase a totalidade do sistema. As poucas rotinas que nao puderam ser escritas nessa linguagem foram escritas em linguagem demontagem 
do processador 8080. A escolha da linguagem " $[$ " foi devida a diversos motivos:

- sendo uma linguagem de alto nivel, permite que a implementacao fique independente de detalhes de maquina;

- permite ao programador indicar enderecos de memoria onde determinadas variáveis devem ser armazenadas;

- uma linguagem que dispớe de compiladores em grande parte das maquinas existentes, o que facilitaria o transporte para outros ambientes;

Este capitulo foi escrito levando-se em consideracyo que as informactes fornecidas pela Digital Research [DI_79a] [DI_79b] ja sejan conhecidas. No entanto, na secgo 5.2 feita uma apresentacgo resumida das principais estruturas interias necessárias à compreensăo dos conceitos desenvolvidos nas secốs seguintes. A terminologia adotada a mesma usada nos manuais da Digital Research, tendo-se evitado a traduca dos termos e das siglas para.facilitar a identificacăo con os termos já tradicionais entre as pessoas que utilizam o Sistema Operacional CP/M.

$\mathrm{Na}$ seço 5.3, a organizaça de un disquete formatado para o CP/M no formato padra ( 8 polegadas, face e densidade simples) é apresentada.

Na segaro 5.4 estendem-se os conceitos da seço 5.3 para disquetes formatados em outros padroge, discutindo-se todas as possibilidades do CPIM. Sro apresentados também os resultados 
obtidos, e a maneira como foram utilizados alguns elementos, ditos reservados do sistema $[P / M$, por uma nova implementacăo que esta senda realizada.

Na. sefro 5.5 é mostrado como o módulo CLP iConsole Command Processor) foi implementado, e discutem-se algumas alteraçes feitas na versao implementada com relaça à versăo original, com o objetivo de melhorar a interface com o usuario.

$\mathrm{Na}$ seço 5.6 discute-se como o sistema operacional implementado, o qual será denominado daqui por diante como CP/M LIE, pode ser testado, mostrando-se o esquema de testes que foram necessarios para poder avaliar a correcaro da implementacăo realizada.

Por fim, na seço 5,7 descreve-se a expansăo efetuada no CPIM para prover os recursos necessarios a uma versao Multiusuário.

5.2. - Apresentaca das Estruturas Internas do CP/M.

0 sistema operacional CP/M é logicamente dividido em cinco partes, tal como mostrado na figural 5.1:

- BIOS (Basic I/0 Systen): é o módulo dependente do hardware que define exatamente os parametros de entrada e salda para os dispositivos perifericos. E' feito especialmente para cada máquina pelo fabricante do equipamento. 
- BDOS (Basic Disk Operating 5ystem): é o mádulo que constitui o nucleo do CP/M. Contém 37 funcoges para tratamento de arquivos, acesso à memória e entradalsalda.

- ECP (Console Command Processor): trata-se do módulo que monitora os comandos do usuario para o CP/M. Executa os comandos residentes do CP/M.

- Area de Porsmetros: é constituida dos 256 bytes do intcio da memoria e é usada pela sistema para armazenar os dados temporários necessarios à sua operaço, tal como o numero do usuario ativo, disco corrente e buffer de comandos do usuario.

- TPA (Transient Program Area): é uma área da memória que nao es usada por nenhum dos módulos anteriores, na qual os programas do usuario e comandos năo residentes do sistema operacional săo executados. 


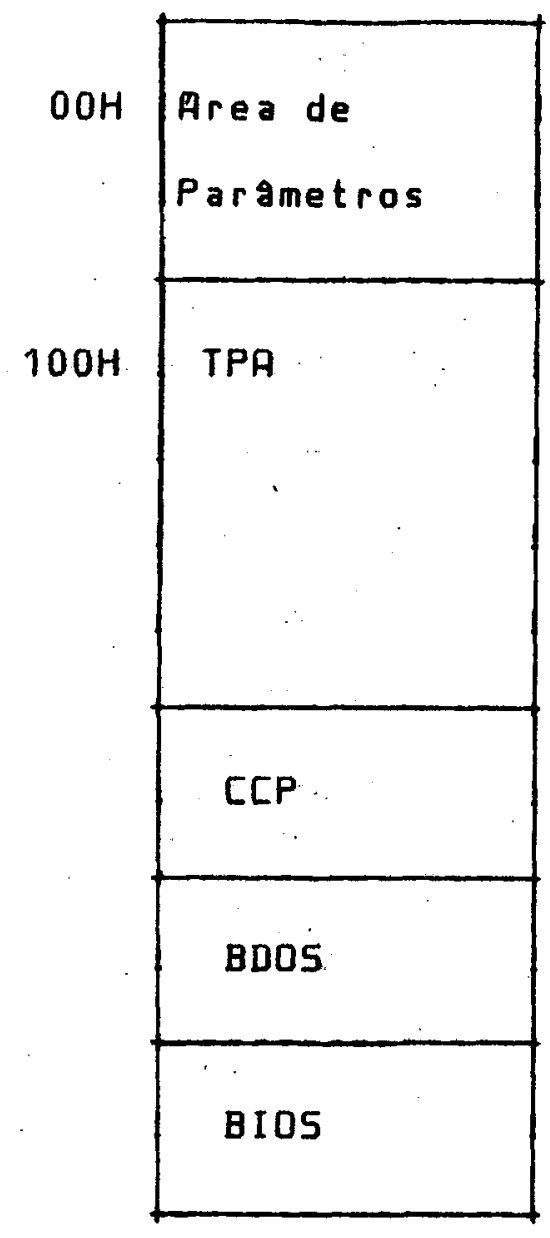

Figura 5.1 - Disposicgo do LP/M na memória.

Como foi dito anteriormente, o BDOS dispoe de 37 funcôes, das quais 13 (as de numero 0 a 12) tratam de manipulą̧a das operacốes de entradalsalda via console ou dispositivos perifericos seriais e as restantes manipulam o subsistema de disco.

No BIos existem tabelas que descrevem as caracterlsticas particulares do subsistema de disco, necessarias ao CPIM; as tabelas fornecem ao BDDs as caracteristicas especificas do subsistema de disco de cada particular equipamento. A seguir sera descritos os elementos dessas 
tabelas.

A cada disco é associada uma area de 16 bytes, chamada de "Disk Parameter Header" (DPH), que tanto prove informaçes sobre o disco como tambem indica areas de servico para certas operaçás do BDOS.

D formato da Disk Parameter Header (DPH) para cada disco é dado abaixo:

\begin{tabular}{|c|c|c|c|c|c|c|c|}
\hline$X L T$ & 0000 & 0000 & 0000 & DIRBUF & DPB & CSV & ALV \\
\hline $16 \mathrm{~b}$ & $16 \mathrm{~b}$ & $16 \mathrm{~b}$ & $16 \mathrm{~b}$ & $16 \mathrm{~b}$ & $16 \mathrm{~b}$ & $16 \mathrm{~b}$ & $16 \mathrm{~b}$
\end{tabular}

onde cada elemento é um valor de 16 bits. 0 significado de cada elemento do Disk' Parameter Header (DPH) e o seguinte:

XLT Endereco do vetor de translaço logico para fisico. Se năo há translacăo de setor, isto é, o numero do setor fisico é ó mesmo que o lógico, seu valor é $0000 \mathrm{H}$.

0000 Valores para uso interno do BDOS (o valor inicial กรัo é importante).

A documentaça fornecida pela Digital Research năo fornece nenhuma informaca sobre o uso ou 0 significado dessas posiçes. Estamos usando em nosso sistema o primeirobyte para armazenar o nemero máximo de entradas de diretorio deste disco. 
DIRBUF Endereço de uma área de 128 bytes para operacónes com o diretorio dentro do BDOS. Todos os DPHs enderecam a mesma área.

DPB. Endereco do "Disk Parameter Block" (DPB), para este disco. Drivers com caracteristicas identicas de disco podem enderecar o mesmo DPB.

CSV Endereco de uma área usada para testar se houve mudanca de disco, através de software. Este endereco é diferente para cada DPH.

Năo especificado como esse teste é realizado pelo sistema CP/M padrao.

No novo sistema CPIM-LIE, este teste foi implementado através da somatoria modulo 256 dos bytes dos registros de diretorio conhecido como Teste de Redundancia [1clica - CRC). Verificamos por experimentaço posterior que o CP/M padrao também faz tal teste dessa forma.

ALV endereço de uma área usada pelo BDOS para guardar a informaço sobre a alocaço do espaco em disco (endereço do mapa de bits).

Caso no sistema existam "n" drivers, os DPHs săo arranjados na memória em uma tabela onde a primeira linha de 16 bytes corresponde a driver 0 e a ditima linha corresponde ao 
driver $n-1$.

Dutra tabela existente, a qual já foi citada no DPH, é a Disk Parametar Block" (DPB). Uma particular DPB pode ser enderecada por uma ou mais DPHs.

D formato do Disk Parameter Block (DPB) é o seguinte:

\begin{tabular}{|c|c|c|c|c|c|c|c|c|c|}
\hline SPT & BSH & BLM & EXM & DSM & DRM & ALO & AL 1 & CK5 & OFF \\
\hline 16b $8 \mathrm{~b} \quad 8 \mathrm{~b}$ 8b $16 \mathrm{~b}$ & 16b & $8 \mathrm{~b}$ 8b $16 \mathrm{~b}$ & $16 \mathrm{~b}$
\end{tabular}

onde cada elemento é um byte ( $8 b)$, ou uma palavra (16b), cujo significado é o seguinte:

SPT o numero total de setores por trilha.

BSH e fator de deslocamento do bloco de alocacaro de dados ("cluster"), determinado pelo tamanho do bloco de alocaço de dados.

BLM determina implicitamente o tamanho do bloco de alocaga de dados. Está intimamente relacionado com o campo BSH.

EXM e a mascara para o "extent", determinada pelo tamanho do bloco de alocafro de dados e o numero de blocos do disco. Na implementaço realizada, foi usado para testar se o próximo 
"extent" do arquivo ainda esta na mesma entrada de diretorio.

Foi verificado que o numero de "extents" na mesma entrada de diretorio depende do tamantio do..bloco de alocacăo de dados ("cluster"). Ou seja, se o tamanho do "cluster" é de $1 K$, em cada entrada de diretorio havera apenas um "extent"; se o tamanho do "cluster" é de $2 K$ havers dois "extents"; se o tamanho do "cluster" de $4 K$ haverá ate 4 "extents"i e assim por diante ate cluster com tamanho de 16K, que o máximo suportado pelo CP/M. Dessa forma, concluiu-se que:

num. de extents por ent. de dir.=16/(EXM+1).

DSM determina a capacidade total de armazenamento do disco (em Kbytes).

DRM determina o numero total de entradas de diretorio que podem ser armazenadas nesse disco.

ALO $\quad$ I

, fornecem a inicializagáo do mapa de bits.

AL $1 \quad$ I

CK5 e o tamantio do vetor de teste do diretorio.

OFF e numero de trilhas reservadas no inicio do 
disco.

As operacớs em arquivos em CP/M săo efetuadas atraves de uma estrutura de 33 bytes para arquivos sequenciais(36 bytes se for arquivo de acesso aleatório), chamada "file Control Block" (FCB). Ds seus elementos fornecem as caracteristicas do arquivo a ela associada. D FCB (File Control Block) quando residente em disco apresenta apenas os 32 bytes iniciais, constituindo uma entrada de diretório. Duando o FCB é transportado para a memoria outros 4 bytes ou 1 byte (dependendo do tipo de acesso ao arquivo, seqüencial ou aleatoriol săo a ele incorporados.

D formato do "File Control BLock" (FCB) é o seguinte:

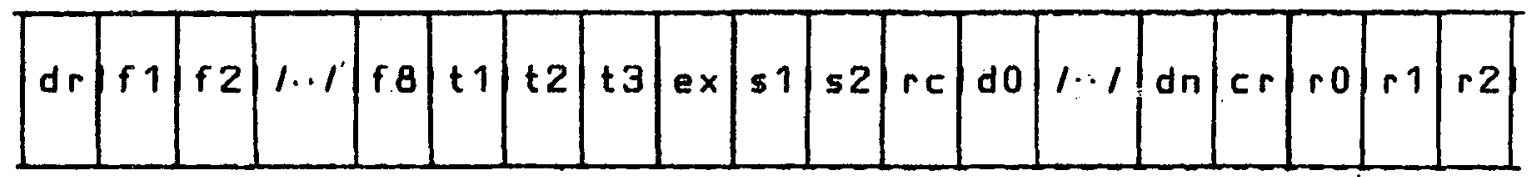

$\begin{array}{lllllllllllllllllll}00 & 01 & 02 & \ldots & 08 & 09 & 10 & 11 & 12 & 13 & 14 & 15 & 16 & \ldots & 31 & 32 & 33 & 34 & 35\end{array}$

onde o significado de cada campo é o seguinte:

dr codigo do driver (numero de 0-16)

$0 \Rightarrow$ usa o driver "default" para o arquivo

$: 1 \Rightarrow$ seleciona o driver $A$

2 ) seleciona o driver $B$

$\cdots$

$15 \Rightarrow$ seleciona o driver $P$

f1...f8 contem o nome do arquivo em caracteres maiusculos, 
sendo que o bit de mais alta ordem dos caracteres é zerado.

t $1, t 2, t 3$ contém o tipo do arquivo em caracteres maidsculos, sendo que o bit de mais alta ordem dos caracteres é zerado.

ex

contem o numero do "extent" corrente, normalmente recebe o valor zero pelo usuario, mas pode variar de 0 a 31 durante operaçose de entradalsalda do arquivo. Um FCB pode alocar espaco de até 16 "clusters" (16 Kbyte para o disco padrăo) para um arquivo, mas se um arquivo cresce mais do que isto é alocado mais uma area de 32 bytes (FCB) para ele. Esse novo FCB armazena um outro "extent" do arquivo.

s1 reservado para uso interno do sistema.

No novo sistema CP/M-LIE, usou-se s1 para armazenar qual foi o maior "extent" usado nesta. entrada de diretorio.

52

reservado para uso interno do sistema. Recebe o valor zero quando as rotinas DPEN, MAKE E SEARCH să chamadas.

No novo sistema CP/M-LIE, separou-se a utilizacaro de 52 en tres partes:

bit $7(80 \mathrm{H})-5 e$ ligado indica que os 4 bits de mais baixa ordem de 52 indicam 0 
numero do driver associado ao arquivo.

bit $6(40 H)-5 e$ ligado indica que o FCB na memoria esta diferente do FCB do disco.

bits 0 a 3 - indica o driver a que se refere o FCB .

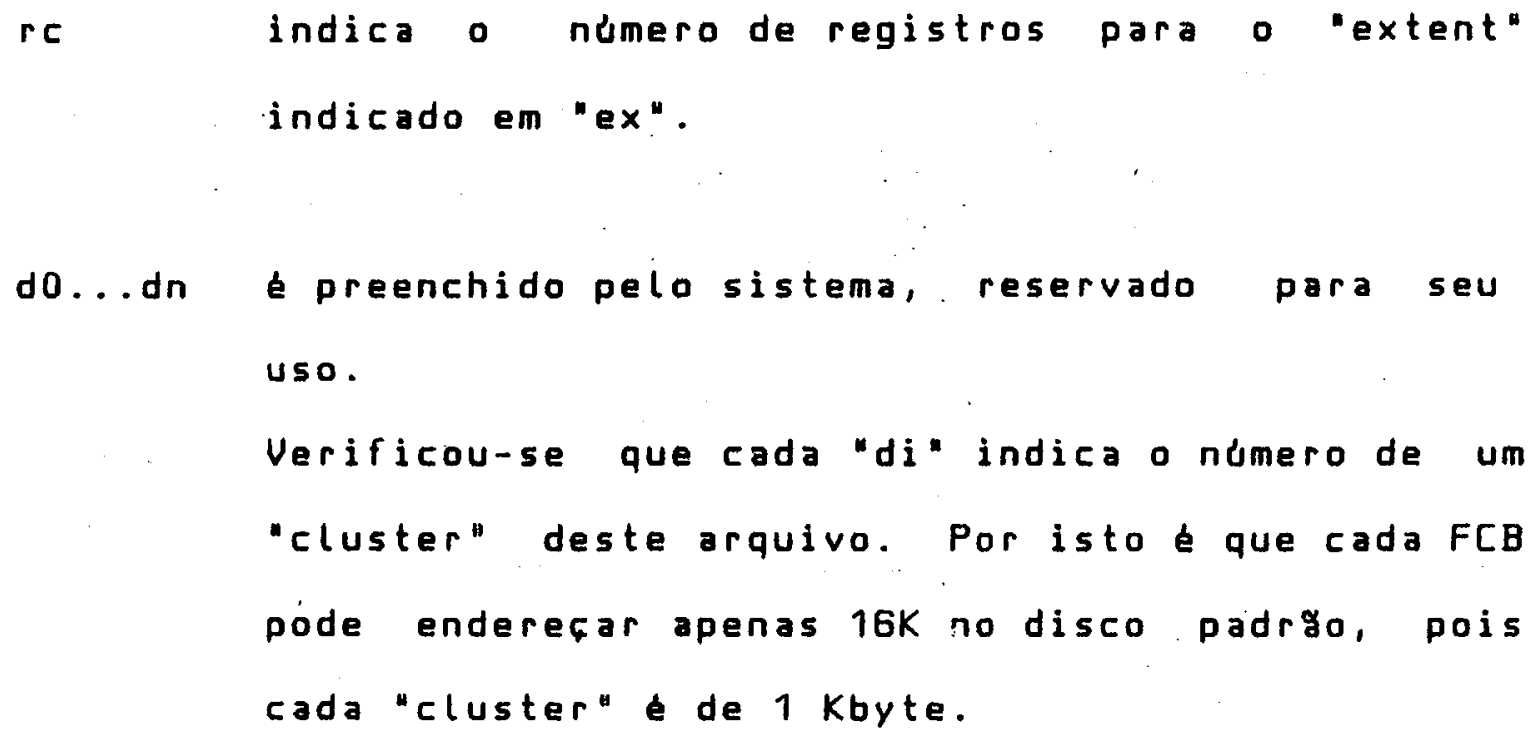

er numero do registro corrente para leitura ou escrita em um arquivo seqüencial, normalmente recebe o valor zero pelo usuário. Está presente apenas quando o FCB está na memória.

ro,r1,r2: so usados apenas para operacôes de acesso aleatorio. Constituem um numero de 24 bits que armazenam o numero do registro lógico do LP/M. a ser acessado. [omo este número pode ir até 65536, săo necessários 17 bits para representá-lo, dal usarem-se tres bytes. ro representa o byte menos 
significativo.

5.3. - Organizacgo de um Disco Padrăo em CP/M.

O disco padra para o CP/M usa o mesmo formato definido pela. I Esse formato divide o disco em 77 trilhas (numeradas de 0 a 76 ), cada uma com 26 setores (numerados de 1 a 26 ) de 128 bytes.

0 CP/M admite o uso de varios outros formatos, entretanto, nesta "seço sera apresentada a organizaçăo de disco em formato padrgo. Independentemente do formato, um registro em CP/M sempre constituldo de 128 bytes, o que é chamado de registro lógico do [P/M. Dispositivos que tenham setores (registro flsico) cujo tamanho e um multiplo de 128 podem ser usados em CP/M, desde que o BIOS mapeie cada setor lógico nos setores flsicos apropriadamente. Todo disco formatado para o CP/M é dividido em tras áreas:

$$
\begin{aligned}
& \text { - Area para o sistema i } \\
& \text { - Area para o diretorio; } \\
& \text { - Area de dados }
\end{aligned}
$$

As trilhas iniciais do disco sar reservadas para o sistema CP/M. No disco padrăo as duas trilhas iniciais săo reservadas. Discos que năo serao usados para o carregamento de sistema podem ter reservadas zero trilhas, o que significa que năo se reserva área para o sistema.

As trilhas restantes sa usadas para o diretorio e área 
de dados, sendo que os registros sago agrupados em numeromditiplo de 128, formando blocos de alocacăo de dados que seráo chamados de "cluster". Os "clusters" săo sempre do mesmo tamanho para um disco e, no disco padrăa, săo constituldos de $B$ registros, englobando assim 1 Kbyte. Um "cluster" a unidade de alocacaro de dadas em disco em CP/M. Dessa forma um arquivo que contenta apenas um byte ou um arquivo que contenha 1020 bytes alocam 1 Kbyte.

Os primeiros "clusters" de um disco săo sempre reservados para a brea de diretório. No disco padro, os dois primeiros "clusters" săo reservados para isso, dando um total de 16 registros lógicos para o diretorio. Cada entrada de diretório e constitulda por 32 bytes; dessa forma o disco padra admite (16*128)/32=64 entradas de diretório.

5.3.1 - Mapeamento dos Registros de um Arquivo em Disco.

- espaco em disco é alocado dinamicamente pelo CP/M para os arquivos conforme a necessidade. Essa alocacaro feita em "clusters", de forma que os arquivos crescem de $1 \mathrm{~K}$ byte em $1 \mathrm{~K}$ byte (no caso do disco padrăo) e o espaco é também liberado de $1 \mathrm{~K}$ byte em $1 K$ byte. Sempre que un arquivo é apagado, o espaco por ele utilizado anteriormente pode ser imediatamente usado por outro arquivo. Dessa forma, o espaco em disco é usado de forma eficiente, mas setores consecutivos de um. arquivo nao necessariamente săo gravados consecutivamente no disco. Ds conceitos que permitem essa utilizaço dingmica do espaco em 
disco sซัo:

- o mapa de alocąaro de bits (Bit Map)

- File Control Block (F[B)

- o arquivo de diretorio

5.3.1.1 - Mapa de Alocaço de Bits (Bit Map)

Para cadandisco configurado pelo sistema CP/M, o BDOS mantém um bloco de bits, cujo tamanho e igual a numero de "clusters" desse disco ( para o disco padrgo este bloco é de 243 bits). Este bloco chamado de Mapa de Bits. Define-se "Cluster" como um conjunto de registros fisicos do disco, que constitui a menor unidade de alocaço de espaco em disco.

Esse mapa lido para a memoria quando o disco é ativado e modificado durante ás operaçôes de escrita. E escrito de volta no disco sempre que um arquivo novamente fechado. Quando é teclado 'Ctrl-c', todos os mapas de bits da memóra sa apagados, e să refeitos os mapas de bits do driver $A$ e do driver corrente.

Cada...bit no mapa representa um "cluster" ( 8 registros de 128 bytes consecutivos) no disco padrăo. As posifós dos bits no mapa de bits e os "clusters" a eles associados săo numerados de 00 a 242. Ds primeiros dois bits 5 ăo associados aos primeiros 16 registros logicas da trilha 2, que contem a area de diretorio (no caso do disco padra). Isso porque os clusters 00 e 01 contém a area de diretorio es bits 00 e 01 no mapa de alocaforo sempre estao com valor igual a um, mesmo que o disco esteja vazio. Isto 
assegura que nunca o diretorio sera danificado por um arquivo.

Quando o BDOS recebe uma requisicaro para criar um arquivo, é feita uma pesquisa no mapa de alocaca de bits até que - primeiro bit contendo o valor zero seja encontrado. Entao o BDos coloca o valor 1 neste bit e coloca o numero desse "cluster" na área de-mapeamento do file Control Block (FCB), criada para esse novo arquivo.

Cada vez que uma operacaro de escrita. é requisitada pelo arquivo, o BDOS verifica o namero do altimo "cluster" no FCB e também o numero do próximo registro e calcula o numero do setor fisico e da tritha onde a escrita deve ser feita. Quando todos os oito registros estiverem preenchidos o BDos automaticamente pesquisa no mapa de alocaço de bits o primeiro bit que contem 0 . Duando o bit é encontrado, o numero do "cluster" a ele associado é colocado no FCB, na área que indica o numero dos "clusters" do arquivo, e o bit recebe o valor 1. Assim, para um arquivo que tenta sete ou menos registros pode-se ver que ele ocupa um "cluster" (1 Kbyte); um arquivo que tenha oito registros ocupa dois clusters, mesmo que o segundo cluster esteja vazio.

A figura 5.2 mostra como o mapa de bits esta associado a alocacaro do espaco em disco, o que feito atraves da alocacaro de "clusters". 


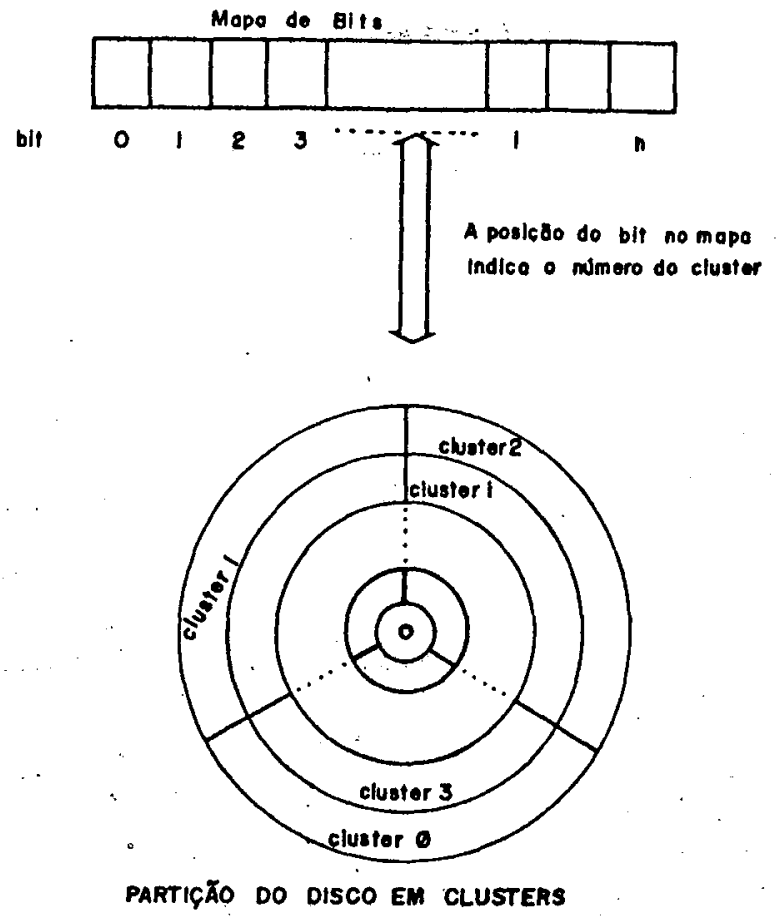
Figura 5.2 - Associagra do Mapa de Bits aos "clusters" do disco.

Este processo de alocacgo de espaço em disco por mapa de bits apresenta resultados importantes:

1. Como o BDos sempre pesquisa o mapa de alocągo de bits a partir do inicio e aloca o primeiro bit livre, componentes logicamente consecutivos de um arquivo podem estar fisicamente em qualquer lugar no disco e nao necessariamente em ordem por trilha e setor.

2. Uma requisicaro de escrita sempre será atendida até que o disco esteja completamente cheio. Dessa forma, se o disco esta cheio e uma requisicgo de escrita solicitada, ocorre um errofatal, a não ser que um programa de aplicacăo tentia previsto tal circunstancia.

3. D espaco em disco ef eficientemente usado, pois 
evita-se a fragmentaço do espaco em disco que ocorre em sistemas em que a especificacăo do tamanho do arquivo deve ser fornecida a priori.

\subsubsection{2. - File Control Block (FCB)}

Um "File Control Block" (FCB) é um bloco para leitura e escrita de 33 bytes ( 36 se for para acesso aleatorio), que contem toda a informacaro necessaria para o bDos encontrar um arquivo en disco e acessar qualquer un de seus campos. Sempre que um arquivo é criado um FCB precisa ser criado para ele.

Deve-se ressaltar que no disco padrăo cada FCB armazena um "extent" do arquivo, de forma que existam tantas entradas no diretorio quantos forem os extents de um arquivo. Alem disso, cada elemento do campo do a dn indica um cluster do arquivo.

5.3.1.3. - Area de Diretório

D BDOS mantém uma área de diretorio para cada disco. Inicializando o disco com o sistema CP/M, o conteddo dos primeiros dois "clusters" (16 registros) lido sequencialmente do disco alocado e mapa de bits para este disco é recalculado a partir dos campos do a dn. Se solicitado que um arquiva seja aberto, a entrada de.diretorio equivalente ao "extent" zero é copiada na área de FCB. Se o arquivo foi aberto para escrita, 
fechar o arquivo...significa copiar de volta o fCl na área de diretorio e atualizar o diretorio no disco imediatamente.

5.4. - Drganizacăo de un Disco de Formato Genérico em [P/M, e Conctusoles obtidas Experimentalmente.

A seguir, os conceitos apresentados na seca anterior sag estendidos para envolver qualquer tipo de disco suportado pelo CP/M. Também serào melhor explicados alguns elementos năo descritos pelos manuais da Digital Research ou que sa descritos superficialmente. Tais conclusores. foram obtidas experimentalmente, tendo sido elaborados para isso muitos testes.

5.4.1 - A Utilizaço dos Bytes do a d15 do F.CB.

A capacidade de armazenagem de um disco é um dos parametros que, entre os varios dispositivos existentes, mais variam. Em un disco padrao, em que cada "cluster" é de 1 Kbyte, e a capacidade formatada do disco, descontada as trilhas do sistema, é de 243 Kbyte, temos capacidade para armazenar no maximo 243 "clusters". Nesse caso um byte e o suficiente para armazenar "o numero de um cluster". Nas entradas de diretório (que correspondem aos FCBs na membria), existem 16 bytes (do a d15) reservados para armazenar os números dos "clusters" alocados pelo "extent" correspondente àquela entrada de diretorio. Quando 
- numero maximo de "clusters" que um dispositivo de acionamento de disco armazena é inferior a 256, pode-se usar um byte para cada "cluster" que cada arquivo alocale, dessa forma os campos de do a d15 s\%o usados byte a byte, permitindo que cada entrada de diretório aloque até 16 "clusters".

Quando um dispositivo de acionamento de discos pode armazenar mais do que 256 clusters, entgo um byte somente nao suficiente para armazenar o numero de un "cluster", sendo necessario o emprego de dois bytes para isso. Nesse caso, os bytes do a d15 de uma entrada de diretorio passam a ser usados em pares, podendo alocar até um máximo de 8 "clusters".

Dessa forma, o uso que fe feito dos bytes do a dis de. uma entrada de diretorio (e de um FCB de um arquivo aberto) depende da quantidade de "clusters" de um disco ser inferior ou superior a 256. Esse parametro é fornecido pelo BIOS a BDOS pela palavra DSM da tábela DPB de um disco (ver secaro 5.2 ).

5.4 .2 - Como os "Extents" sago Armazenados nas Entradas de Diretorio.

No CP/M padra cada "extent" aloca sempre um máximo de 16 Kbytes. No entanto, cada "cluster" pode ser de $1,2,4,8$ ou 16 Kbytes, de acordo com o que é indicado pela palavra BSH do DPB de un disco (ver sefgo 5.2). Isso significa que cada "extent" pode alocar respectivamente $16,8,4,2$, ou 1 "cluster" no máximo. Foi visto que em un disco padrgo, os "clusters" sao de 1 Kbyte, e portanto cada "extent" necessita de 16 "clusters" para ser preenchido totalmente. Como cada entrada de diretorio tem 
espaco para especificar 16 "clusters" (em um disco com menos que 256 "clusters" no máximo, o que é o casol, cada "extent" é armazenado em uma entrada de diretorio.

Consideremos discos em que o tamanho do "cluster" é de 2 Kbytes e o disco tem capacidade para armazenar menos do que 256 desses "clusters". Nesse caso, cada "extent" (que sempre tem 16 Kbytes no máximol ira necessitar de apenas 8 "clusters" no máximo para ficar cheio e uma mesma entrada de diretorio tera entao capacidade paracarmazenar até 2 "extents" do arquivo. Da mesma forma, em discos com um máximo de "clusters" inferior a 256 e tamanho do "cluster" de $4 K$, $8 K$ ou $16 K$ bytes, cada entrada de diretorio terá capacidade para armazenar respectivamente 4, 8 , ou 16 "extents" de um arquivo.

Consideremos agora discos em que o tamanho do "cluster" é de 2 Kbytes e com capacidade para armazenar mais de 255 desses "clusters". Nesse caso, cada "extent" tambem iránecessitar de apenas 8 "clusters" no máximo para ficar cheio, porem como agora é necessário o emprego de dois bytes para especificar o numero de um "cluster", cada entrada de diretario terá capacidade para armazenar apenas um "extent". Essa é a razo pela qual em CP/M nă podem existir discos com mais do que 255 "clusters" de 16 Kbyte, pois o tamanho minimo de um "extent" en CP/M é de 1 Kbyte. Em discos com um namero de "cluster" superior a 255 e com tamanho do "cluster" de $4 K, 8 K$, ou 16 Kbytes, cada entrada de diretório terá capacidade para armazenar respectivamente 2,4, ou 8 "extents" de un mesmo arquivo. 
5.4.3 - Como săo Usados os Campos re e ex do FCB.

Uma mesma enitrada de diretorio (e portanto um FCB de um arquivo abertol pode armazenar de 1 a 16 "extents" desse arquivo. No entanto, existe apenas un re um exem cada entrada de diretorio ou FCB. O campo re, normalmente especificado como o numero de registros lógicos armazenados em um "extent" de um arquivo, é na realidade o namero de registros lógicos armazenados no Ultimo "extent" da entrada de diretorio. Os demais "extents" de uma entrada de diretório sa considerados como cheios a o seu campo re năo é armazenado.

Da mesma forma, o campo ex de uma entrada de diretório ou FCB refere-se ao numero do maior "extent" armazenado naquela entrada de diretorio. Por exemplo, um disco com "cluster" de tamantio de 4 Kbytes e um maximo de "clusters" inferior a 256, possui entradas de diretorio que podem armazenar até 4 "extents". Nesse caso, o campo ex de uma entrada de diretorio que armazene os numeros dos "clusters" iniciais de um arquivo podera ter os valores $0,1,2$, ou 3 . A enitrada seguinte desse diretorio (se existir) poderáter os valores $4,5,6$, ou 7 , e assim por diante.

Note-se que para arquivos usados seqüencialmente, como e o caso de arquivos de texto ou programas, esse uso dos dois campos permite que se possa acessar o arquivo corretamente, pois năo existem 'buracos' no meio do arquivo, ou seja, registros faltando no meio do arquivo. Nesse caso, sabendo-se qual.é o Ultimo "extent" armazenado no arquivo equal a quantidade de registros armazenados nesse "extent", pode-se obter o tamanho 
exato do arquivo e, portanto, sabe-se quais registros fazem efetivamente parte do arquivo.

No entanto, para arquivos usados através de acesso aleatorio, pode-se gravar um registro sem que tenham sido gravadas os registros anteriores. Dessa forma, a existencia de 'buracos' no: arquivo se torna posslvel e o esquema de uso dos campos re ex adotado năo é capaz de indicar explicitamente quando um registro esta ou nåo gravado. O que se faz nesse caso é o seguinte:

em operaçes de escpitar permite-se escrever qualquer registro que se queira. Isso é feito calculando-se em que "extent" esse registro estaria se todos os registros precedentes existissem, alocando-se esse "extent", alocando-se dentro do "extent"... o "cluster" correspondente e gravando-se dentro desse "cluster" o registro solicitado.

em operacoócs de leitura, é verificado se o "extent" em que o registro deve estar existe e se o "cluster" correspondente a esse registro nesse "extent" existe. Se os dois existem, e oxtent" ngo for o ultimo de uma entrada de diretório, o BDOS considera que o registro solicitado existem pois dentro de um cluster nao é posstuel saber exatamente quais registros foram efetivamente gravados. Se o "extent" for o ultimo de uma entrada de diretório, pode-se ainda testar se o registro solicitado naro superior ao ultimo registro gravado nesse "extent", através do campo rc. Percebe-se assim, que é possivel ler um registro que ngo tenha sido gravado, se esse registro estiver armazenado em um 
"cluster" em que ao menos um outro registro foi gravado.

\section{4 .4 - 0 Uso dos Campos 51 e s2 de um FCB}

Os campos s1 e s2 do FCB săo apresentados na documentaço fornecida pela Digital Research como reservados para uso interno do sistema e nenhuma informaça adicional é dada. Na nova implementaca feita, esses campos foram usados da maneira descrita a seguir:

o campo s1 foi usado para indicar o numero do ultimo "extent" usado numa entrada de diretório;

o campos2, foi usado na versao do CP/M-LIE para tres propositos:

1. 0 bit 7 ligado indica que os 4 bits menos significativos de 52 contén o namero do driver a que se refere este FCB.

2. 0 bit 6 ligado indica que o FCB na memória está diferente do FCB armazenado no disco.

3. Os bits 0 a 3 (os bits menos significativos) indicam - nomero do driver a que se refere este FCB. Esta informaço é necessária, pois a informąăo presente no campo 'dr', usada para indicar a que driver o fCB se refere, somente é valida quando o FCB é usado para abrir a arquivo. Nesse instante, o valor zero nesse campo indica que o FCB se refere ao disco corrente. Em operaçoses subseqüentes o disco corrente 
pode ser alterado; no entanto, o FCB continua referindo-se ao mesmo disco onde foi aberto e o valor zero agora deixa de ter significado. 0 uso feito dos bits 0 a 3 do campo s2 sempre indica especificamente a qual disco um FCB se refere.

$5.4 .5-0$ Uso do [ampo "EXM" de uma DPB.

- campo EXM da tabela DPB de um disco fornece uma máscara de bits que indica os "extents" presentes na mesma entrada de diretario. Isto d, em um disco com "cluster" de tamanho igual a 1 kbyte, cada entrada de diretorio armazena um "extent" do arquivo; assim, quando é feita a máscara do numero do "extent" com EXM, que nesse caso é igual a 0 , o resultado será igual a 0 , significando que ngo há outro "extent" nesta mesma entrada de diretorio. No caso de um disco com menos de 256 "clusters" e com os "clusters" de tamanho igual a 2 Kbytes, o campo EXM é igual a 1. Quando é usada a mascara com o numero do "extent", o primeiro bit é mascarado, de forma que os nameros 0 e 1 săo considerados pertencentes à mesma entrada de diretório, tal como 2 e 3 , e assim sucessivamente.

- campo EXM do FCB pode ser usado para indicar o numero de "extents" existentes por entrada de diretorio da seguinte forma:

num. extents por ent. diretório=16/(EXM+1) 
5.4 .6 - O Uso do Campo CKS da DPB.

D. campo CKS indica o numero de entradas de diretório que devem ser testadas e, correspondentemente, no BI0S deve ser reservado espaço de tamanho igual a esse valor, cujo endereco é fornecido ao BDOS atraves do campo CSU da DPH de cada disco. E' recomendado que o valor de CKS devaser igual ao numero de entradas de diretorio (DRM), mas tal valor de teste é deixado para livre escolha do usuario pode ser especificado menor do que o numero de entradas de diretório se desejado.

No novo sistema, o teste de entradas de diretorio, cujo objetivo é confirmar que um disco nå foi trocado sem que o CP/M fosse avisado disso, foi implementado através da somatória módulo 256 dos bytes dos registros de diretorio Cconhecido como Teste de Redundancia Ciclica - CRC). Verificamos por experimentafa posterior que o CP/M também faz o teste de diretório dessa forma.

5.5. - A Implementaço do CCP Efetuada.

0 CCP (Console Command Processor) foi implementado inicialmente como um programa normal, executavel pelo sistema operacional da mesma forma que um programa de aplicacaro comum, porém armazenado em disco juntamente com os demais módulos do sistema e na como um programa, onde cada programa é armazenado individualmente em um arquivo proprio. Armazenado junto com o 
sistema operacional, esse programa é carregado juntamente com este quando o sistema é inicializado ou reinicializado ("Cold Boot" ou "Warm Boot") e, portanto, executado sempre que o sistema operacional reassume o controle do processadori. passando entao a monitorar os comandos solicitados pelo usuario.

Além disso, sendo carregado junto com o sistema Operacional, ocupa na memoria os enderecos de memoria mais altos disponiveis, $\operatorname{logo}$ abaixo dos demais modulos do sistema (Figura 5.3). Essa disposiço é importante, pois permite que esse programa execute o carregamento de outros programas solicitados pelo usuario, o qual é efetuado nos enderecos mais baixos de memória. Além disso, se o programa carregado năo necessitar dos enderecos de membria usados pelo CCP, desobriga o recarregamento do CCP a partir do disco quando o programa do usuario terminar.

Para o desenvolvimento do sistema operacional, situaços especiais de teste tiveram que ser resolvidas. Um ponto importante para a elaboraço do ambiente de teste levou em conta que o CCP pode ser tomado como um programa comum, a menos de sua posicao particular tanto de armazenagem em disco como na membria. Por isso, durante a fase de depuraço foi criado um ambiente de teste que usa esse fato para permitir manter na memoria todo o conjunto de programas necessário.

0 Apendice 2 deste trabalio traz uma listagem completa do programa fonte do CCP, em linguagem " $[$ ". 


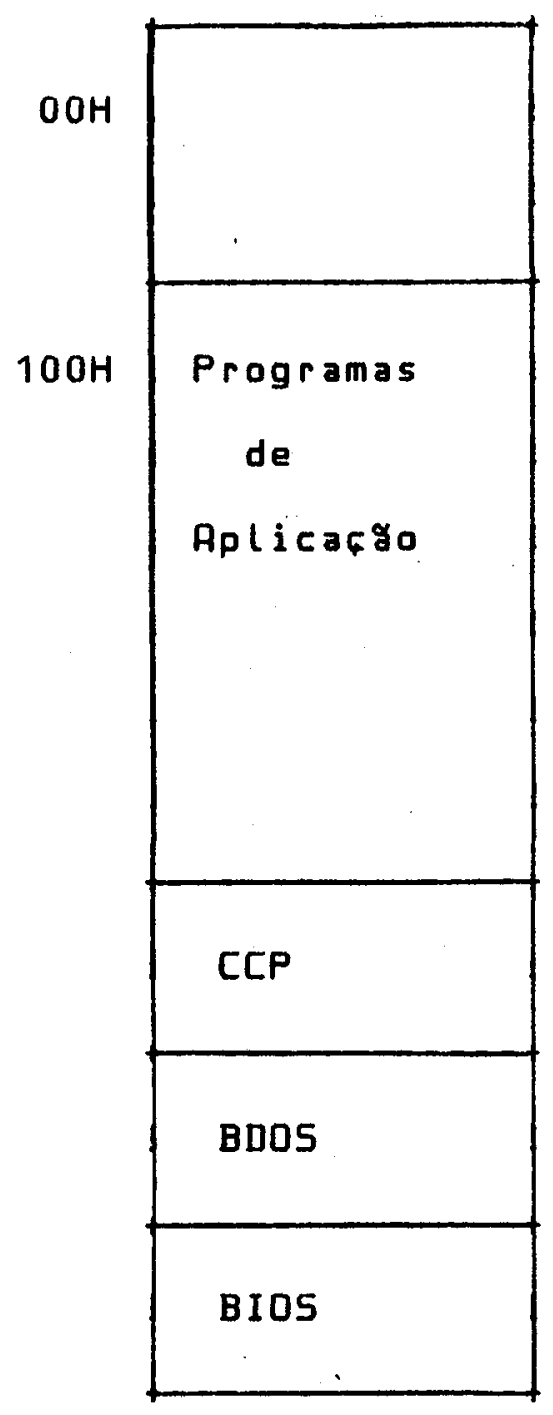

Figura 5.3 - Disposicăo do CP/M na memória.

5.5.1. - Descricăo Sumária dos Comandos do CCP, tal como Implementados.

No CCP implementado, a indicaço do nome de um arquivo pode ser feita: completamente, quando todos os caracteres do nome sao indicados, ou parcialmente, quando algumas posiços podem ser substituidas pelos caracteres '?' $e$ ' $*$ ' para a indicacao de 
posicăes no nome onde qualquer caracter é valido. Esses caracteres nao podem ser usados na especificaço do Disco. Na descricgo dos comandos a seguir, a indicacgo "nome-de-arquivo" significa que o nome deve ser indicado completamente a indicaGăo. "especificacăo-de-arquivo" significaque nomes podem ser indicados tanto completa quanto parcialmente.

A seguir sergo descritos os comandos que foram implementäos no CCP desenvolvido.

DIR - Lista o Diretório do disco

Formato: DIR [especificacgo-de-arquiva]

Significado: Lista os nomes dos arquivos que correspondem a especificaço-de-arquivo indicada. 5\%o listados 4 nomes de arquivos por linha, na ordem de sua ocorrencia no diretório do disco especificado.

REN - Altera o nomé de um arquivo

Formato: REN nome-novo=nome-vel ho

Significado: o nome do arquivo indicado como nomevelho é substituldo pelo nome-novo.

\section{ERA - Apaga um arquivo do disco \\ Formato: ERA nome-de-arquivo}

Significado: 0 arquivo indicado apagado do disco. Esse comando foi implementado de maneira diferente do CPIM padrao, onde esse comando pode ser usado com uma especificaço parcial do nome do arquivo. A alteraço foi feita para evitar que se apaguem 
arquivos acidentalmente. Para suprir essa mesma funça foi entăo criado o comando DEL.

DEL - Apaga arquivos do Disco

Formato: DEL especificaço-de-arquivo

Significado: Os arquivos que correspondem à especificafgo-de-arquivo indicado săo apagados do disco. Para que a operacago seja completada, o usuario deve confirmar o comando.

TYPE - Escreve arquivos

Formato: 'TYPE nome-de-arquivo

Significado: Escreve no terminal o contedo do arquivo indicado.

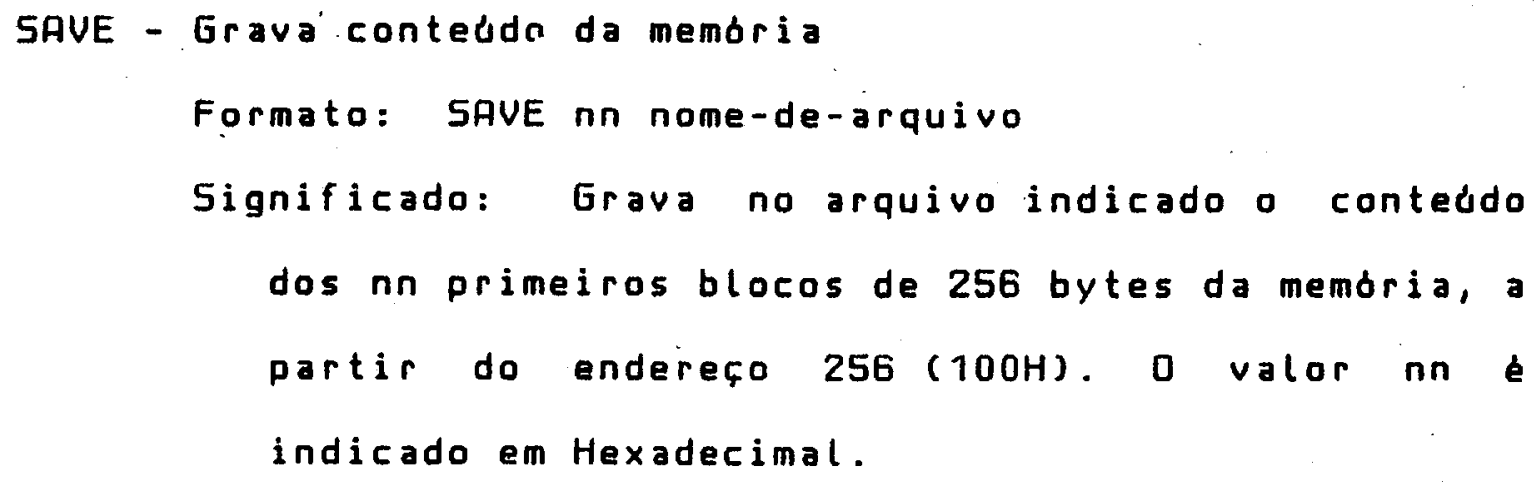


comando do usuário, para que o programa possa analisar os pargmetros indicados.

USER - Indica usuário

Formato: USER nn.

Significado: Indica o numero do usuario. O valor nn deve ser um indicado entre 0.:e 15 em decimal. Esse comando passara a ter um significado adicional na versăo multiusuario do sistema:

Qs nomes dos comandos foram mantidos em ingles por razos de compatibilidade com o sistema operacional CPIM padrao. Ds nomes dos outros comandos que foram criados, tambem foram dados em ingles; para manter-se homogeneo o conjunto de nomes de comandos.

Nao hà no entanto nenhuma dificuldade em adotar-se nomes em portugues.

5.6. - Ambiente de Teste do Sistema Operacional CP/M-LIE.

Um problema enfrentado para o desenvolvimento do Sistema Operacional consistiu na elaboraca de um plano de teste. Essa tarefa é particularmente problematica quando se trata de um sistema operacional, uma vez que todas as ferramentas e técnicas disponiveis e tradicionalmente usadas nas fases de depuracăo năo săo aplicáveis quando se trata do desenvolvimento de um 
sistema operacional. Por exemplo, ngo e posslvel que se apliquem tecnicas de rastreio, imprimindo-se determinadas variácis em pontos chaves de um programa, uma vez que a proppia rotina de impressão estaria sendo testada. Também năo se pode empregar os programas de auxilio depuraço existentes pelo fato de eles efetuarem chamadas às rotinas do sistema operacional para a comunicaca com o usuário. Por outro lado, como a maior parte do sistema foi escrito em linguagem "c", nă se tem disponivel com facilidade os enderecos, tanto de variabueis quanto de comandos chave para a depuraço.

A soluço adotada consistiu em manter-se na memória simultaneamente dois sistemas operacionais: o 5istema CP/M original e a nova versăo desenvolvida. Para efeito da discussa que se segue seráfeita a designaço do BDOS e do CCP de cada sistema como BDOS-0 e CCP-D para o sistema original, e BDDS-L e CCP-L para o novo sistema desenvolvido. 0 BIDS é o mesmo para os dois sistemas.

Dispondo do sistema original, um programa de depuraço normalmente usado (DDT) pode ser empregado bem como as técnicas usuais de rastreio. O problema passou enta a ser o de conseguir um sincronismo na operaça dos dois sistemas, de maneira que ngo houvesse conflito, apesar de ambos usarem posiços de memória comuns (aquelas especialmente definidas no padra CP/M, tais como endereço de chamada do BDos, area de acesso a disco, "buffer" de comandos do usuário, etc).

- problema de sobreposicăo da execucăo dos dois sistemas operacionais foi controlado fazendo-se com que o controle fosse inicialmente todo do sistema original e, a medida que mais e mais funços fossem tornando o novo sistema confibvel, mais e 
mais controle foi sendo passado ao novo sistema, até que o sistema original pudesse ser totalmente desativado, podendo entao ser substituido pelo novo sistema.

A primeira fase de testes consistiu na verificacao das funcốs do BDDS-L correspondentes a leitura e escrita de dados na console. Isso foi feito usando-se o DDT para carregar o BDOS-L em endereco de memoria na conflitante com o sistema original e escrevendo-se programas que chamavam diretamente o BDDS-L sob a supervisgo do DDT, que continuava chamando o BDOS-D para escrever suas proprias mensagens.

A segunda fase de testes consistiu na verificacaro das demais funç̋es do BDOS-L que tratam de dispositivos de entrada e salda que nao a console e nem disco. Nestes testes estro envolvidas as rotinas de entrada e saida na console com salda paralela na impressora. A tatica de testes usada foi a mesma da primeira fase.

A terceira fase de téstes consistiu na verificacao das funçoses do BDOS-L com acesso a disco. Inicialmente a mesma tatica anterior pode ser usada e com isso cada funço pode ser individualmente testada.

Como uma fase complementar de testes, tendo garantido o funcionamento corretó das funç8es de entrada salda na console, alguns programas simples, que nao colocassem a sua propria pilha no final da memória, tal como o 'XDIR' $e$ o ' $D$ ', foram testados para operar com o novo sistema. Para isso, usando o DDT, o programa era carregado para a memoria e inseridos num endereco 
alto de memória (que ngo entra em conflito com a programa, e nem com o BDOS-LJ.os seguintes comandos:

\section{H, BDDS-L}

SHLD 6

CALL 100

JMP $\quad 0$

a seguir o DDT executa esses comandos, o que faz com que o BDO5-0 seja desativado, ativando o BDDS-L que passa a ser acessado pelo programa, e a seguir passa o comando para o programa carregado. Ao final do programa, o retorno do comando reinicializa o sistema e reativa o sistema original, passando o controle ao [CP-O.

Dessa forma, o BDOS-L pode ser suficientemente testado. para poder ser usado sem o apoio do BDOS-Q.

A quarta fasa de testes consistiu na verificacão do CCP-L. Para isso, inicialmente o CCP-L foi carregado na memória como um programa comum, com o seu comando de carregamento de outros programas desativado. Dessa forma, todos os seus comandos puderam ser testados. 


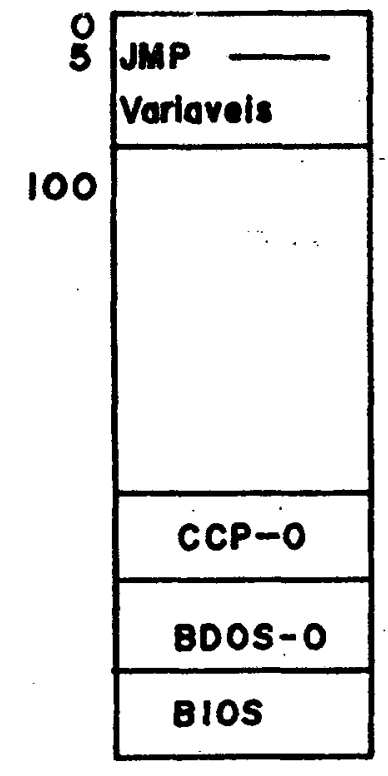

o)

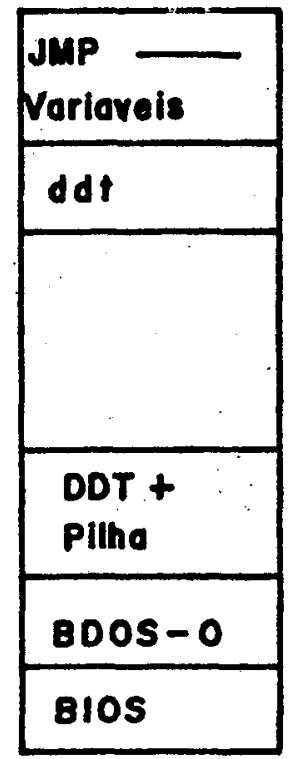

b)

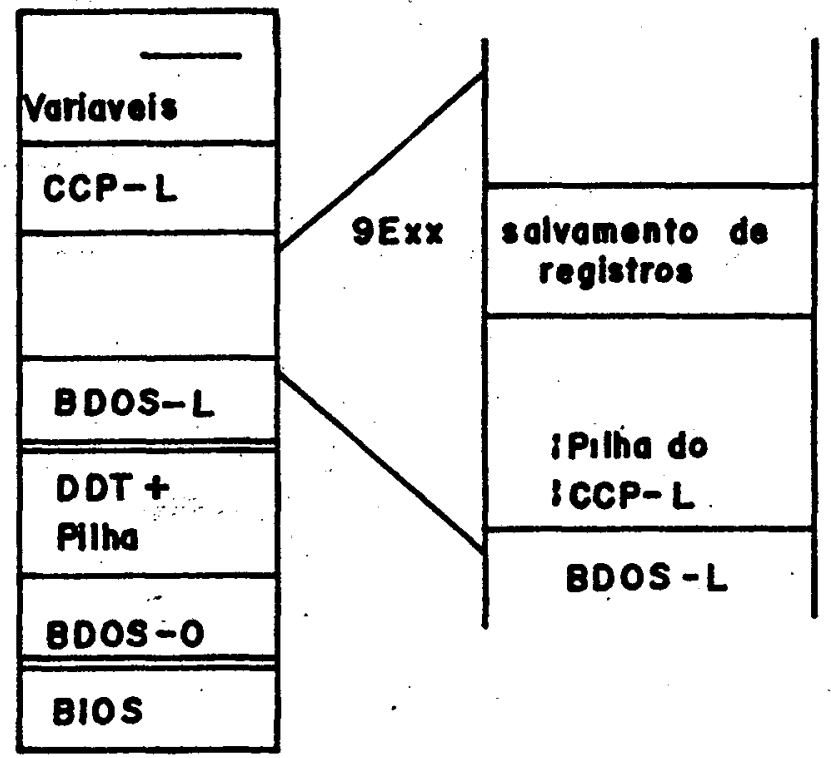

c)

d).

Figura 5.4. - Disposicgo: da memoria para teste.

A quinta fase de testes consistiu na verificacaro de todo o novo sistema operacional em operacaro integrada. Para isso foi montado o ambiente mostrado passo a passo na Figura 5.4. Cada parte dessa figura é explicada a seguir:

a) aparece o esquema de memória existente com a operacão normal do $[P / M$.

b) aparece o esquema de membria quando o DDT é executado, onde se nota que o CCP-D é substituido pelo próprio DDT. Nesse ponto, a pilha usada pelo sistema origina-se na 
posiçั $100 \mathrm{H}$.

c) aparece a disposicăo de memória quando o BDOS-L e o CCP-L operando como um programa normal estyo na memoria. Nesse ponto, deve-se considerar a disposicaro das pilhas usadas pelos varios módulos presentes na memória. 0 BDO5-0, que foi utilizado para o carregamento dos demais modulos esta agora desativado, e portanto nao necessita de espaco para pilha. 0 DDT usa uma pilha interna, que năo afeta os demais módulos. 0 BDOS-L já estará usando uma pilha interna, e somente o C[P terá, como um programa comum, a pilha no topo da memoria. Como existem enderecos usados pelo BDO5-L nesse ponto, é necessario que se tome a precaucăo de năo haver conflito nesse ponto.

d) mostra um detalhe dessa regigo de memoria. Executando a mesma sequencia de instrucóces da fase tres, o BDOS-L e o CCP-L estargo em operacăo, tendo sido desativados a BDDS0 a o CCP-O. D novo sistema operacional pode entgo ser testado em operafăo real.

O Ultimo passo consiste na gravaça do BDOS-L e do CCPL nas trilhas do disco reservadas ao sistema, para que durante o carregamento do sistema (Warm Boot) este seja carregado, e o novo sistema. Como o sistema operacional escrito em linguagem "[" e maior do que o sistema original, este năcabe nas 2 trilhas reservadas para is50. Existem tres alternativas para isso:

- criar um novo formato de disco, com mais trilhas reservadas, e alterar a rotina de carregamento, para carregar as trilhas adicionais;

- substituir o boot do sistema original por um novo boot, 
que obtenha o sistema em outras trilhas que náo. as duas originais;

- Manter o sistema em ROM, em um espaco de enderecamento que năo entre em conflito com os programas de aplicacăo.

No segundo caso, as duas trilhas ariginais na seriam aproveitadas para sistema, porem representa uma alternativa mais favorăvel a novas alteraçôes posteriores. Como se pretende continuar a expandir esse novo sistema, e por ora năo se ira usar o sistema em aplicacores reais que demandem grande eficiencia, essa alternativa foi provisoniamente adotada. Quando o desenvolvimento do sistema estiver completado, a primeira alternativa poderá ser implementada, ou pode-se gravar a maior parte do sistema em EPROM, num espaco de enderecamento que permita o chaveamento entre a memoria de usuario a do sistema operacional.

5.6.1. - Avaliaços Efetuadas no CP/M Implementado.

0 BDOS do novo sistema operacional pode ser melhor testado depois que o CCP foi implementado, permitindo que o BDDS e o CCP fossem testados em operaço real. D sistema foi testado em uma maquina que dispore de discos de $8^{\prime}$ e de $5^{\prime} 1 / 4$, com formatos de disco para densidade dupla ou simples, e para face simples ou dupla.

Alem disso o sistema foi testado em situaçes reais de execucao de programas escritos para esse sistema, tendo os programas sido executados normalmente, sem nenhuma alteracgo em 
relą̧̃o à sua execuço sob o sistema da Digital Research.

No entanto, o tamanio do codigo gerado pelo compilador utilizado é cerca de duas vezes e meia maior do que o código suprido pela Digital Research; essa caracteristica restringe o uso de varios programas escritos para o CP/M que necessitam de toda a memoria disponivel. Esse problema pode ser sanado colocando essa implementaço em EPROM, operando fora do espaco inormal de endereçamento dos programas de aplicaço.

5.7 - Expansa do Sistema para uma Versa Multiusuario.

A primeira providencia para que um sistema possa se tornar multiusuario corresponde à implementaço de proteçes nos arquivos de cada usuario, para controlar o acesso a cada arquivo. Para que isso pudesse ser feito, foi necessario criar o conceito de area do usuario. Para tanto, um novo camando, que permitisse a identificaço de um usuário como pertencente a uma certa área. Esse comando recebeu a nome de LOGIN. Esse novo comando poderia ser implementado como um novo comando do CCP ou como um programa a parte. Devido ao fato de ser pouco usado Capenas para se entrar em uma area, e a seguir năo ser mais requisitado), optau-se pela sua implementacaro como un programa a parte. Esse programa e descrito na sub-seça 5.7.5.1, e uma listagem completa do programa fonte em linguagem " $[$ " é apresentada no Apendice 3 deste trabaltho. Assim, ao entrar no sistema, um usuario devera executar - programa LOGIN para se identificar e obter acesso a sua área. 
5.7.1. - Como o Esquema de Proteça foi Implementado.

0 Sistema Dperacional CP/M padra oferece a possibilidade de distribuir os arquivos armazenados em um disco entre 16 usuarios, identificados por um numero especificado em decimal de 0 a 15 , .... atraves do comando USER. Esse comando na representa uma boa alternativa para atribuica de protecão a arquivos, uma vez que pode ser dado a qualquer hora, permitindo que qualquer usuario mude a qualquer instante a seu numero, bem como naro tem associado nenhum esquema. de protecara as arquivos.

Apresenta, no entanto, a vantagem de identificar cada arquivo gravado no disco com um numero de usuario "dono" do arquivo. Essa identificacaro é feita atraves do primeiro byte do FCB ("UserCode") do arquivo no diretorio e, apesar de ser usado para armazenar um namero de 0 a 15 , 05 demais valores que pode armazenar năo têm significado.

A indicaço de área para a versăo multiusuario deve obrigatoriamente poder ser implementada sem alterar a estrutura básica do CP/M; isso significa que o numero de bytes de um FCB armazenado em disco nao pode ser alterado. Dessa forma, o byte "Usercode" do FCB passou a ser usado paraindicar a area a que um arquivo pertence. Para năo entrar em conflito com as especificaçases originais do CP/M, o comando USER continua a ser usado como antes, identificando usuários de 0 a 15 , e comando LOGIN permite que se estabeleca a área do usuario, a qual sao dados numeros de 16 a 223.

- esquema de protecgo de arquivos é baseado na área a 
que o usuário pertence, a qual somente pode ser estabelecida pelo comando LOGIN; usando o comando USER o usuario pode acessar qualquer área de 0 a $223(0 H$ a $O D F H)$, porém com o codigo de proteço obtido pelo comando LOGIN. 0 ndmero 229 (OESH) ja é usado para indicar que uma entrada no diretorio corresponde a uma posicgo livre no diretorio (e ngo a um $F[B)$, e por isso ngo poderia ser usada para indicar um numero de área. 0 numera 224 (OEOH) foi designado como a área onde o arquivo de usuários (que nao deve pertencer a nenhuma área de usuarios estarágravado em um disco. Um disco que ngo tenha um arquivo nessa área irá ser considerado como um disco preparado por uma versăo năo Multiusuaria (a versa original) do CP/M e, dessa forma, sera tratado como ná tenda nenhum arquivo em alguma área de usuário.

Assim, passam a existir dois numeros que permitem ao usubrio ter acesso a qualquer arquivo: o numero de sua área (obtido pelo camando LOGIN) e o numero de usuario (obtido pelo comando USER). Sempre que o numero de area for igual ao numero de usuario, o usuário estara acessando arquivos de sua propria área, e o acesso aos arquivos se farápelos codigos de acesso do usuario de cada arquivo. Sempre que as numeros de area e de usuario forem diferentes, o usuário estaráasessando arquivos de áreas que năo săo suas e o acesso aos arquivos se fará pelos codigos de acesso externo de cada arquivo.

Ds dois numeros de área e de usuario sao mantidos nas posicốs 12 e 13 para permitir a restauraço desses numeros depois de cada reinicializacaro do sistema ("Cold Boot"). A posicgo 4, originalmente usada para armazenar o numero do disco "default" atual e numero do usuario, passa a ser usada apenas para armazenar o numero do disco "default", uma vez que agora a 
posifgo usada para armazenar o numero do usuario passa a ter todos os seus bits usados para armazenar esse numero. As posicós 8 a 11 năo foram usadas por corresponderem a enderecos do vetor de interrupcoles do Micro-processador 8080 .

Dessa forma, para efeito de protecaro, o sistema passa a contar com a seguinte estrutura:

- ao entrar no sistema, antes de efetuar um comando LDGIN, - usuario náo estará associado a nenhum numero de área e tera, portanto, acesso apenas a arquivos com os numeros de usuario de 0 a 15 , com o acesso que estiver especificado para usuarios externos em cada arquivo dessas áreas, porém sem poder alterálos. Pode igualmente criar arquivos nessas áreas;

- após executar um comando LDGIN, o Usuario teráacesso a todos os arquivos da area indicada, podendo alterar o código de acesso de qualquer arquivo dessa áreai

- executando comandos USER, o usuario pode passar para qualquer outra area porem, a menos da área onde o LOGIN foi indicado, o acesso a arquivos segue o padra de autorizaçoses de acesso especificado para usuarios externos em cada arquivo e nao pode alterar o codigo de acesso de nenhum arquivo. Além disso, somente pode criar arquivos se a área indicada no comando USER for uma das de námero 0 a 15. 
5.7.2. - Tipos de Protecăo.

Existem seis tipos de protecgo que podem ser associados a um arquivo, sendo tres para o usuario dono da área e tres para usuários externos à área. Essas proteçós să as seguintes:

Para o usuario Dono da Area:

- Apaga - indica se o usuario pode apagar ou nao a arquivo;

- Escreve - indica se o usuario pode alterar ou nao o arquivo. Corresponde a protecaro já existente no CP/M, reconhecida como R/O (indica que o arquivo somente pode ser $(i d o)$;

- Le - indica se o usuario pode ler ou năo o arquivo.

Para os usuarios Externos à área:

- Escreve ' indica se o usuario pode alterar ou naso arquivo

- Le - indica se o usuario pode ler ou năo o arquivo.

- Executa - indica se o arquivo pode ser executado pelo usuário.

Ds arquivos que contên programas podem sempre ser executados pelo usuário dono da area e, portanta, náo precisam de um bit que condicione essa operaço. Por outro lado, um usuario externo à área nunca poderá apagar um arquivo, prescindindo também de um bit que condicione essa operacaro.

A proteça de cada arquivo é armazenada no diretório do disco, no FCB de cada arquivo, usando para isso o bit 7 (bit de paridade) de cada byte usado para armazenar o nome e extensa de 
cada arquivo. A atribuicaro de cada bit para indicar as formas de

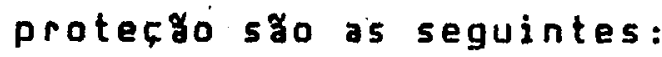

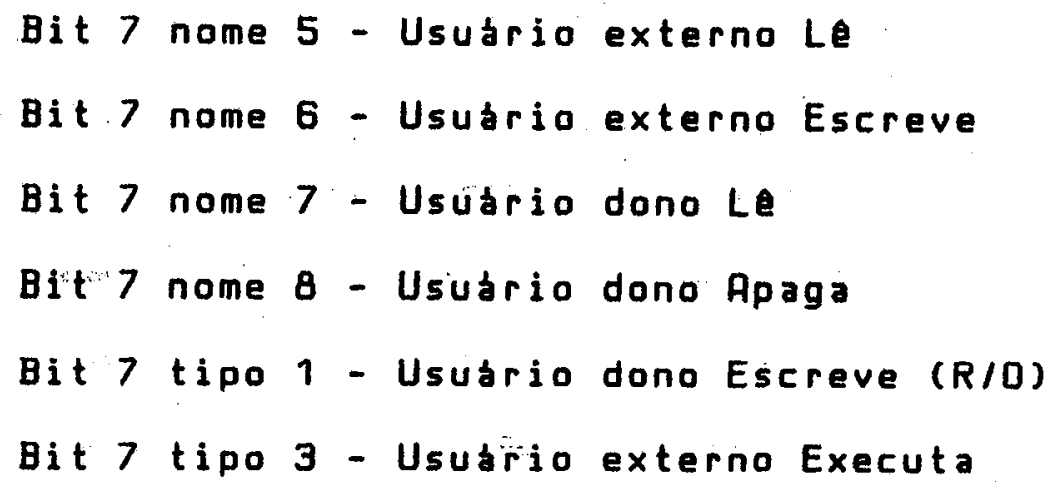

Note-se que obit correspondente ligado $(=1)$ impede que a operafăo correspondente seja efetuada e desligado $(=0)$ permite a operaço.

Note-se tambem que um usuario externo năo pode nunca apagar um arquivo que ná é seu e um usuario pode sempre executar um arquivo que é seu. Nao foram atribuldos meios de alterar esses dois casos para năo ser necessário usar os bits 7 dos caracteres 1 a 4 do nome de um arquivo; o que pela especificacá do CP/M deve ser deixado para uso por programas de aplicacaro (ver figura A1.b no apendice 1 deste trabalhol.

5.7.3. - Descriço do Arquivo de Usuários

Para que um disco possa ser usado para incluir arquivos de usuários com código de área superior a 15, e necessario que seja criado un arquivo denominado "TABUSER" com codigo de area igual a $224(\mathrm{OEOH})$; contendo a descriço de cada usuário. Isso é feito através de um programa especial desenvolvido, '. denominado 
ACNT (parodiando o programa com funcoges semelhantes no sistema R5X-11M do PDP-11), o qual permite ainda a identificacaro dos usuários autorizados, juntamente com a especificacao da palavrachave de identificaço de cada usuario. A listagem completa do programa fonte do ACNT em linguagem "C" encontra-se no Apendice 4 deste trabalho.

- Arquivo de usuarios consiste de 208 registros de 32 palavras, alocados desde a criacgo do arquivo, contendo os seguintes campos:

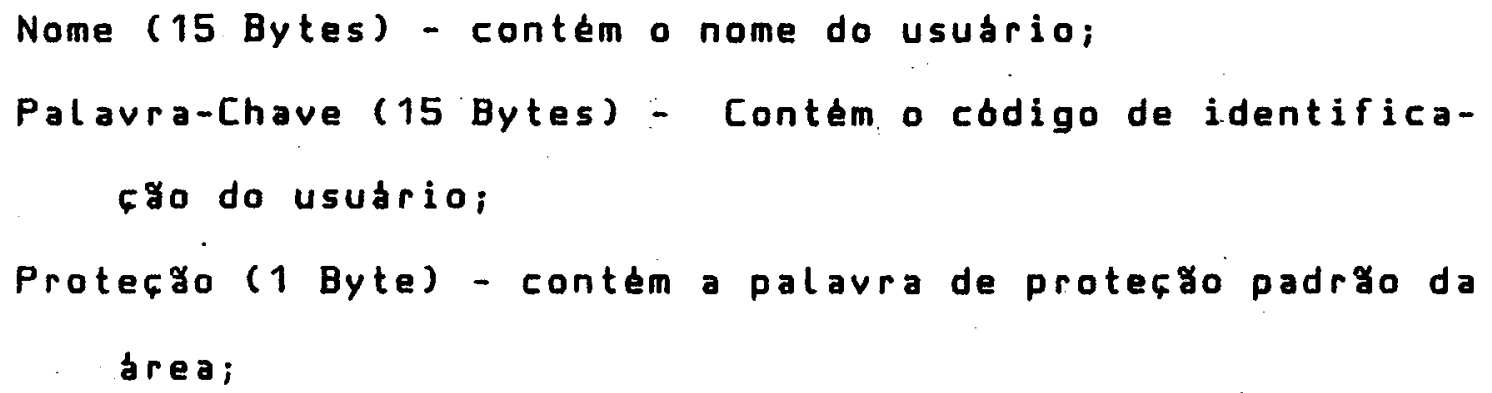

5.7.4. - Palaura de Proteção Padrao da Area.

Guando um novo usuario é incluldo no Arquivo de Usuários é atribuido a ele um conjunto de proteç一es padrão com que os arquivos criados em sua área săo inicializados. Esse conjunto de protecoles é especificado em um anico Byte, onde cada 
bit é atribuldo a uma forma de proteço posslvel.

O significado de cada bit nessa palavra é oguinte:

Bit 0 - Obrigatoriamente 0

Bit 1 - Ususrio Externo Le

Bit 2 - Usuário Extérno Escreve

Bit 3 - Usuário Dono Le

Bit 4 - Usuário Dono Apaga

Bit 5 - Usuário Dono Escreve

Bit 6 - Arquivo do Sistema

Bit 7 - Usuário Externo Executa

Note-se que um bit ligado $(=1)$ indica que a operaço correspondente esta proibida. OHit. 6 corresponde à operaça já existente no CP/M de indicar que o nome do arquivo naro deve ser listado em. um comando DIR (ver figurata no apendica 1 deste trabalhol.

5.7.5. - Programas Utilitarios Desenvolividos.

Para dar suporte ao novo esquema de protecaro de arquivas, dois novos programas foram desenvolvidos, os quais ja foram mencionados na secáo anterior. Estes sergo descritos a seguir. 
5.7.5.1. - C Comando LOGIN.

Esse comando esta implementado como um programa de aplicacgoe, portanto, acionado executando-se esse programa a partir da area onde ele esteja gravado. Em un disco usado com a versaro Multiusuario do Sistema preconiza-se que esse programa seja mantido na área zero. É executado entrando-se com o comando:
A)LOGIN
O programa ira perguntar ao usuario:

Nome do Usuário:

em resposta o usuario devera indicar o seu nome armazenado no Arquivo de Usuários. A seguir o programa irs perguntar:

\section{Palavra-Chave:}

em resposta o usuario devera indicar a sua palavra-chave correspondente. Note-se que essa palavra ngo sera ecoada no terminal. A seguir o programa iráverificar no arquivo de usuarios se existe uma entrada correspondente e, havendo, estabelecerá o numero da área e numero de usuario com o valor apropriado. Nesse ponto o usuario terá obtido acesso aos arquivos de sua área.

Este programa foi escrito em Linguagem " $[$ ", como um 
programa de aplicąăo comum, cam a diferença que esse programa usa as novas funçós do Sistema Dperacional apresentadas na seço 5.7 .6$.

Em um sistema que for inicializado a partir de um disco para o qual ja tenha sido criado o Arquivo de Usuarios, pode-se colocar o comando LOGIN em um arquivo de comando que seja executado sempre que o sistema for inicializado, forcando o usuario a ter sempre definido um numero de área.

\subsubsection{2. - 0 Comando ACNT.}

Esse comando esta implementado como um programa de aplicação, portanto, é acionado executando-se esse programa a partir da area onde ele esteja gravado. Em um disco usado com a versa Multiusuario do Sistema preconiza-se que esse programa seja mantido na área de um usuário responsável pela manutenço desse disco. Inicialmente deve ser colocado na área zero, para a criaçăo do Arquivo de Usuarios e, a seguir, depois da criaça da area desse usuário, deve ser levado para essa area, e retirado da área zero. E' executado entrando-se com o comando:

\section{A > ACNT.}

- programa irá verificar se existe no disco o arquivo "TABUSER" na área especial $224(O E O H)$. Se năo existir, este será criado. A seguir será solicitado ao usuario uma operaça a ser executada, através da pergunta: 


\section{DPERACAO ?}

Existem 4 sub-comandos do subcomando ACNT que podem ser solicitados: LISTA, CRIA, RETIRA e FIM. O usuatio pode responder digitando apenas a primeira letra do comando. Oprograma passa entao a executar o comando solicitado.

\section{Subcamando LISTA:}

Este subcomando lista no terminal o Arquivo de Usubrios, incluindo o nome de cada usuário, sua palavra-chave, código de proteço padrăo numero da área do usuario.

\section{Subcomando CRIA:}

Este subcomando permite a colocaca de un novo usuario no Arquivo de Usuários. Ao ser solicitado, o programa pergunta em sequencia:

$$
\begin{aligned}
& \text { Nome do Usuario: } \\
& \text { Pal aura-Chave: } \\
& \text { Proteço Padrao: }
\end{aligned}
$$

Se năo houver mais espaço no arquivo ou se já existe um usuario com o mesmo nome e mesma Palavra-chave, o comando CRIA ngo é efetuado, indicando ao usuario o motiva. 0 Código de Proteço Padra deve ser dado em Hexadecimal. Uma vez criado, o programa atribui o numero da area do usuario, distinto de todas os demais existentes, e informa esse numero ao usuario. 
Subcomando RETIRA:

Este subcomando retira o usuario do Arquivo de Usuarios. Ao ser solicitado, o programa ACNT pergunta: .

Nome do Usuário:

Palavra-Chave:

Uma vez localizado esse usuario, ele é retirado do arquivo Liberando o numero da área correspondente para usuarios futuros.

Subcomando FIM:

Este subcomando encerra a execucga do programa ACNT.

Este programa foi escrito em Linguagem " $[$ ". como um programa de aplicacaro comum, com a diferenca que esse programa usa: as novas funcồes do 5istema Dperaçional apresentadas na seça 5.7.6. para a criaço e acesso ao Rrquivo de Usuários, mantido na area especial 224 (OEOH).

5.7.6. - Extenszes ao BDOS.

Para a realizaço da extensao ao CP/M que o torna multiusuario, várias alteracóes tiveram que ser feitas em varias funcăes já existentes, assim como novas funçes tiveram que ser criadas. No Apendice 1 está uma listagem do novo BDOS com essas alteraçäes jà incluidas. 
Foram atribuldos significados a mais tres palavras da area de variácis do CPM. Seus enderecos e seus respectivos significados 5 ชัo os seguintes:

Palavra 12 - Armazena o número do usuário corrente;

Palavra 13 - Armazena o numero da Area corrente;

Palavra 14 - Armazena o codigo de protecăo padra da área corrente.

As palavras de endereco 8 a 11 nă foram utilizadas por corresponderem a endereços de interrupca do Micro-Processador 8080 .

As funçôes alteradas s̆go as seguintes:

Funço 15 - Dpen File: Deve verificar se o arquivo pode ser lido ou escrito pelo usuario atual;

Funco 16 - Close File: Deve verificar se o arquivo pode ser escrito pelo usuario atual;

Funça 19 - Delete File: Deve verificar se o usuário atual é o dono do arquivoe, se o for, se ele pode apagar o arquivo;

Funcăo 20 - Read Sequencial: Deve verificar se o usuário pode Ler o arquivo;

Funcaro 21 - Write Sequencial: Deve verificar se o usuario pode escrever o arquivo; 
Funçăo 22 - Make File: Deve verificar se o usubrio e dono, ou se a área é menor do que 16;

Funcao 23 - Rename file: deve verificar se o usuario é o dono e, se ofor, se ele pode escrever no arquivo.

As funcóes criadas să as seguintes:

Funço 50 - Set/Get Full User Code: Verifica o conteddo do registrador E. Se for igual a OFFH retorna no registrador $A$ o numero do usuario corrente. Se for outro valor, atribui esse numero como o usuario corrente;

Funço 51 - Set/Get Login Code: Verifica o contedudo do registrador E. Se for igual a OFFH, retarna no registrador $A$ o numero da area corrente. Se for outro valor, atribui esse namero como a area corrente;

Funço 52 - Set/Get Protection code: Verifica o conteddo do registrador E. Se for igual a OFFH, retorna no registrador $A$ o codigo de protecaro corrente. Se for outro valor, atribui esse numero como o código de protecao corrente. 
5.7 .7 - Alteraç8es no CCP.

o CCP original foi alterado en duas de suas funcóes originais: inicializacăo do sistema e comando de execuço de programas.

Quanto à inicializaço do sistema, foi incluida a busca dos valores de Usuario Corrente, area Corrente e Codigo de Protecgo Corrente, respectivamente, nas posicoles 12 a 14 , e a correspondente reinicializacgo desses valores no BDos.

Quanto a execufgo de programas, foi incluida a verificacaro de se o dono do arquivo a ser executado a usuario corrente pois, se ngo o for, a execuço proibida.

\section{8 - Conclusores}

D sistema operacional CP/M foi originalmente concebido como um sistema operacional monousuario. Mas como é um sistema amplamente usado em microcomputadores de 8 bits, possuindo uma grande quantidade de software ja desenvolvido para ele, é bastante interessante conseguir-se a sua expansa para um sistema operacional multiusuario.

Ho ser concebido o sistema de processamento de dados distribuldo pelo Grupo de Instrumentaço Eletranica do IFOSC, verificou-se que seria vantajoso construir tal expansăo multiusuario para o CPIM; porém, isso obrigou a que se dispusesse de um sistema com as mesmas caracteristicas do CP/M já existente, 
para, a partir dal, obter a expansão para a versăo multiusuário. Dessa forma começou a implementaçă do sistema CP/M-LIE.

Depois de desenvolver a versao monousuario do CP/M, partiuse para a ampliaça desse sistema para a versao multiusuario, implementando-se a parte de protecăo a arquivos e tambem a separaço dos usuarios em áreas espectficas.

Note-se que o próprio processador na permite esquemas de protecăo invioláveis, uma vez que năo existem posicốs de memória protegidas e nem instrucores protegidas no conjunto de instrucares do processador. Dessa forma, todo o esquema de protecaro implementado baseia-se no fato de que as novas funcoses incluidas no sistema năo sag chamadas pelos programas ja existentes a sua existencia, bem como o significado das posicóes 12 a 14 de memória, sgo desconhecidas do usuário. Se o usuário escrever programas que usem essas novas funcibes (tal como - foram os programas LOGIN e A[NT) ou se o usuario manipular diretamente as posiçós 12 a 14 , todo o esquema de proteça pode ser arbitrariamente manipulado por qualquer usuario.

Deve-se ressaltar que devido as proprias limitaços do processador, tem-se que o sistema operacional implementado tem caracterlsticas de um sistema multiusuario; porem, nao é um sistema que admite multiprogramaço pois nao admite concorrencia. No entanto, essa caracteristica năo afeta o desempenho do sistema implementado no IFOSC, pois nessa arquitetura cada processador executa um programa independente dos demais. 0 acesso. aos arquivos, que feito de maneira centralizada, tem o problema de concorrencia resolvido pelo gerenciador de memoria cache. 
CONCLUSEES E LINHAS DE FUTURAS PESQUISAS

6.1 - Introduço

O sistema operacional CPIM padra foi originalmente concebido como um sistema monousuario. Mas como é um sistema operacional grandemente usado en microcomputadores de oito bits, e possui uma grande quantidade de software disponivel para ele, tornou-se interessante utiliza-lo no sistema de processamento de dados desenvolvido pelo Grupo de Instrumentaço. Eletronica do Instituto de flsica e Quimica de Sro Carlos. Como foi visto no capltulo 2 desta dissertacro, trata-se de um sistema de processamento de dados distribuldo.

Esse sistema operacional, tema desta dissertaço, que foi desenvolvido no Laboratorio de Instrumentaça Eletrónica (LIE) do Instituto de Fisica e Quimica de 5ao Carlos, demonstrou que é factivel desenvolver totalmente um sistema operacional multiusuario a partir de conhecimentos basicas definidos no sistema operacional. CP/M, de tal forma que atenda a todas as especificaçes desse sistema e que se mantentia a execuca de aplicativos sob o sistema CPIM.

- $A$ esse novo sistema operacianal foi dado o nome de 
CPIM-LIE, e foi em sua grande maioria desenvolvido na línguagem "[", com algumas poucas rotinas de integraca escritas en linguagem assembler do processador 8080 .

Dispondo de um sistema operacional totalmente compativel com o sistema operacional CPIM, do ponto de vista de aplicativos e da estrutura de arquivos, mas agora com toda a documentafăo sobre tal sistema, pode-se desenvolver um sistema com os recursos necessários para atender às necessidades de um ambiente multiusuário.

\section{2 - Conclusbes Gerais}

Como se dispơe do código fonte do sistema operacional CP/M-LIE, pode-se adapta-lo às especificacóes que o ambiente exigir. Consequientemente foi simples expandir o sistema operacional CP/M-LIE para um sistema operacional multiusuario, plenamente adaptado a arquitetura de hardware que havia sido montada. Tambem permitiu que a interface com, o. usuario apresentasse novas caracteristicas, que se julgaram interessantes, através de modificaços no módulo CCP.

Plém disso, tendo sido escrito em uma linguagem de alto nivel, o sistema pode ser levado para qualquer sistema computacional que disponta de un compilador " $C$ ".

Uma outra caracterlstica importante que foi incorporada à implementaça é o gerenciador de memória cache. Através dele é feito o controle de concorrencia dos varios usuarios aos arquivos que estarocentralizados. Além disso o esquema de cache acelera a 
execucaro do sistema como um todo, mantendo na memóia os registros mais acessados pelos usuarios em geral.

D algorltmo de controle implementado constitui-se em um algorltmo de busca sob demanda, com reposicgo baseada no uso, alocarido sempre umsespaco fixo de memória. Para substituifá de blocos na memoria cache, o algoritmo emprega uma combinaça do algoritmo LFU (Least Frequently Used) com o LRU (Least Recently Used). O algorltmo implementado reune as vantagens do LFU com as do LRU, pois escolhe para substituicgo de blocos no cache aquele que esta há mais tempo sem ser usado dentre os blocos menos frequentemente acessados. Além disso; Localiza rapidamente a presenca de um bloco no cache e qual o seu endereca, năo sendo também oneroso em tempo para manutenço da estrutura de acesso. Dessa forma o algoritmo desenvolvido mostra-se altamente conveniente para ser implementado na arquitetura utilizada.

\section{3 - Linhas de Futuras Pesquisas}

\section{Pode-se considerar que o amago desse trabalho consistiu} no desenvolvimento de um sistema operacional para

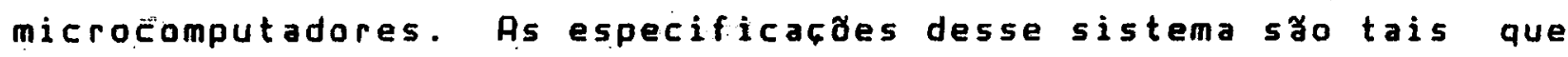
permitem que programas desenvolvidos para o sistema operacional CPIM sejain executados sob esse sistema sem alteraçes. No entanto, sendo um sistema autonomo; muitas novas caracteristicas podem ser-lhe acrescentadas: 


\section{3 .1 - Substituiço do Microprocessador}

Uma possibilidade o seu transporte para outras arquiteturas, $t a l$ como por exemplo o sistema IBM-PC ou compativeis. Nesse caso, ter-se-ia um ambiente CP/M em execuço em um $P[$. Essa alternativa ngo tgo vantajosa quanto a sua implementaço em oito bits, pois a grande maioria de software desenvolvido para o PC requer um ambiente MS-DDS. No entanto, camo o ambiente de programas .COM do DDS é identico a CP/M, o transporte do CPIM para o IBM-PC disporia ao menos desses programas. Alem disso, essa possibilidade e interessante no caso de se substituir o processador 280 da arquitetura implementada no Laboratorio de Instrumentacăo Eletronica por um processador. B086 ou 80286 .

\subsection{2 - Dtimizar o Uso de Unidades de Disco}

\section{Dutra alternativa interessante constitui-se na} alteraça do módulo gerenciador da estrutura de disco, para que um outro formato seja manipulado pelo sistema. Um exemplo seria a manutencro de disquetes em formato do M5-D05, em microprocessadores de oito bits. Um sistema que fosse capaz de manter disquetes simultaneamente nos dois formatos seria interessante por razoses de compatibilidade.

Porem, mais importantedo que isso, é fato de que pode ser criado um novo formato de disco, que aproveite melhor os recursos oferecidos pelas novas unidades disponiveis, e de acordo 
com as necessidades especificas da arquitetura implementada. Assim, seria desejál que se pudesse manter as estruturas convencionais para acesso a disquetes, mantendo dessa forma a compatibilidade com outros sistemas e, ao mesmo tempo, permitindo que as unidades de disco rigido irremoviveis fossem otimamente aproveitadas.

\subsection{3 - Acesso a Bases de Dados Distribuidas}

Quanto à implementaço realizada, o sistema operacional foi colocado na máquina de maneira que cada estaca de trabalho dispre do sistema completo. Isso tem a vantagem de permitir que cada estacaro de trabalho possa operar sozinha se tiver que acessar apenasios seus disquetes locais. Por outro lado, essa forma de implementaço impede que se explore totalmente a concorrencia que de outra forma poderia ser conseguida pelo sistema. Por exemplo, o acesso a arquivos éfeito de forma que. somente um processador pode acessa-lo para escrita. Isso impede que, por exemplo, uma base de dados possa ser compartilhada por mais do que uma estaço de trabalho, pois o controle é feito a nivel de arquivo - o processador central naro sabe a uso que cada estacgo de trabalho faz dos registros que the passa.

Uma alternativa de implementaça seria manter a parte de gerenciamentade arquivos do sistema operacional centralizado no processador central. Com isso, o processador central disporia de toda a informaço sobre o uso que se faz dos registros de dados e seria possivel entgo efetuar a protecaro a nivel de 
registro. No entanto, cada estaço de trabalho nao mais poderia operar sozinha e seria necessario implementar novas funcoses no BDos, para permitir a um programa de aplicaca solicitar elou liberar o travamento de registros de arquivos.

6.3.4 - Desenvolvimento de Processadores de Comando Alternativos

Em um sistema operacional, a grande dificuldade de desenvolvimento está centralizada nos módulos de gerenciamento, tais como os gerenciadores de arquivos, memória, etc. 0 módulo processador de comandos do usubrio pode muitas vezes ser visto simplesmente como um programa de aplicacaro usual, com a unica caracteristica adicional de ser ativado pelo sistema quando nao houver outro programa em execucao. Nesse sentido, o módulo CCP do sistema operacional CPIM pode ser substituldo por outro, com as caracteristicas desejadas pelo usuario.

Normalmente, o CCP é carregado junto com o restante do sistema operacional e portanto ocupa memoria cou é carregado ao final da execucăo de cada aplicativo e portanto gasta tempo. de carregamentos. O seu tamanho deve ser mantido o menor possivel, incorporando apenas os recursos que sejam indispensáveis: No entanto, na arquitetura utilizada, pode-se explorar o recurso de manter o Processador de Comandos em um banco de ROM, eliminando a necessidade de mante-lo diminuto. Pode-se assim considerar a possibilidade de se desenvolver um outro Processador. de Comandos mais poderoso, contendo recursos que sejam desejaveis ao uso que se pretende fazer desse sistema. 


\section{IMPLEMENIACXO DQ BDQS}

Esta implementaço foi desenvolvida em sua maior parte na linguagem de programaço $C$, com algumas rotinas de inicializacăo em assembter do processador 8080. A primeira versăo do BDOS implementada era constituida por 21 rotinas, cujas caracterlsticas sera explicadas a seguir:

- BD05: Rotina escrita em assembler, que coloca no topo da memória dispontuel (AOFF hex) os parametros de entrada para as chamadas do BDDS.

-BDOSC: Rotina escrita em linguagem C. E' a rotina principal, que analisa e executa o conjunto de chamadas do BDos.

- BDOSI: Rotina escrita em linguagem $[$, que inicializa as variáveis globais usadas e o endereco dos registradores.

- BDDSF : Rotina escrita em assembler, que restaura as registradores usados pelas demais rotinas, para o 
retorno ao programa de aplicacăo.

- CRIAENTDIR (drv): Rotina escrita em linguagem $C$, que cria a entrada de diretório que está no FCB atual e a grava em disco.

parametro:

drv -s numero do driver onde será gravado o FCB.

- GRAUADIRBUF: Rotina escrita em linguagem $C$, que grava o registro de diretório mais recentemente lido pela rotina LEDIRBUF, já possivelmente alterado.

- GRAUAENTDIR: Rotina escrita em linguagem C, que grava uma entrada de diretorio apontada pela variavel global FCBm, na entrada de diretorio já previamente Localizada, apontada pela variáuel global FCBp2.

- GRAVAREglog (a): Rotina escrita em linguagem $[$, que grava o registro lógico do CP/M, na trilha já posicianada, do endereço de DMA já estabelecido.

parametro:

a -) numero do registro ldgico.

- LEDIRBUF (drv, reg): Rotina escrita em linguagem $C$, que deixa 
na area de diretório o registro solicitado.

pargmetros:

drv -) namero do "driver" em que será lido o registro;

reg - $\rightarrow$ numero do registro que será lido.

- LEENTDIR (drv, ed): Rotina escrita em linguagem $[$, que traz a entrada de diretorio 'ed' do driver 'drv' para a membria apontada pela variácel global FCBPZ, retornando zero se nao há erro:

- LEREglogicD (a): Rotina escrita em linguagem $[$, que le a registro logico do CPIM, na trilha já posicionada. parametro:

à -) número do registro lógico.

- LIMPBMAP ( $n$ ): Rotina escrita em linguagem $[$, que limpa o bit referente ao "cluster" do registro ' $n$ ' no mapa' de bits.

- NBIOS: Rotina escrita em assembler, que prepara o endereco da funcao solicitada na tabela de jumps. 0 inlcio da tabela está indicado em 100 Hex. 
- ONDISK (drv): Rotina escrita em linguagem C, que inicializa todos os parametros para acesso posterior ao disco que esta especificado na variável 'drv'.

- PCLUSTERLIURE (dru): Rotina escrita em linguagem $[$, que procura o primeiro "cluster" livre do disco que esta no "driver" 'dru'. parametro: drv - sumero do driver. retorna o numero do cluster livre ou zero se o disco está cheio.

- PNOME (tipo, inlcio, ncomp): Rotina escrita em linguagem [, que pesquisa no diretório a existencia do arquivo indicado pela variavel global FCBm, e retorna em qual dos registros do diretório ( 0 a 3 ) o encontrou, ou OFF Hex se nชัo o encontrou.

parametros:

tipo -) indica o tipo de pesquisa a ser efetuada:

0 = procura somente arquivos do usuario atual,

1 = procura árquivos de qualquer usuário, (até) os que ja foram apagados.

inicio - numero da primeira entrada de diretorio a ser pesquisada.

ncomp -) numero de posicôes a serem comparadas para a pesquisa: 


$$
\begin{aligned}
& 11 \text { = ngo compara o campo 'EX' do FCB } \\
& 12 \text { = compara o campo 'EX' do FCB }
\end{aligned}
$$

- POSIC (ncluster, reg, drv): Rotina escrita em linguagem [, que posiciona triltia e setor do disco especificado en drv, dado "o número do "cluster" a numero do registro dentro desse "cluster".

parametros:

ncluster -) numero do "cluster";

nreg -) numero do registro dentro do "cluster";

drv $\rightarrow$ numero do "driver", cujo disco será posicionado.

- SETADRV (drv): Rotina escrita em linguagem C, que estabelece o "driver" a ser usado, e indica o endereco de seu DPH, na variavel global 'DPHI'.

parâmetro:

drv -) numero do "driver" a ser estabelecido.

- SETBMAP ( $n$ ) : Rotina escirta em linguagem $c$, que liga o bit referente ao "cluster" do registro' $n$ ", no mapa de bits.

- SETARQUIVD (tipo, avanca): Rotina escrita em linguagem $C$, que estabelece os pargmetros para acesso a arquivos. 


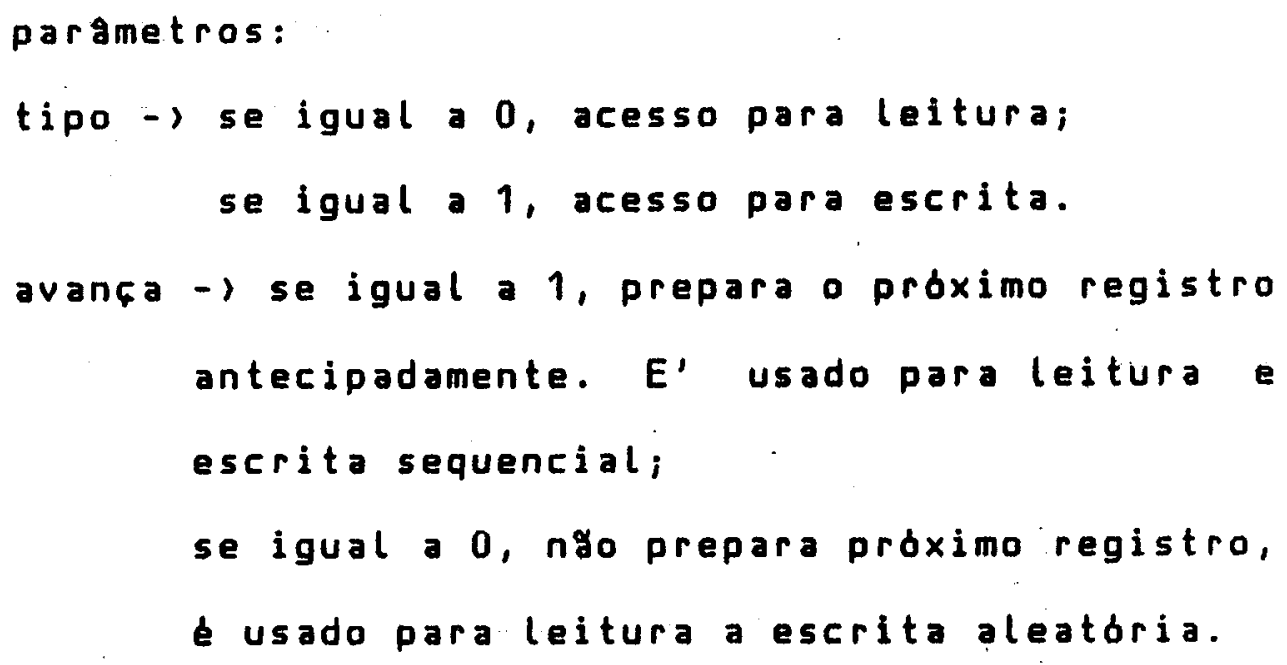

- TCHARI: Rotina para entrada de dados, escrita em linguagem C, que verifica quando os caracteres devem ser ecoados na console e na impressora.

- TCHARD: Rotina para salda de dados, escrita em linguagem $[$, que verifica quando os caracteres devem ser ecoados na console e na impressora.

Para a realizaço da extenção a CP/M que o torna multiusuário, várias alteraços tiveram que ser feitas em várias das funcós já existentes, bem como novas tiveram que ser criadas. Foram atribuldos significados a mais tres palavras da area de variáveis do CPM. Seus endereços e seus respectivos significados syo os seguintes:

Palavra 12 - Armazena o numero do usubrio corrente; 


$$
\begin{aligned}
& \text { Palavra } 13 \text { - Armazena o numero da Area corrente; } \\
& \text { Palavra } 14 \text { - Armazena o codigo de protecro padra da area } \\
& \text { corrente. }
\end{aligned}
$$

As palavras de endereço 8 a 11 năo foram utilizadas por. corresponderem a enderecos de interrupga do Micro-processador BOBO.

As funçoses alteradas sŏo as seguintes:

Fungao 15 - Dpen File: Deve verificar se o arquivo pode ser ou lido ou escrito pelo usuario atual;

Funcro 16 - Close File: Deve verificar se orquivo pode ser escrito pelo usuario atual;

Funcao 19 - Delete file: Deve verificar se o usubrio atual e o dono do arquivo, e se for, se ele pode apagar o arquivo;

Funcag 20 - Read Sequential: Deve verificar se o usuario pode ler - arquivo;

Funcaro 21 - Write Sequential: Deve verificar se o usuario pode escrever o arquivo;

Funço 22 - Make File: Deve verificar se o usuário é dono, ou se a área é menor do que 16; 
Funço 23 - Rename File: deve verificar se o usuario é o dono, e se for, se ele pode escrever no arquivo.

As funçbes criadas săo as seguintes:

Funcao 50 - Set/fet Full User code: Verifica o conteudo do registrador E. Se for lgual a OFFH, retorna no registrador $A$ o numero do usuario corrente. Se for outro valor, atribui esse numero como o usuario corrente;

Funcyo 51 - Set/Get Login Code: Verifica o conteddo do registrador E. Se for igual a OFFH, retorna no registrador - numero da área corrente. Se for outro valor, atribui esse namero como a area corrente;

Funço 52 - Set/Get Protection Code: Verifica o conteddo do registrador E. Se for igual a OFFH, retorna no registrador $A$ o código de protecăo corrente. Se for outro valor, atribui esse námero como o código de protecgo corrente.

Existem seis tipos de protecro que podem ser associadas a um arquivo, sendo tres para o usuario dono da area, e tres para usuarios externos à área. Essas protecres sao as seguintes:

Para o usuario Dono da. Area:

- Apaga - indica se o usuário pode apagar ou ngo o 
arquivo;

- Escreve - indica se o usubrio pode alterar ou ngo o arquivo. Corresponde à protecgo ja existente no CP/M, reconhecida como R/O (indica que o arquivo somente pode ser (ido);

- Le - indica se o usuário pode ler ou năo o arquivo.

Para os usuários Externos à área:

- Escreve - Indica se o usuario pode alterar ou ngัo arquivo

- Le - indica se o usuário pode ler ou năo arquivo.

- Executa - indica se o arquivo pode ser executado pelo usuário.

A protecro de cada arquivo é armazenada no diretório do disco, no FCB de cada arquivo, usando para isso os bits 7 (bit de paridadel de cada byte usado para armazenar o nome e extensado, de cada arquivo. A atribuifăo de cada bit para indicar as formas de proteçăo so as seguintes:

Bit 7 nome 5 - Usuário externa Le

Bit 7 nome 6 - Usuário externo Escreve

Bit 7 nome 7 - Usuário dono Le

Bit 7 nome 8 - Usuário dono Apaga

Bit 7 tipo 1 - Usuário dono Escreve (R/O)

Bit 7 tipo 3 - Usuario externo Executa 
Note-se que o bit correspondente ligado $(=1)$ impede que a operaço correspondente seja efetuada, enquanto desligado $(=0)$ permite a operafăo.

A figura HI explica melhor o esquema de protecro implementado na versão multiusubrio do sistema CP/M-LIE.

BIT

\begin{tabular}{|c|c|c|c|c|c|c|c|}
\hline 7 & 6 & 5 & 4 & 3 & 2 & I & 0 \\
\hline $\begin{array}{l}\text { usuAinio } \\
\text { ExTEnNo } \\
\text { EXECUTA }\end{array}$ & $\begin{array}{l}\text { AROUIVO } \\
\text { DE } \\
\text { SISTEMA }\end{array}$ & $\begin{array}{c}\text { DONO } \\
\text { ESCREVE }\end{array}$ & $\begin{array}{l}\text { DONO } \\
\text { APAEA }\end{array}$ & $\begin{array}{l}\text { DONO } \\
\text { LE }\end{array}$ & $\begin{array}{l}\text { USUARIO } \\
\text { EXTERMO } \\
\text { ESCREVE }\end{array}$ & $\begin{array}{l}\text { USUÁRIO } \\
\text { EXTERMO } \\
\text { LE }\end{array}$ & 0 \\
\hline
\end{tabular}

BIT LIGADO $(=1)$ - OPERAGTO PROIBIOA

GIT DESLIGADO $(=0)$ - OPERACTOO PERMITIOA

Figura A1.a - Palavra de protefáo padrao estabelecida pela área do usuário.

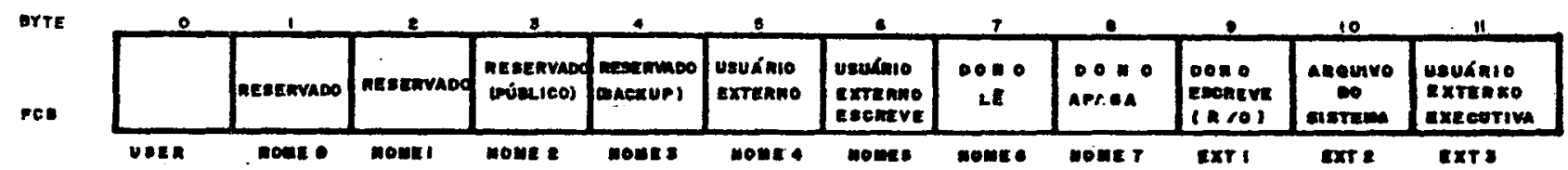

Figura Al.b - Proteçao de cada arquivo individualmente, no seu FCB.

Nota: A indicaçao de proteçao é armazenada no bit 7 da palavra cprrespondente da entrada de diretorio de todos os "extents" do arquivo. 


\section{LISIAGEU DO BROS}

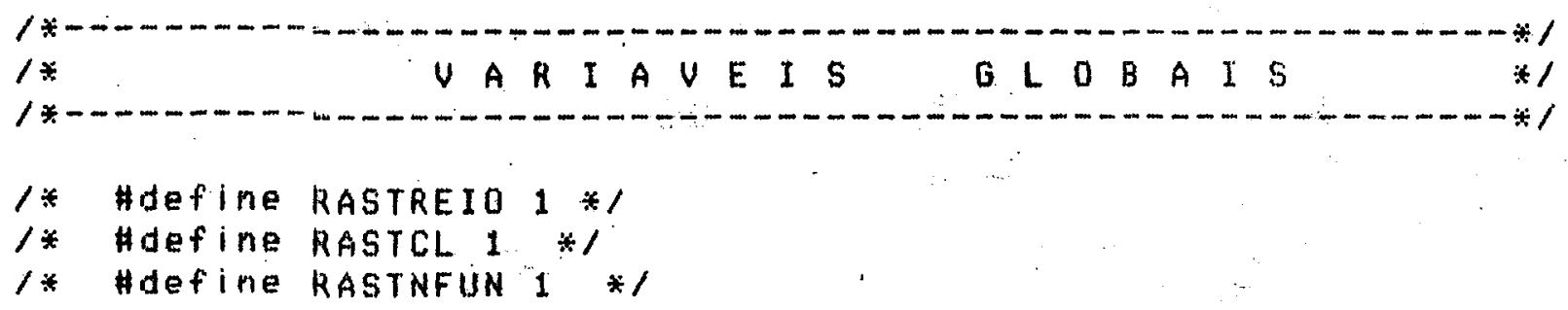

char *ender, *reg_a, *reg_b, *reg_c, *reg-d, *reg_e, *reg_h, * reg_l, *reg. *regaux, regt, drvatual;

int *par_bc, *par_de, *par_hl;

char ectravan ecimpr, *pc, somat, user, proxpesq;

int mx, ne, Mt, ned, nentidr, login, diskmo, ndma, salvihl;

char dbdrv; $/ *$ Driver de onde fol lido o ultimo doreg*

int dbreg; $/$ Reglstropresente na area de diretorio *

struct dphst $\{$ char $* x 1 t$.

$w[6]$,

*idirbuf;

struct dpbst $x d p b$;

char *CSV:

*alv; \} *dphl, *dpdph;

struct dpbst a int spt;

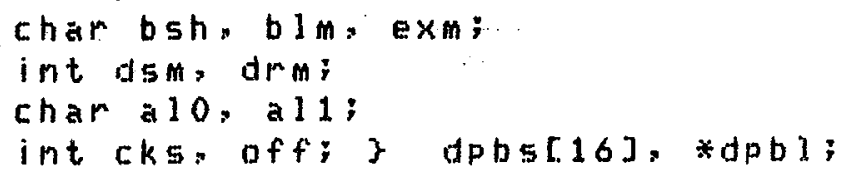

struct febdsy, char usercode.

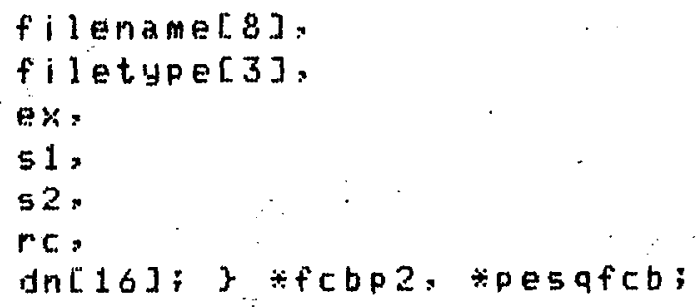

struct febmst, t char drivercode.

filename[8],

filetype[3].

$e x$,

51 .

$52:$

re:

$\operatorname{dn}[16]$.

cr:

$r 1, r 2, r 3 ; 7 * f \in b m$;

char *mensagl, $]=\{"$ "

"ERRO BDOS: DRIUEA INEXISTENTE\$", 
"ERRO BDOS: ERRO NA LEITURA"",

"ERRO BDOS: ERRO NA ESCRITA\$",

"ERRO BDOS: ARQUIVO INEXISTENTE\$" ...

"ERRO BDOS: DISCO CHEIO\$",

"ERRO BDOS: DISCD R/O\$"\};

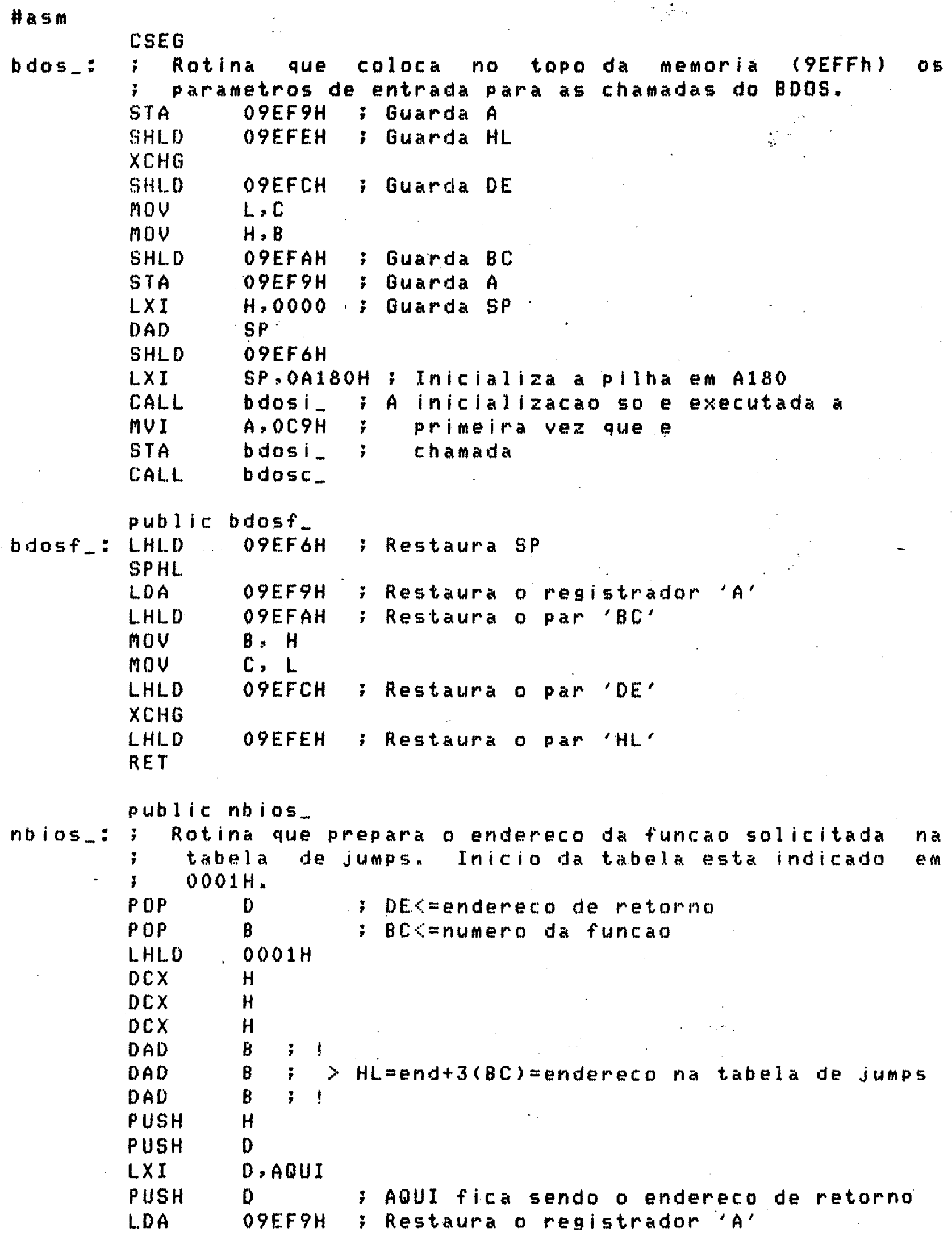


$X \mathrm{CHG}$

LHLD O9EFAH ; Restaurar O Par 'BC'

MOU B. H

MOV $C, L$

LHLD OQEFCH ; Restaurar o par 'DE'

$X \mathrm{CHG}$

PCHL

I Jump para o endereco contido em HL

AQUI: SHLD OQEFEH : Guarda HL

$X C H G$
SHLD

MOV L.C

MOV H,B

SHLD O९EFAH ; GuaMda BC

STA OQEFGH : Guarda A

RET

Henda 5 m 
posic (ncluster, nreg, drv)

/* Esta rotina posiciona trilha e setor do disco atual, dado o $* 1$ numero do cluster e o numero do reglstro dentro desse cluster

char ncluster, nreg, orvi

$t$ static int n1, trilha, setor;

\#ifdef RASTREIO

esc('P'); esc('O'); esc('s'); esc('I'); esc('C'); esc(10); esc(13);

Hendif

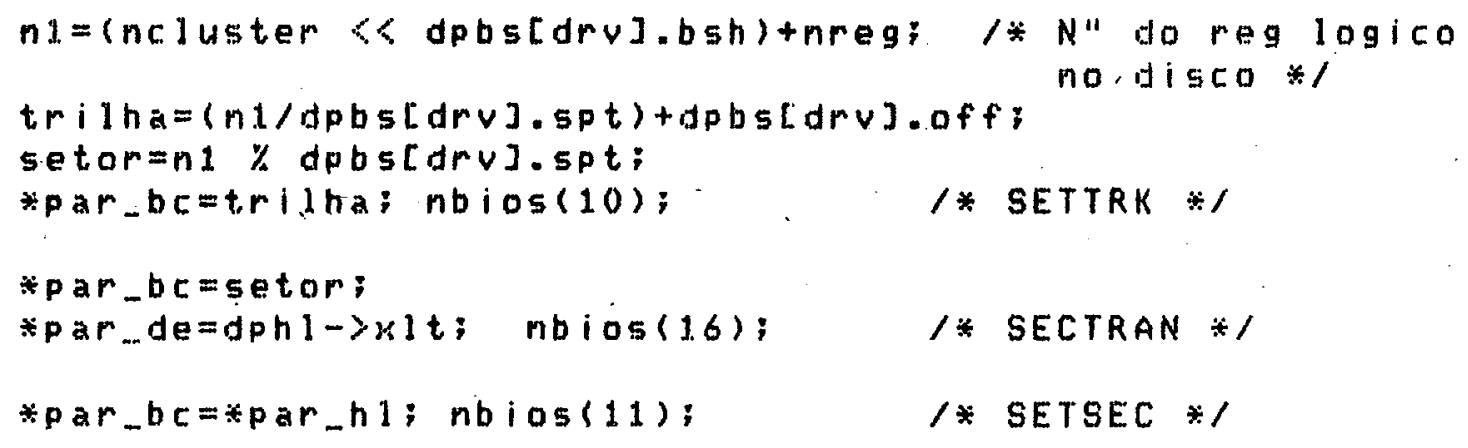


e $15 e$

$+P C$;

y

returnosion

/* 0 disco esta cheio $: 1$

$j$

criaentoir $(\Delta r v)$

1* Esta rotina cria a entrada je diretorio especificada pelo "fcbp" atual. e grava-a em disco łl

\{ char drv;

static: int i, j:

static ohar

\#ifdef RAGTREIO

esc('C'); Esc('E'); esc('N'); esc('T'); esc('D'); esc $(10) ; \operatorname{esc}(13)$;

Hemitif

setadru(dru);

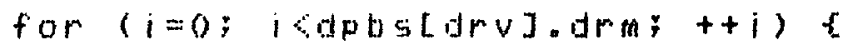

lemtair(drv, i);

if (frap?-2usercode $==0 x E 5)\{$

for $(j=0 ; j<16 ;++j)$

$f[b m-2 d n[j]=0 ; \quad / *$ zer $\quad$ os Dn $* /$

$f \in b$ 助 $P c=0$;

for $(j=0, \quad \beta c=f(c b p 2, \operatorname{regt}=f(b m ; j<31 ;++j)$

$+t+p c=4++r e g t ;$

fcbp $2-3 u s e r c o d e=u s e r ;$

$+c b p 2->s 1=f c b p 2->52=0$;

gravadi mbut();

$r \in t u m p(i \% 4) ;$

子

3

?

return $(O x F F)$; 


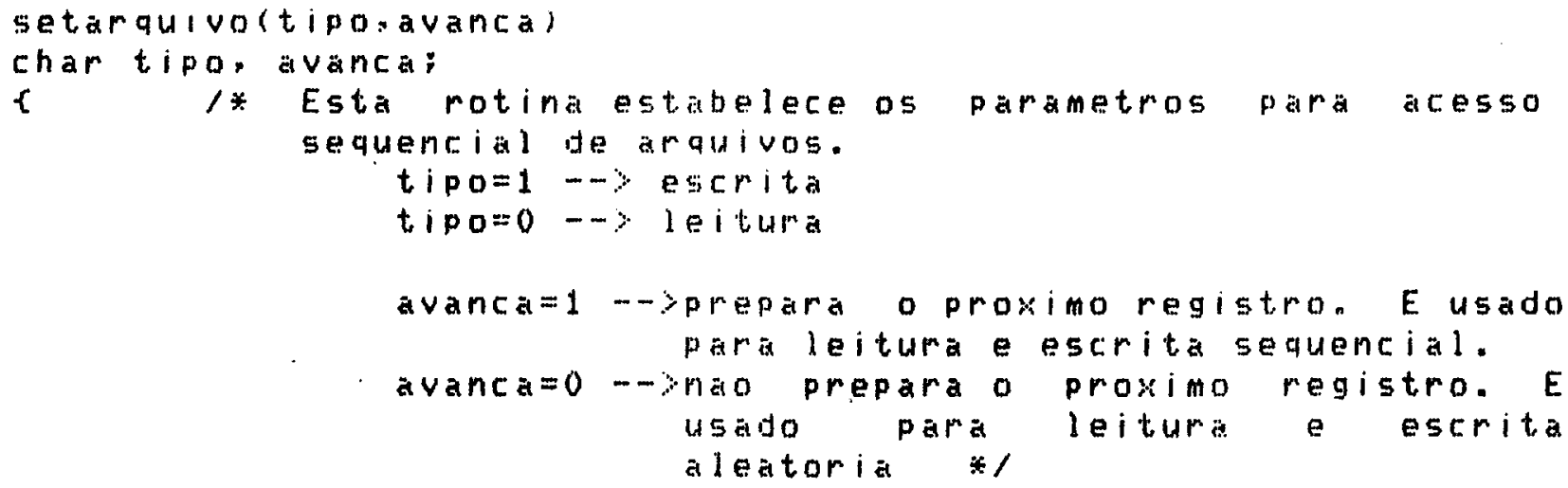

* Testar se existe o registropedido.

liaso nao exista: ma escrita-y aloca

na leitura-y erro

if $(f c b m-y d n[r e g t 1]==0) t$

if $(t i p Q=0) / *$ E leitura $* /$ metumn (1); / Registro (cluster) inexistente 


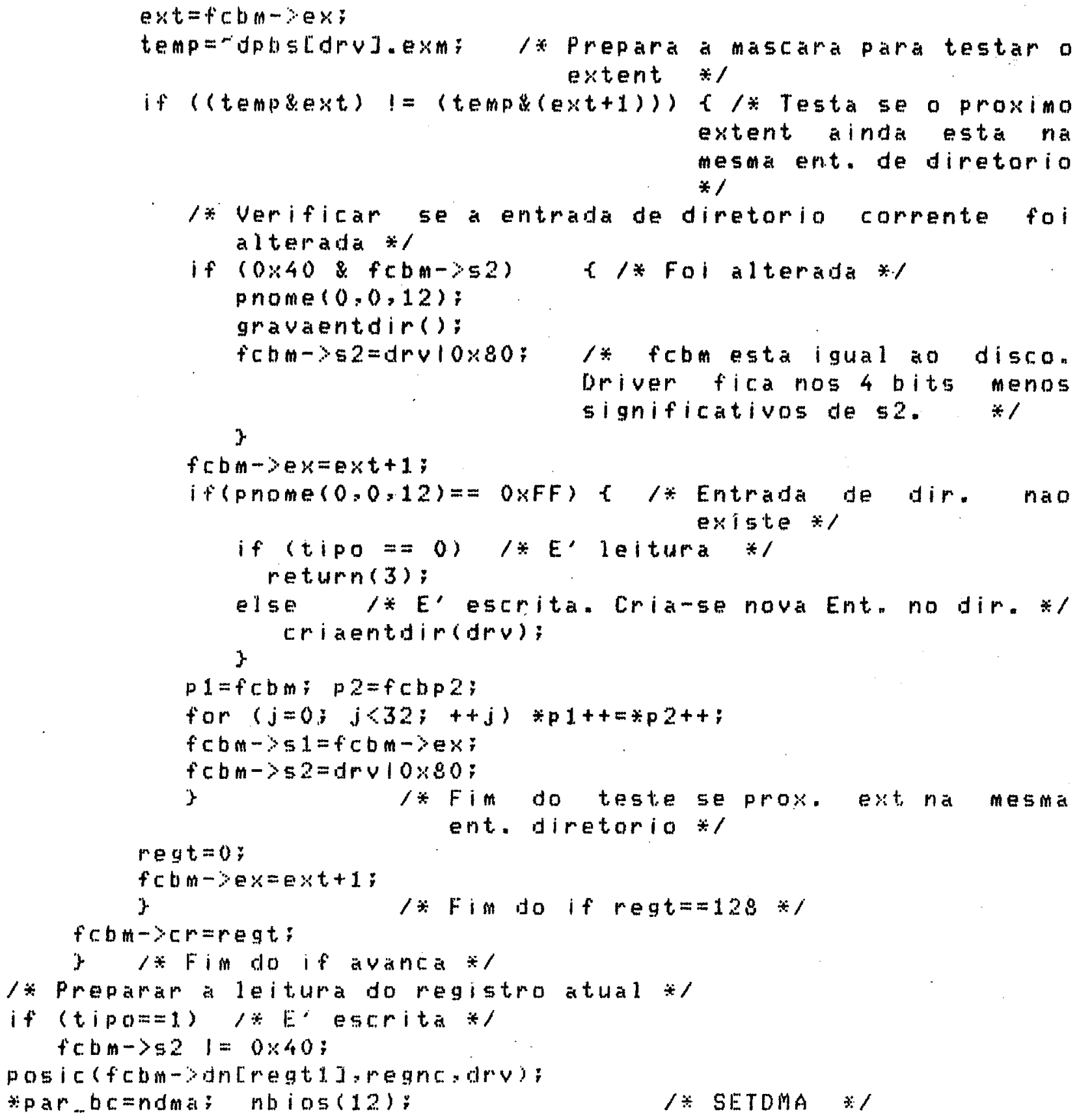


reg.. $c=0 \times 9 E F A ; / *$ Aponta Dara o numero da funcáo (A) *

reg $d=0 \times 9 E F D$;

reg $\mathrm{g}=0 \times 9 \mathrm{EFC}$

$\operatorname{reg} 1=0 \times 9 \mathrm{EFE}$;

reg. $h=0 \times 9 E F F$;

Par bc $=0 \times 9 E F A$;

$P$ ar .. de $=0 \times 9 E F C$;

Par $\mathrm{AH} 1=0 \times 9 \mathrm{EFE}$

U $5 \mathrm{r}^{\mathrm{n}}=0$ :

$10 \mathrm{gin}=0$;

diskro=0; $\quad / \approx$ bit $=0 ;$ driver $R / W * /$

nd $m a=0 \times 80$;

proxpesq=0;

drvatual $=0$;

dQ d $v=0 \times F F$;

dbreg=OxFF;

/ Nenhum registro de diretorio foi 1 ido

return;

J

/

tchari () / Rotina que verifica quando os caracteres devem ser ecoados na console na impressora para entrata 隹/

\{

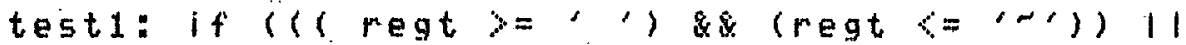

$((\mu) g t)=8) \& \&(\mu \in g t<=10))$

$11($ regt $==13)) /$ Sao caracteres graficos ou

f. ectiava $=0$

\#if def RASTREIO

\#end if

enc $(\% \%$ ) ;

e $15 \mathrm{e}$

if (regt $==19) t \quad / * e^{\prime \cdots} 5 * /$

nbios (3); regt $=$;reg.z;

while (regt $!=17$ ) /: Enquanto nao e' "⿴囗十

f ribios(3); regt=:reg.. a; $\}$

ectrava $=0$;

nbios(3); regt=*reg_a; $\quad *$ obtem o carater

3

e 1.5

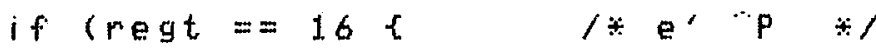

erimpr $=\left(\operatorname{simp} \mathrm{r}^{\mathrm{n}}==0\right)$;

ntios (3); regt $=$;reg-a;

goto testi:

\}

else

if $(\operatorname{megt}==3) \quad / \because e^{\prime \prime C} \because /$

nbios (1):

else

ectrava=1; / Nao e' Caracter imprimivel

3 


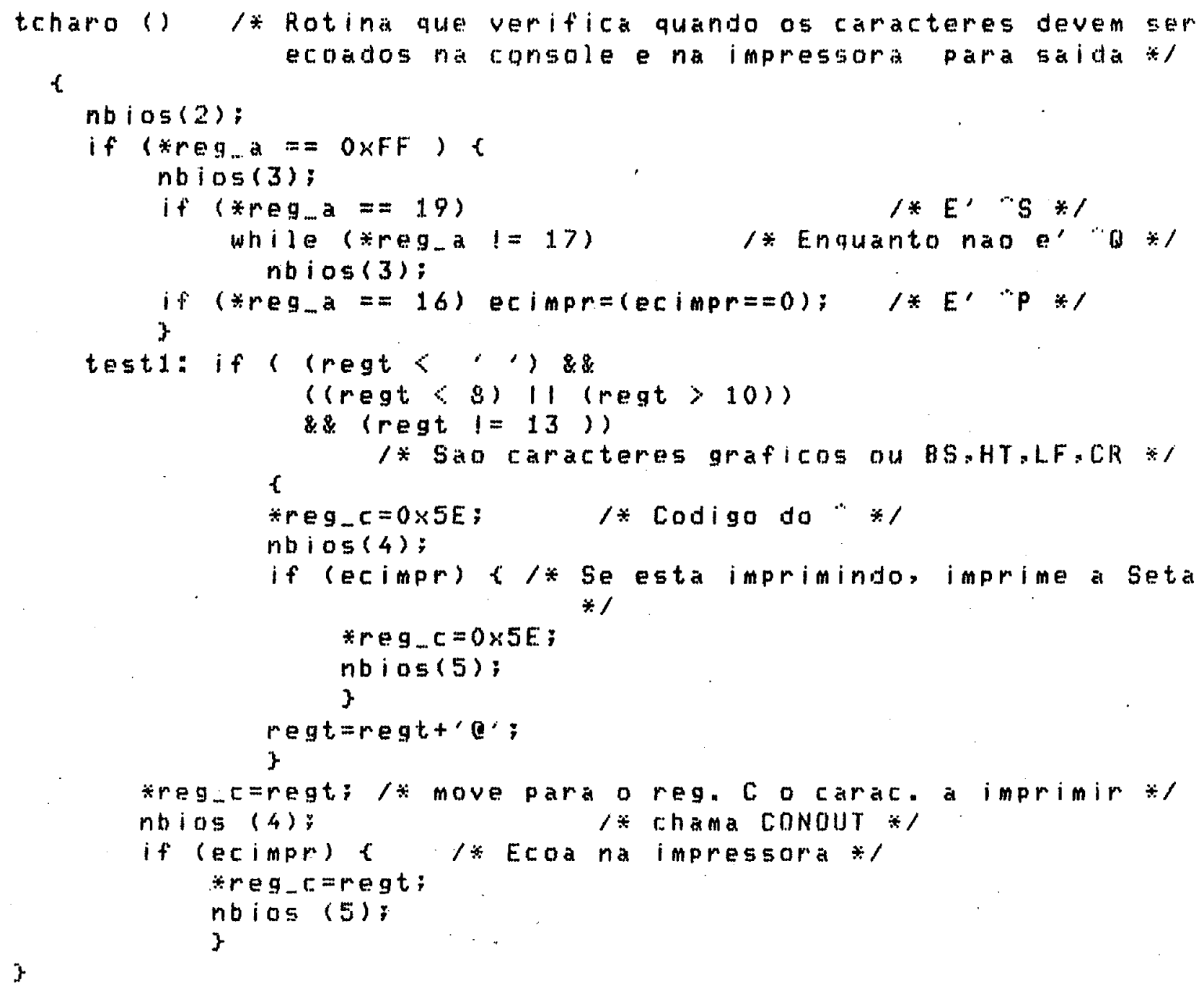




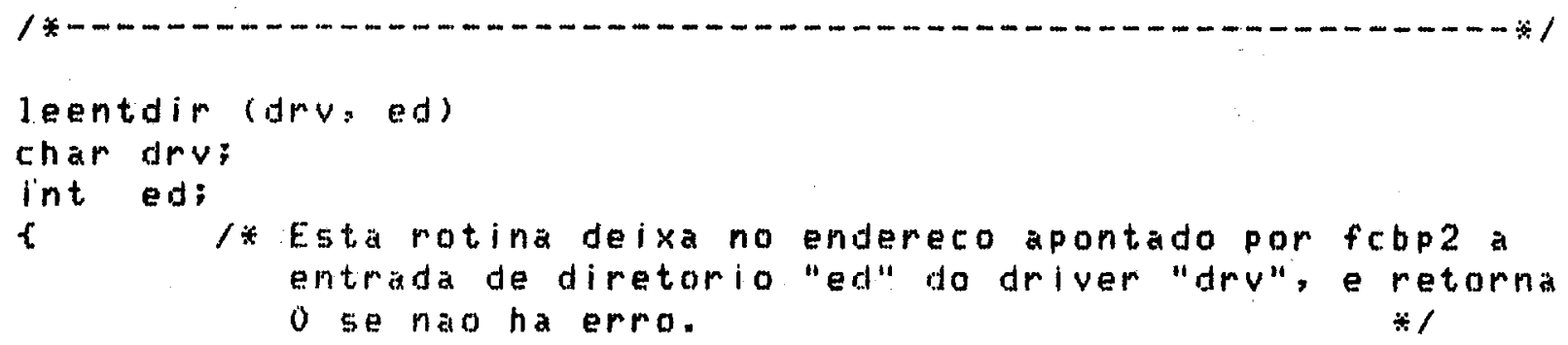




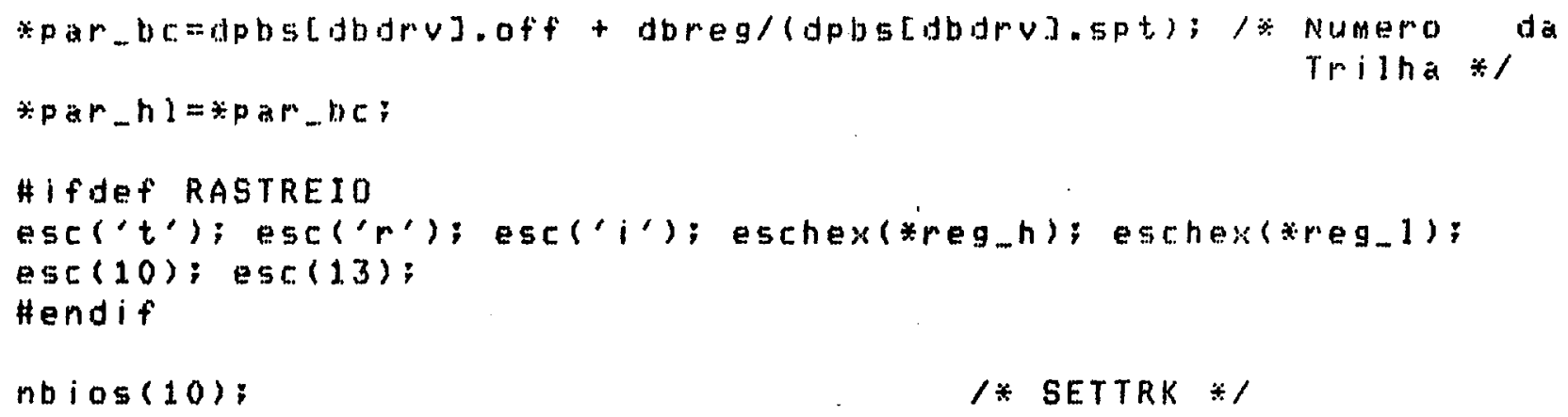




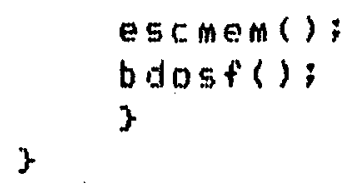

1* Esta rotina grava o registro de dimetorio mais recentemente lido pela motina ledirbuf, ja possivelmente alterado. *l 


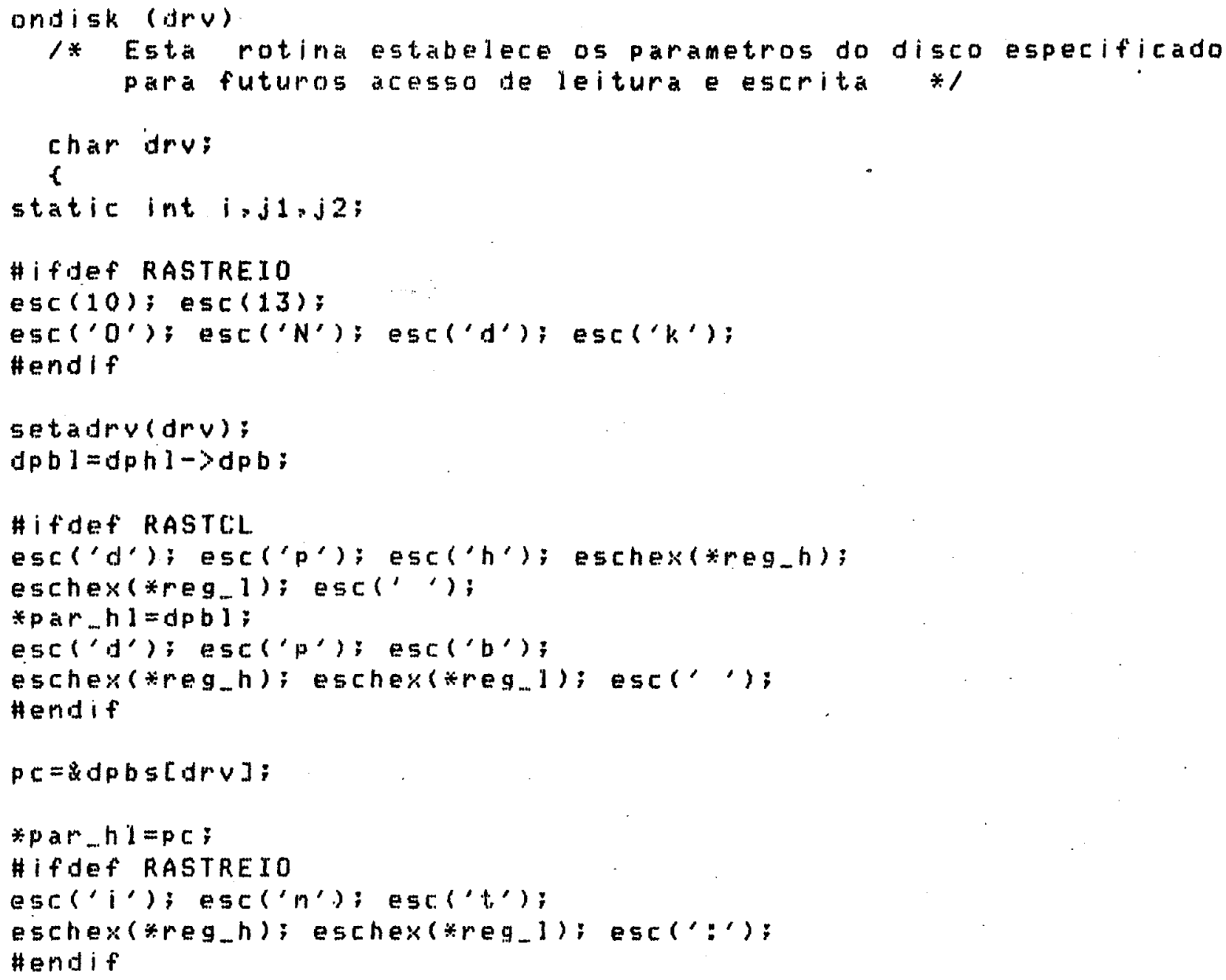


for $(i=0 ; i<$ nentdim; $i++)$ t leentdir(drv; i); /* Ler cada entrada de diretorio*/

* Preparar os valores de teste je diretorio *

if $((i / 4) ; \Delta p b s[d r v] . c k s)$ $*((d p h l-y c s v)+(i / 4))=50 \mathrm{mat}$;

1* Ligar os Bits dos Clusters usados por arquivos no Bit Map */ i.f (fcbp2-rusercode ! = OKES) (

\#ifdef RASTCL

esc('a')iesc('p');esc('q');

\#endif for $(j 1=0 ; j 1<11 ; j 1++)$ esc(febp2->filename[j1]);

\section{\#ifdef RASTCL}

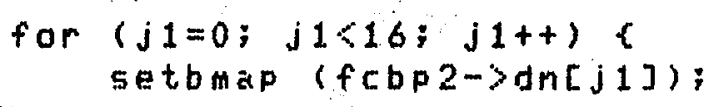

\#endif esc(',); eschex(febp2->dricj1]);

\#ifdef RASTCL

\#endif

$$
\text { esc(10); esc }(13) \text {; }
$$

$$
j 2=i
$$

\}

$d p h l->u[0]=j 2$;

$\operatorname{login} 1=(1<\langle d \mu v)$ :

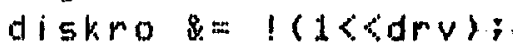
return(0);

3

pnome $t$ tipo, inicio, ncomp)

/ Rotina que pesquisa no diretorio a existencia do arquivo indicado por "fcom" es retoria em qual dos registros do diretorio $(0$ a 3$)$ se o encontra, oufFh se nao o encontra.

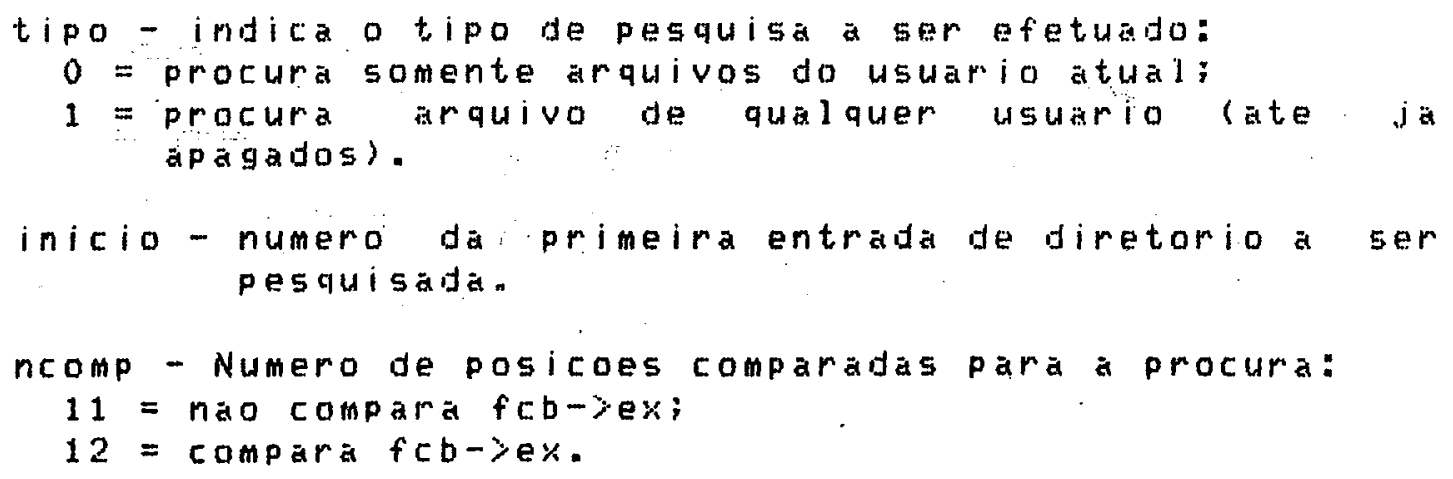

0. significado de fcb->st indica o maigr extent usado numa entrada de diretorio. 
A rotina pnote verific fcb-rs2, cujo significado e' o seguinte:

bit 7 (0)80) Ligado indica que feb->s2 bits $0-3$ tem o numero do driver;

bit 6 (0.40) Ligado indica que o fcb na memoria esta diferente do disco;

bits 3-0 (OxOF) indica o driver a que se refere o fcb.

$\because 1$

chap tipo, inicio, ncomp;

\{

static int j1: n;

if $(\sim(f \mathrm{com}->\mathrm{si} 2 \& 0 \times 80))<$

$n=f c b m-r d p i v e r c o d e ;$

if $(n==0$. I $n==\prime ? ') \quad n=$ druatual:

else $n=n-1$;

fcbm->sz=n 1 ox80; /* s2<-numero do dmiver em que o arquivo

$f C b m->E 1=f \in b m->e x ;$

3

else

$n=f c b m->52 \& 15$

setadpv(p);

\section{\#if def RASTREIO}

esc('p'); esc('N'); esc('n'); eschex(n); esc(10); esc(13);

\#enitif

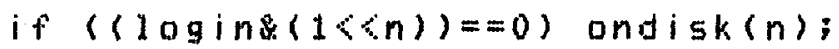

nentidiadph 1->u[0]; $\quad /$ Numero de entradas no diretorio

1: Ler cada entrada do diretorio $\%$

for (ned=inicio; ned s= nentidim; nedt+) \{

leentdir(noned); / Ler cada entrada de diretorio $*$

for $(, j 1=0 ;, j 1<11 ; j, 1++)\{$.

regt $=(\langle f c b m-\rangle f i$ lename[j1])\& $0 x 7 F) ; /:$ Limpa o bit de

if (megt $==$ '?') contimue; / passa para o proximo

caracter $* 1$

if (regt $!=((f c b p 2-y f$ ilename[j1J)\& $0 \times 7 F)$ ) goto pnome1;

j

if $($ ncomp $==12)$ \&

1* Tendo que comparar o extent. e' feita a mascara

( dpbs[n].exm) e compara-se os bits restantes */

regt $=f c b m-2 e x$;

if $(($ pegt\&( $($ apbs[n].exm)) !=

$((f c b p 2->e x) \&(-d p b s[n] . e x m)))$ goto pnome1: 3

if ( $(t$ ipo! $=0)$ II (fcbp2->usercode $==$ user $))<$

\#ifdef RASTREID

esc('n'); esc('e'); esc('d'); eschex(ned); esc(10); esc(13);

\#endif

return $(n e d \% 4)$;

3

pnome 1: ; 
$-176-$ 


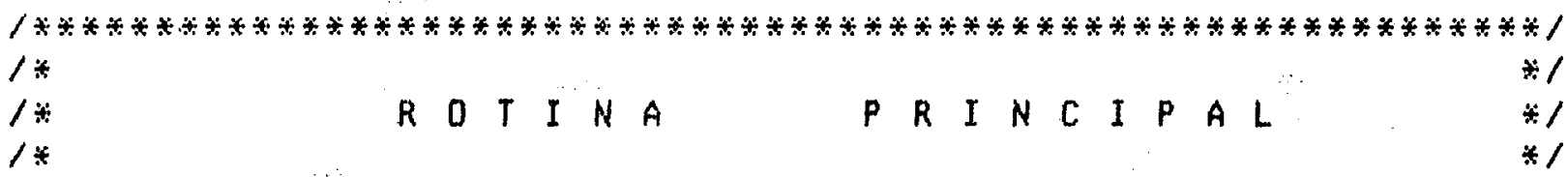

/

bosc()

\{

static char salv_a,salv, b.salv_c, salv.d. salv_e, flag;

static int 5 allivide, $i, j ;$

$s a l v-d e=* p a r^{n}$ de;

WI HEF RASTNFUN

esc('\#'); eschex (*reg_c);

Heridif

switch $(* n \in g-c)\}$

case 0: $\%$ SYSTEM RESET

nbios (1): / jmp WBOOT $\% /$

break;

CASE 1: $/ *$ CONSOLE JNPUT $* /$

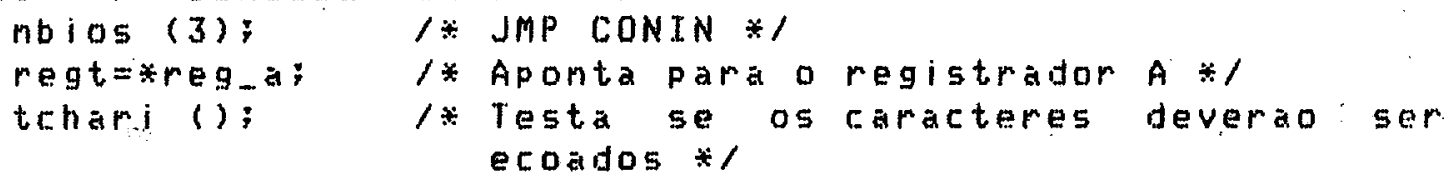

*meg-c=megt; /

if (ectrava $==0) t \quad / *$ Ecoa no terminal $* /$

\#IfDEF RASTREID

nbios, (4): $/$ Ehatha CONDUT:

Hendif

$\operatorname{Re}\left(\operatorname{cH}^{\prime}\right) ;$

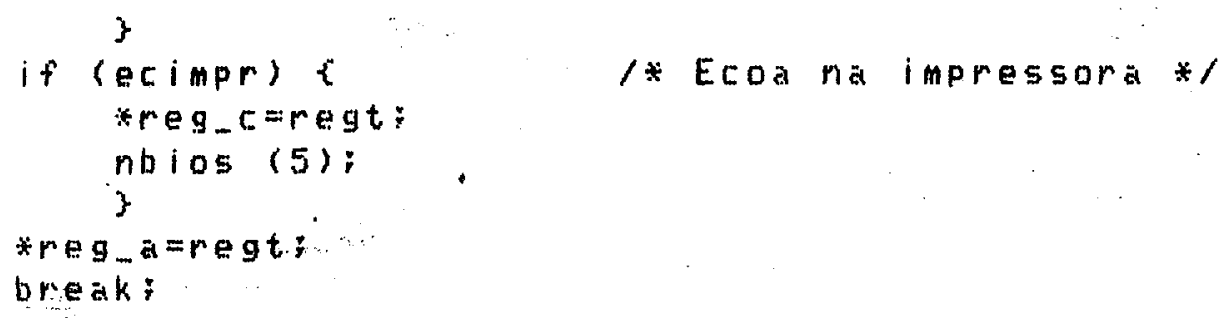


nbios $\{5\rangle ; \quad / *$ jmp L.J.ST $* /$

break;

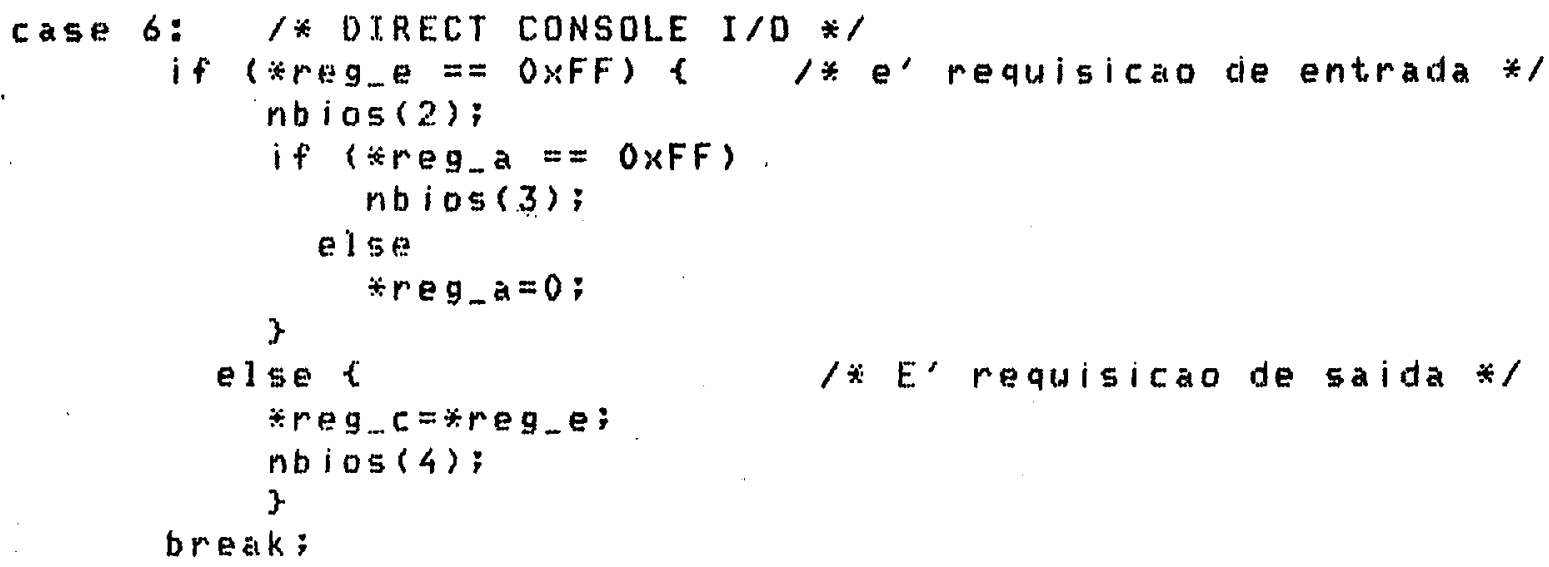




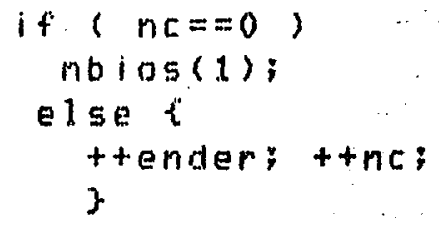




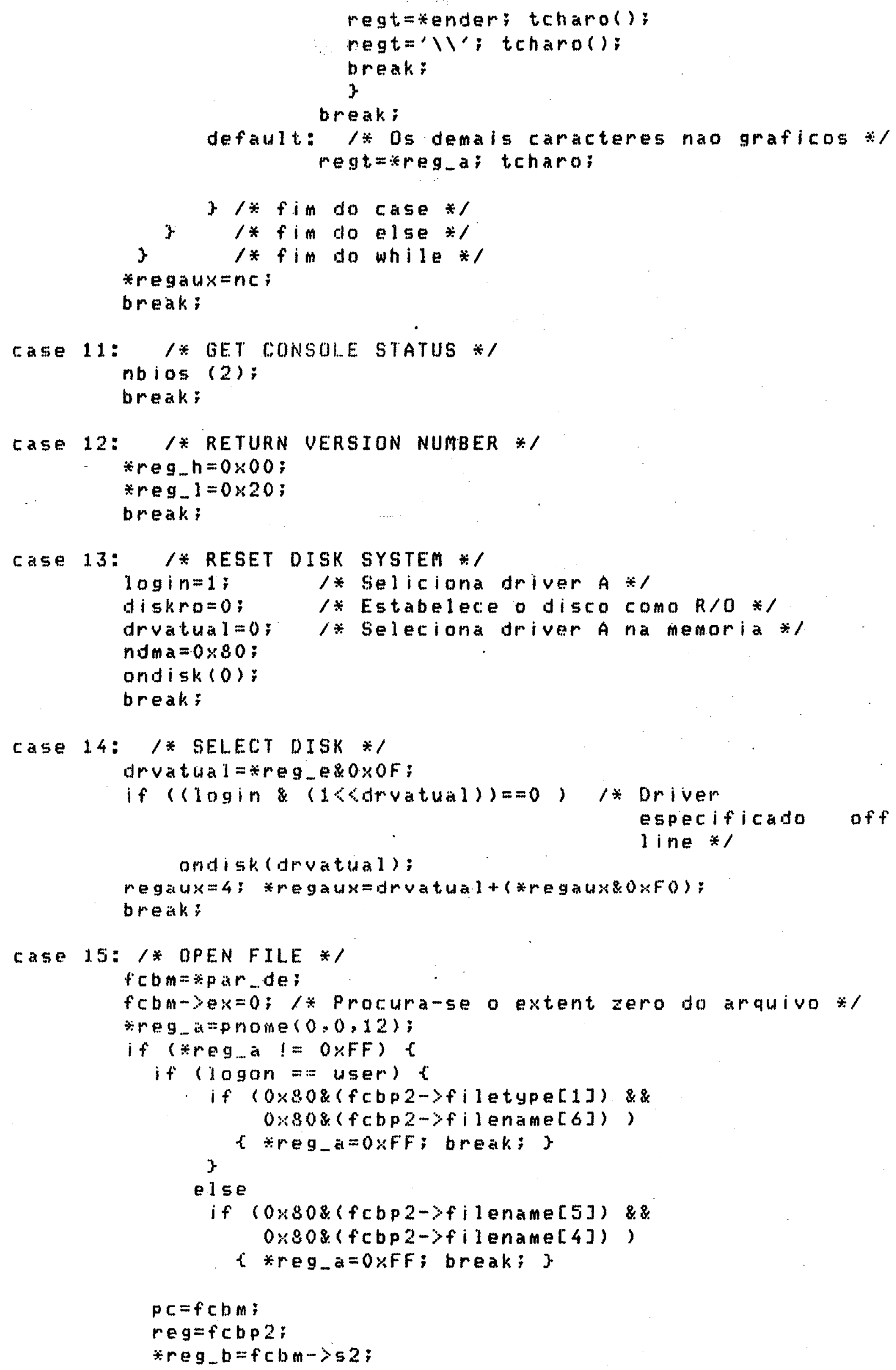




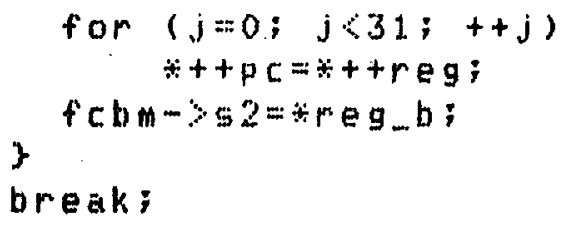

break:

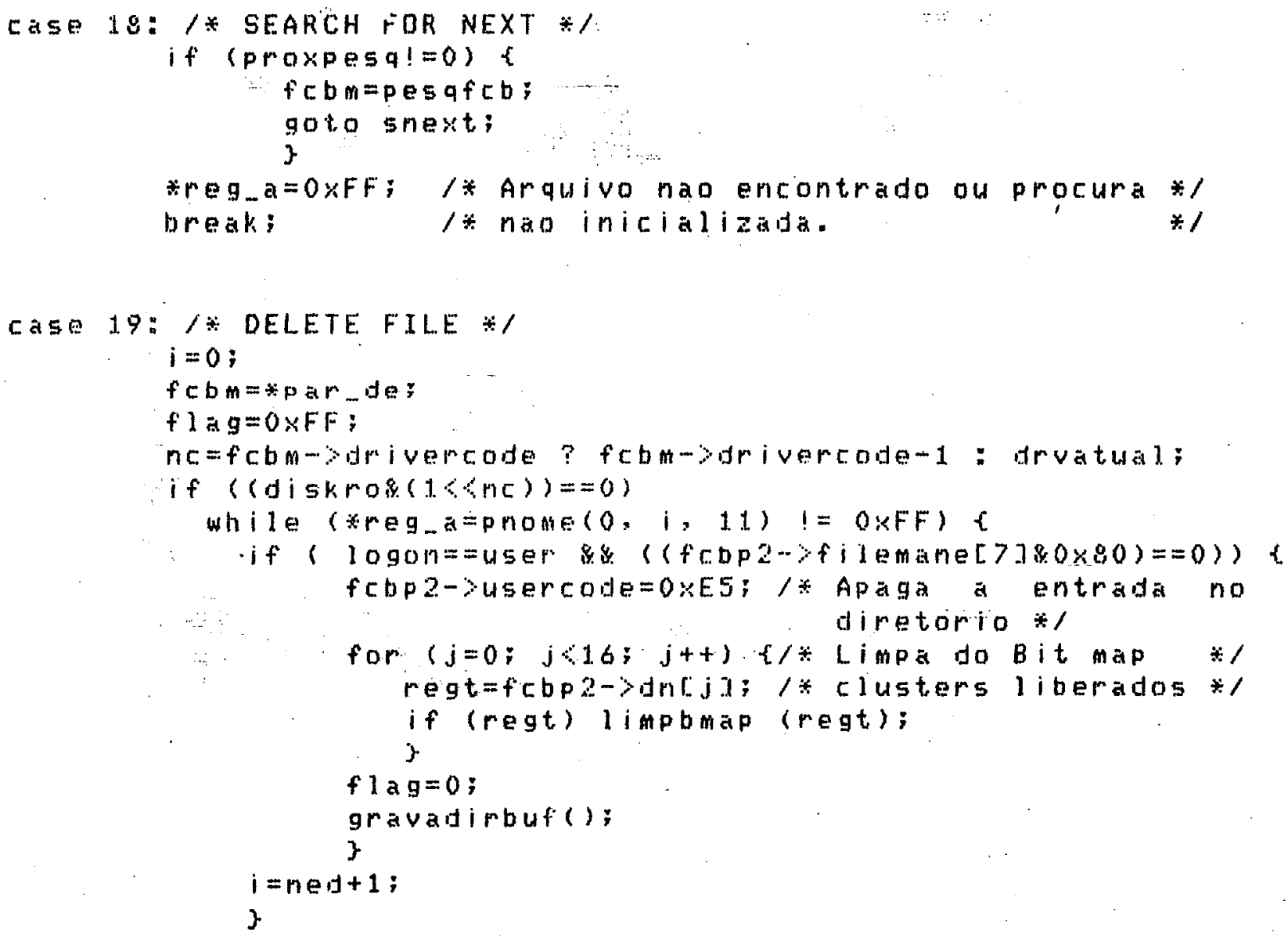




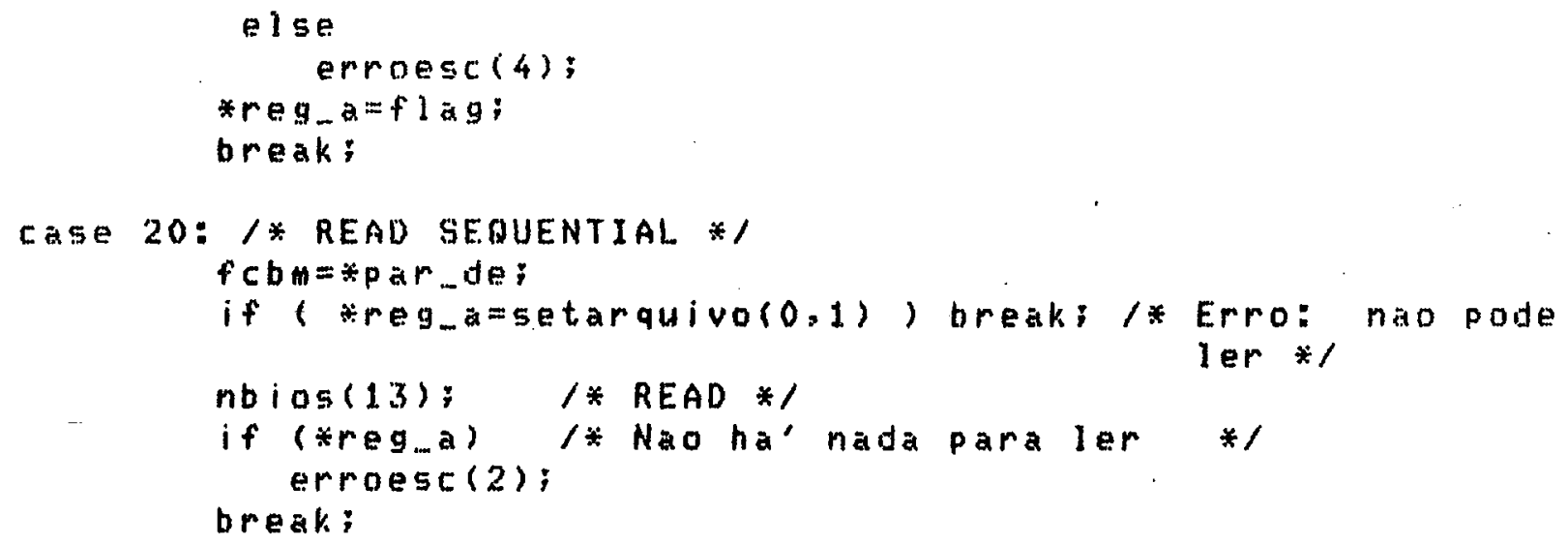




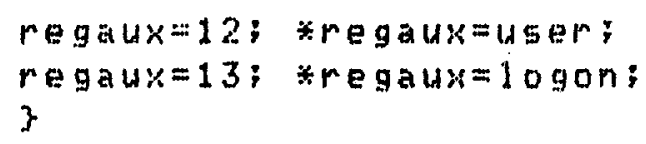




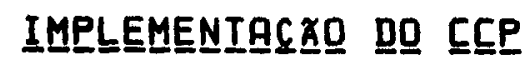

D CCP foi implementado como um programa comum, executavel pelo sistema operacional da mesma forma que um programa de aplicacăo comum, porém armazenado em disco juntamente com os demais módulos do sistema, e năo como um programa, considerando que cada programa é armazenado individualmente em um arquivo proprio. Armazenado junto com o sistema operacional, esse programa é carregado juntamente comeste quando o sistema é inicializado ou reinicializado ("Cold Boot" ou "Warm Boot"), e portanto, executado sempre que o sistema operacionat reassume o controle do processador, passando enta a monitorar os comandos solicitados pelo usuário.

Documentaça de cada Comando e cada Rotina Implement ados.

Rotina BDOSA

char bdosa (nfunc, parDE)

char nfunc;

int parDE;

A funço bdosa acessa; a partir de um programa escrito em linguagem "C", as funcóes do módulo BDOS do Sistema 
Dperacional. O numero da fungago é indicado em "nfunc", e o parametro da funcao do BDOS, indicado no par de registradores DE, é indicado em "parDE". D valor de retorno da funço do BDos, indicado no registrador $A$ é o valor de retorno da funcaro. Esta rotina esta escrita em Assembler do Micro-processador 8080 .

\section{Rotina NOMARQ}

nomarq( )

A funcăo nomarqutiliza-se da técnica de "máquina de estado finito" para analisar o nome do arquivo que esta na Lintia de entrada teclada pelo usuario, a a partir dele criar - FCB cujo endereço é indicado pela variável global "endf $c b "$.

Retorna:

o - Se ngo havia '*' ou '?' no nome do arquivo

1 - Se havia '*' ou '?' no nome do arquivo

2 - Se houve erro no nome do arquivo

\section{Rotina TESTCHAR}

testchar()

Esta rotina le um caracter da linha de entrada teclada pelo usuario, e verifica se o caracter esta em uma das 6 categorias validas pela máquina de estado finito executada pela rotina "nomarq", as quais sao:

Separador - retorna o valor 0

Ualido $\rightarrow$ retorna o valor 1

* -) retorna o valor 2 


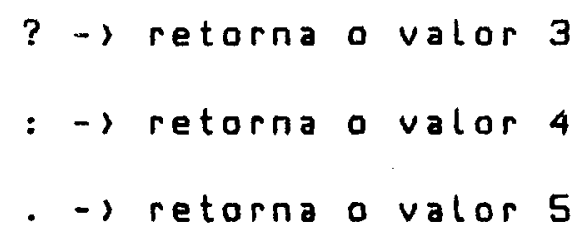

Módulo de Inicializacăo do CCP

Este módulo inicializa no BDOS as variáveis de usuario e disco atual "default". Além disso, inicializa as variáais usadas pelos demais módulos do [CP, tais como endereço do "buffer" de entrada de comandos e endereço do FCB dos arquivas manipulados.

Módulo de Reconhecimento de comandos

Analisa cada linha de entrada digitada pelo usuario, e determina qual dos comandos reconhecidos pelo CCP foi solicitado pelo usuario.

Módulo de execucão do Comando USER

Atribui o numero de usuário indicado como o usuário corrente. Na versăo multiusuario do sistema pode ser qualquer valor entre 0 e 223. Na versaro original, pode ser qualquer valor entre 0 e 15.

Módulo de execucăo do comando TYPE

Verifica se o usuário indicou um nome de arquivo năo amblguo, e se o arquivo existir, escreve no video cada caracter de cada registro lógico do arquivo, até encontrar o caracter $26(\wedge Z)$ ou até esgotar o arquivo.

Módulo de exequçăo do Comando REN 
Verifica se existe o arquivo com o nome velho indicado, e se năo existe um arquivo com o nome novo indicado. Se tudo estiver certo, o nome é trocado.

Módulo de execucra do Comando ERA

Apenas apaga o arquivo solicitado, se ele existir. Se a expecificafăo do arquivo for amblgua, isto é, algum campo do nome contiver "*" ou "?", năo apaga nenhum arquivo.

Foi implementado diferente do comando ERA da versao CPIM original, pois poderia ocorrer do usuario apagar arquivos apenas par engano, o que pode ser desastroso. D comando DEL explicado a seguir aproxima-se mais da versăo CP/M original, por permitir que a especificacaro do arquivo possa ser amblgua.

Módulo de execucaro do Comando DEL

Apaga todos os arquivos que correspondam à especificaça indicada pelo usuário.

Mádulo de execucão do Comando SHVE

Determina o numero de registros de 128 Bytes que devem ser gravados. A seguir apaga o arquivo com o mesmo nome que pode eventualmente existir, e a seguir cria o novo arquivo, gravando o numero de registros determinado.

Modulo de execucro do Lomando DIR

Usa as funcores Search for first e Search Next do BDOS para listar os nomes de todos os arquivos gravados no disco, nomes esses que se ajustem na especificacăo indicada. 
Módulo de Carregamento de Programas

Carrega para a memoria o programa indicado, prepara a area de FCB principal e FCB secundario, e passa a execucão para o endereço de memória $0100 \mathrm{H}$ através de uma instruça CALL.

Para a alteraça do sistema monousuário em multiusuário, o CCP implementado inicialmente foi alterado em duas de suas funcores originais: inicializaço do sistema e comando de execucaro de programas.

Quanto à inicializaço do sistema, foi incluida a busca dos valores de Usuario Corrente, Area Corrente, e Código de Protecăo Corrente respectivamente nas posiçoses 12 a 14 , e a correspondente reinicializacăo desses valores no BDDS.

Quanto à execucaro de programas, foi inclulda a verificacaro de se o dono do arquivo a ser executado é o usuário carrente, pois se năo o for, a execuça é proibida. 


\section{LISIEGEQ DQ CER}

\section{$\#$ a $5 \mathrm{~m}$}

\#endas

$$
\text { call mà in }
$$

\begin{tabular}{|c|c|c|c|c|c|c|c|c|}
\hline $1 \ddot{*}$ & & & & & & & & $* 1$ \\
\hline$/$ & $\mathrm{C}$ & $\mathrm{C}$ & $p$ & - & Console & Comatid & Processor & $* 1$ \\
\hline 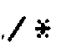 & & & & & & & & $* 1$ \\
\hline
\end{tabular}

/

Char $\because \operatorname{con} 2 \operatorname{mog}[\mathrm{g}]=\{$

$$
\begin{aligned}
& \text { "USER", } \\
& \text { "TYPE", } \\
& \text { "REN", } \\
& \text { "ERA ", } \\
& \text { "DEL ": } \\
& \text { "SAVE" } \\
& \text { "DIR "\}; }
\end{aligned}
$$

cham $\because \operatorname{mensag2[]}=\{$

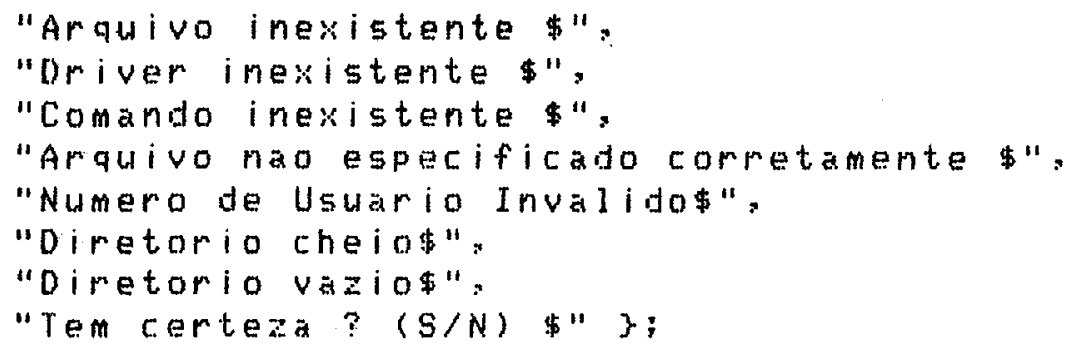

char $\because p, \forall p c, \quad x e n d f c b$, a, cont, somat;

int itha: *pont, mum:

testchar()

i

i Esta rotina le wo caracter da linha de entrada teclada pelo usuario. e verifica se o caracter é:

Separador - yetorma flag 0 ;

valido $->$ retorna flag 1 ;

* - $\rightarrow$ retorna flag 2 ;

? - b metorna flag 3 :

- - metorna flag 4 ;

$\div /$

- - > retorna flag 5:

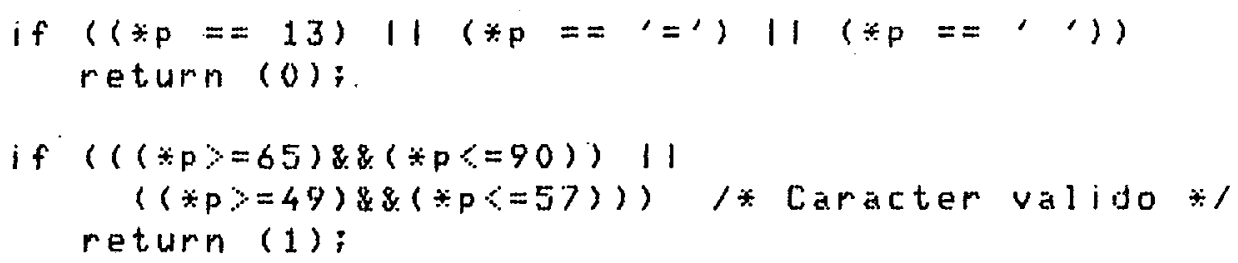




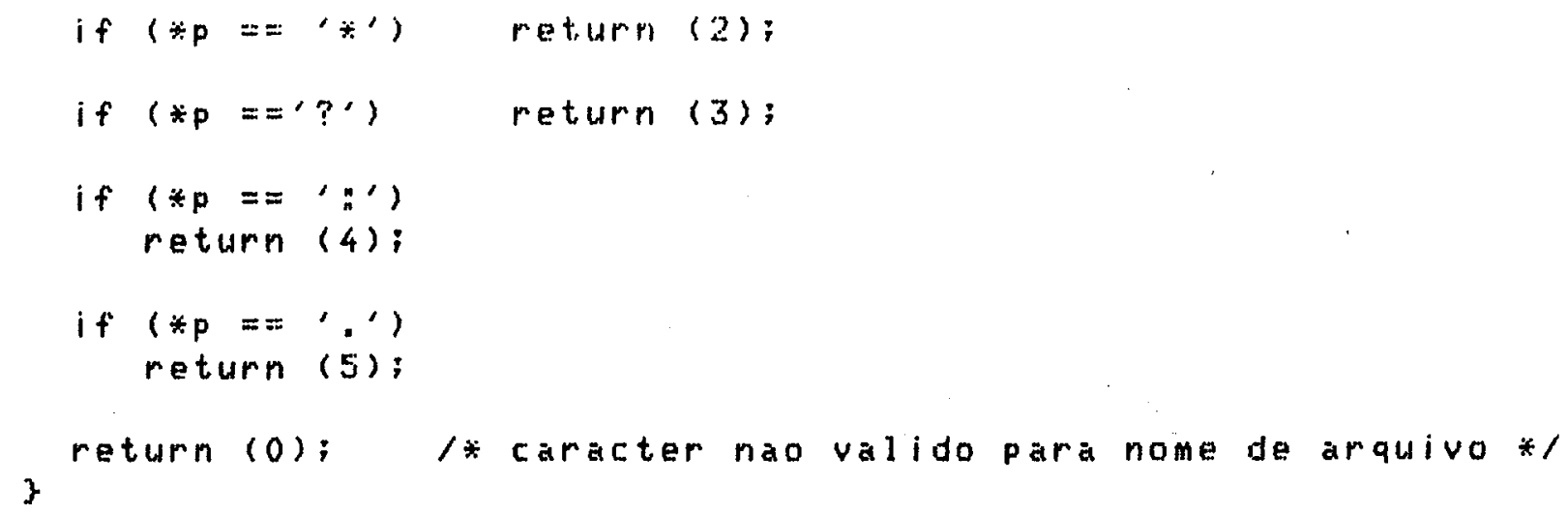




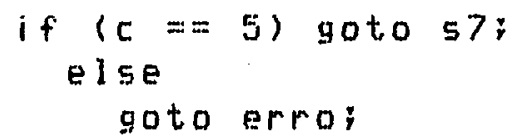


main()

$\{$ - Esta potina executa os comandos do CCP $\because /$

static char achow, *auk;

static int $i, j$;

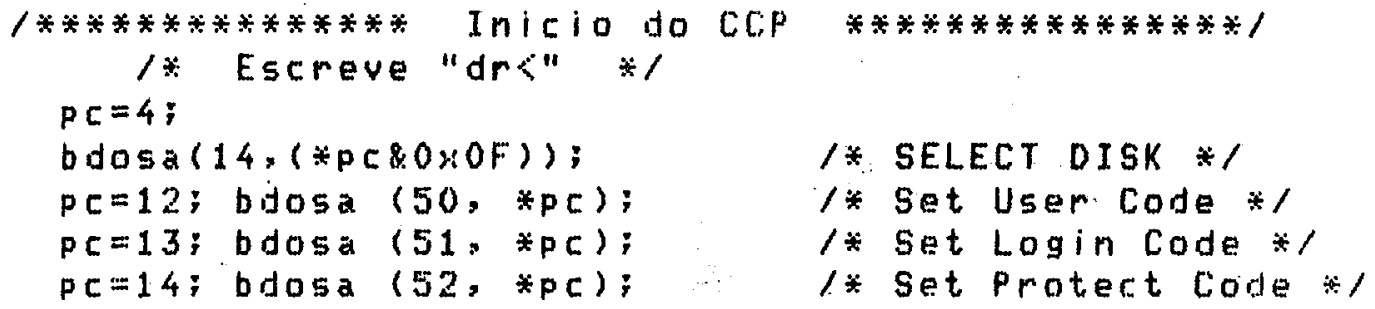




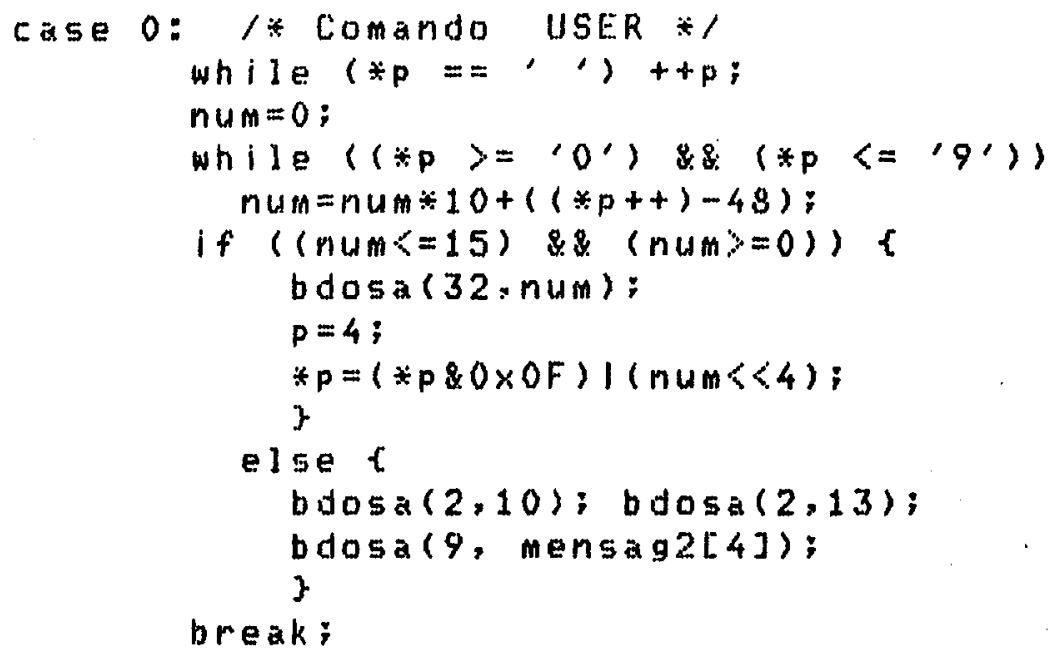




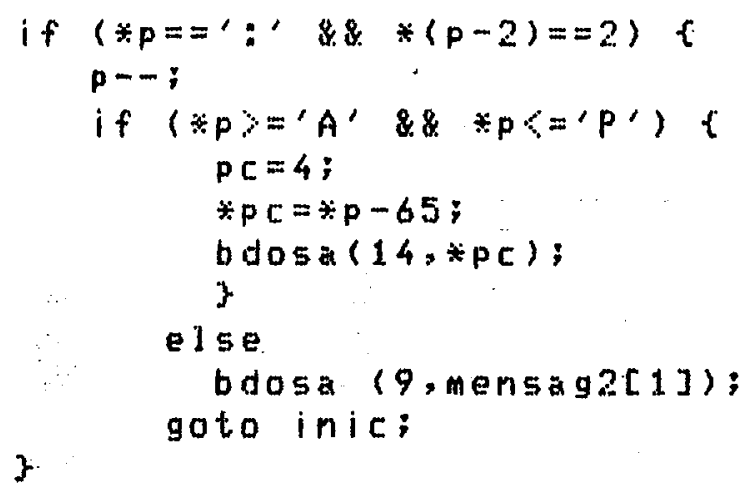

\#asm 


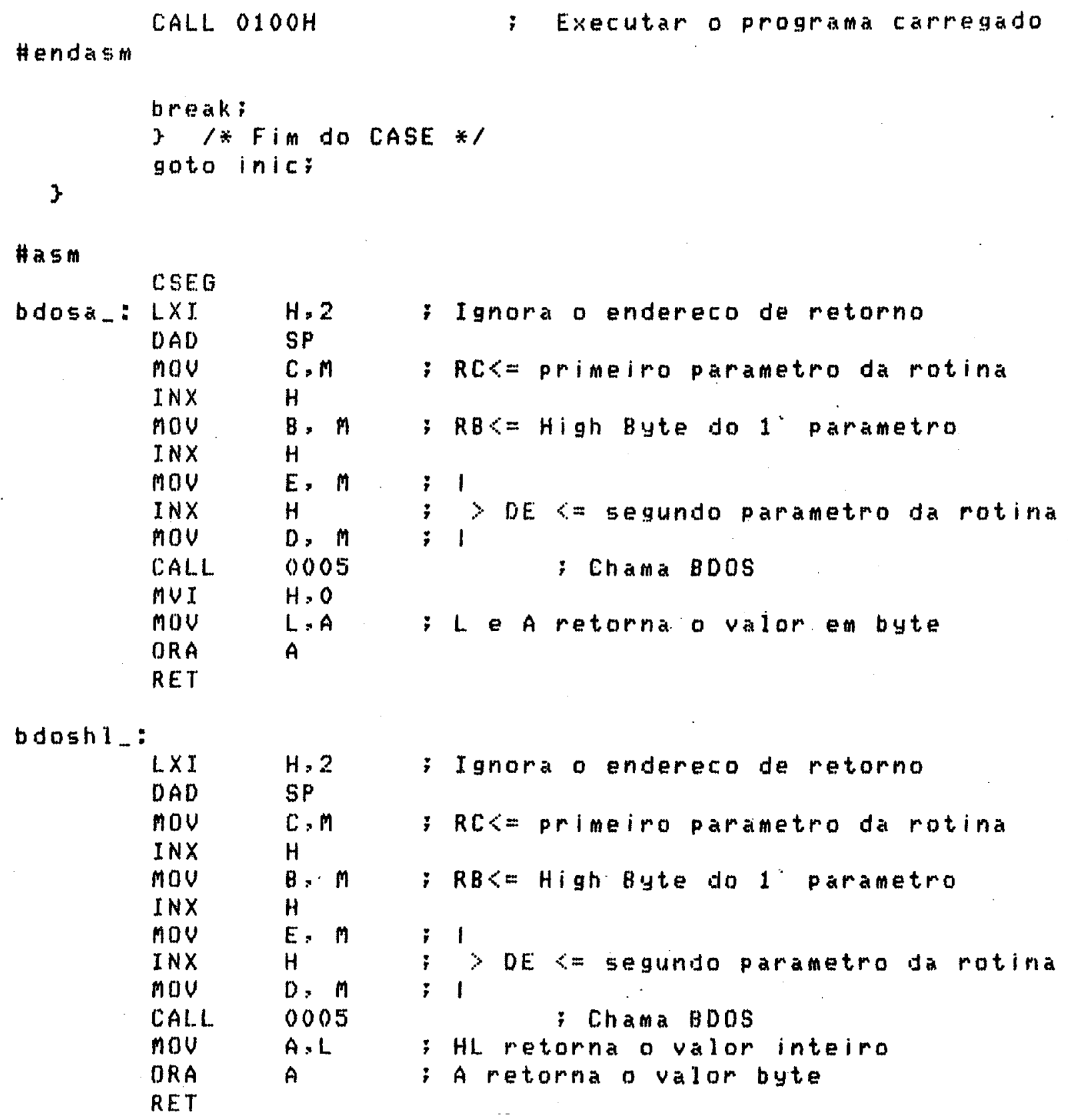

MOU

DRA

C,M $\quad$ RCS $=p r i m e i m o$ parametro da rotina

$H$

B:M ; RB<E High Byte do 1 parametro

H

E:M ; 1

$H$; $>D E<=$ segundo parametro da rotima D. $M ; 1$

RET

Hendasmi 


\section{LISIBGEM DQ IMPLEMENIAGXQ DQ COMANDQD LDGIN}

Este programa foi escrito em Linguagem " $[$ ", como um programa de aplicaço comum, com a diferenca que esse programa usa as novas furcớes do 5 istema Operacional.

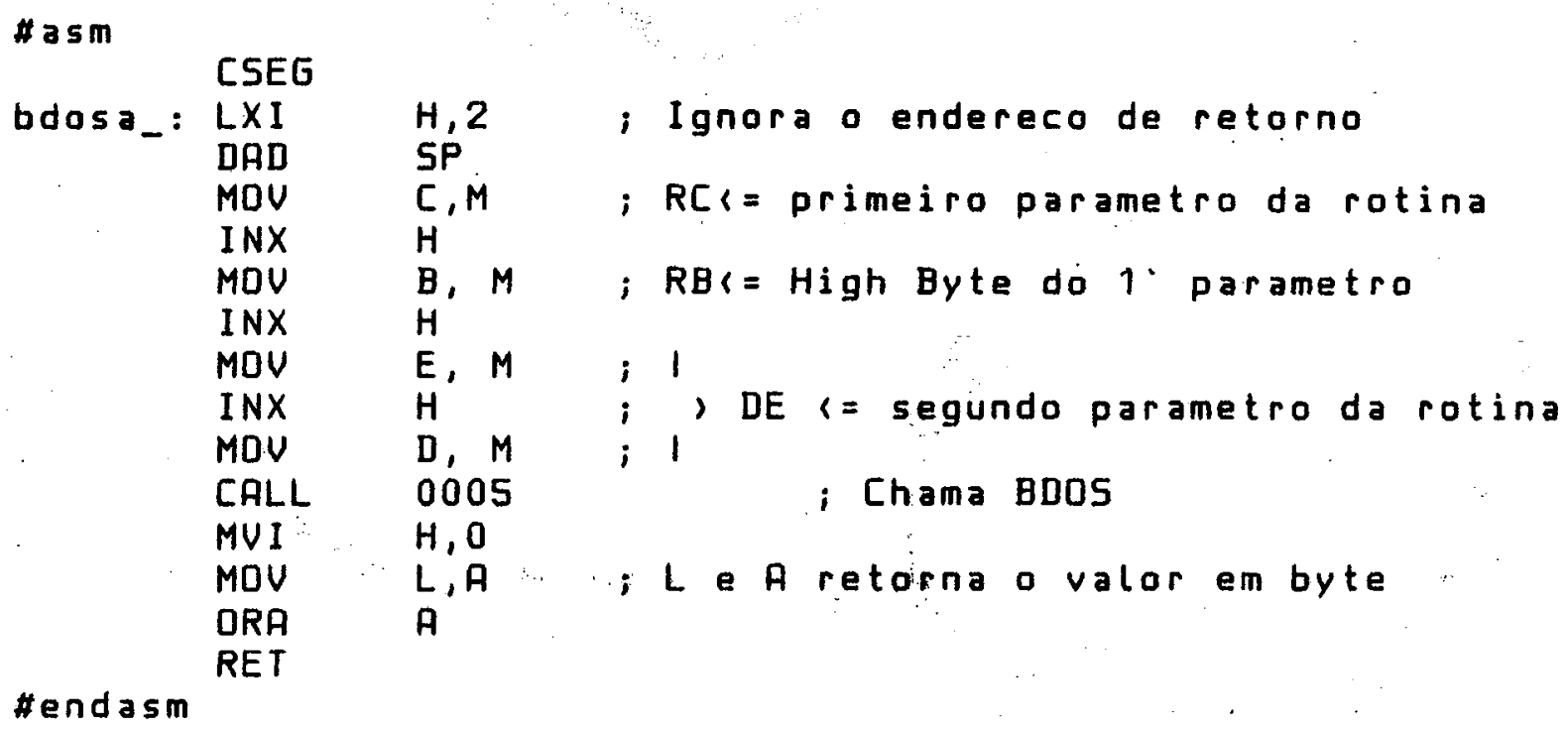

l****************************************************************1

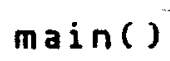




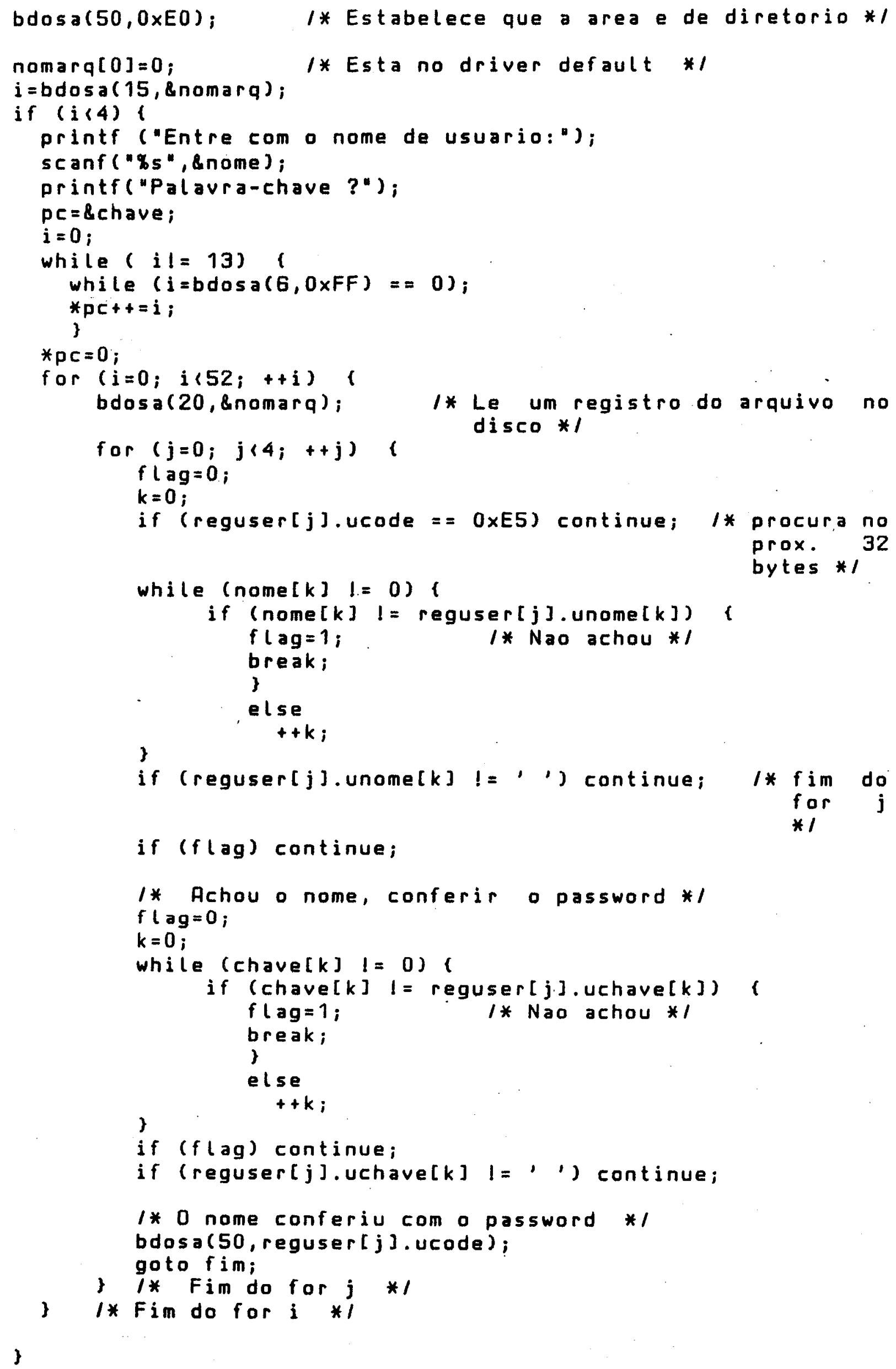


else $l$

printf ("Estrutura de usuario nao inicializadaln"); \} bdosa $(50$, user $)$;
fim:

; 


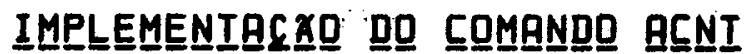

Este programa foi escrito em Linguagem "C", como um programa de aplicacăo comum, com a diferenca que esse programa. usa as novas funcốs do Sistema Operacional para a criacăo e acesso ao Arquivo de Usuarios, mantido na área especial 224 $(\mathrm{OEOH})$.

D Arquivo de usuários consiste em 208 registros de 32 palavras, alocados desde a criaga do arquivo. Cada registro contem os seguintes campos:

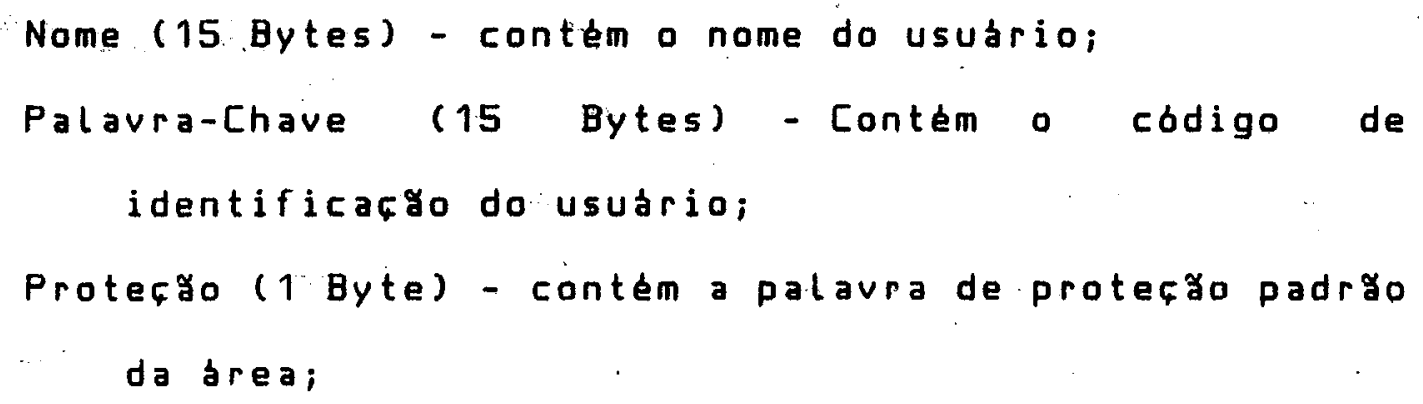

o número 229 (OE5H) associado ao número da área indica que o registro correspondente do Arquivo de Usuários năo esta senda usado para armazeriar nenhum usuário.

Quando um novo usuario e incluto no Arquivo de Usuarios, the el atribuldo um conjunto de proteçes padră com que 
os arquivos criados em sua área sao inicializados. Esse conjunto de protecŏes é especificado em um unico Byte, onde cada bit é atribuido a uma forma de protecaro posslvel.

O significado de cada bit nessa palaura e o seguinte:
Bit 0 - Obrigatoriamente 0
Bit 1 - Usuário Externo Le
Bit 2 - Usuário Externo Escreve
Bit 3 - Usuário Dono Le
Bit 4 - Usuário Dono Apaga
Bit 5 - Usuário Dono Escreve
Bit 6 - Arquivo do Sistema
Bit 7 - Usuário Externo Executa

Note-se que um bit ligado $(=1)$ indica que a operaça correspondente está proibida. 0 Bit 6 corresponde à operacă já existente no CP/M de indicar que o nome do arquivo năo deve ser listado em um comando DIR. 


\section{LISIAGEU DO COUANDO ACNI}

\#西 5 it

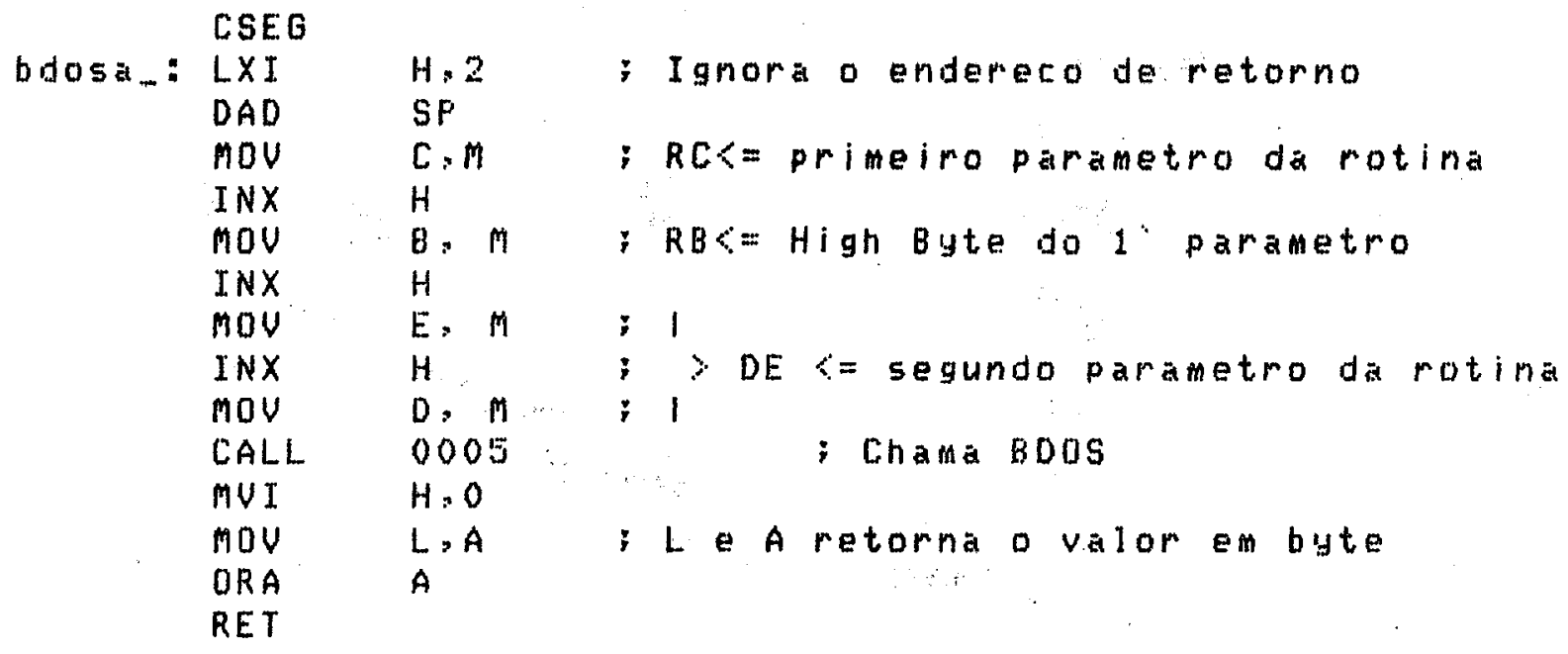

\#endasin

$\operatorname{matin}()$

I* Esteprográna faz a criacao ou atualizacao da tabela de usuarios das ameas jo sistema CP/M-LIE. .

\{

static char flag, user, E5[128], op[10], nome[16], chave[15];

static char nomarq[35]=

"?TABUSER VO $\quad$ TO

static int i, j, k:

static struct reguser1

\{ char unome[15], uchave[15], uprotec, ucode; \}

reguser $[4]$;

Hsen=bdosa $(50,0 \times F F)$;

bdosa $(50,0 \times E 0)$;

nomarq $[0]=0$ :

$i=b$ dosa (15: thomarq);
1*Verificar " e salvar a area compente.

* Indicar a area do arquivo de usuarios.

/* FCB indica o disco default $* 1$

1*Abrir o arquivo te usharios. $\therefore$

if $(i>4) t \quad /$ Veriflcar: se ele nao existe entao...

bdosa ( $52,0 \times 06)$; $/ *$ Indicar a protecao a ser usada $* /$ bdosa (22, snomarq); f: para criar o arquivo de usuarios. */ for $(i=0 ; i<128 ;++i) E 5[i]=0 \times E 5 ;$ Prepara um registro so de Es. */

for $(i=0: i\langle 52 ;++i)$ bdosa(21, \&E5); / $\quad$ Cria espaco para 208 usuarios.*/

bdosa (16: Homarq); /* Fecha o arquivo para por no disco.:

bdosa (15: Homarq);

1* Abre o arquivo novamente. $\because 1$ 
$O P[O]=0$;

while (op[o]!='F') $(/ \%$ Atender a todos os pedidos do usuamio.*/ printf ("Operacao? (Retira. Cria, Lista. Fim) ");

scanf ("\%s", \&Op); $/$ Receber wh dos comanitos do op $[0]=\operatorname{toupper}(\mathrm{OP}[\mathrm{O}])$;

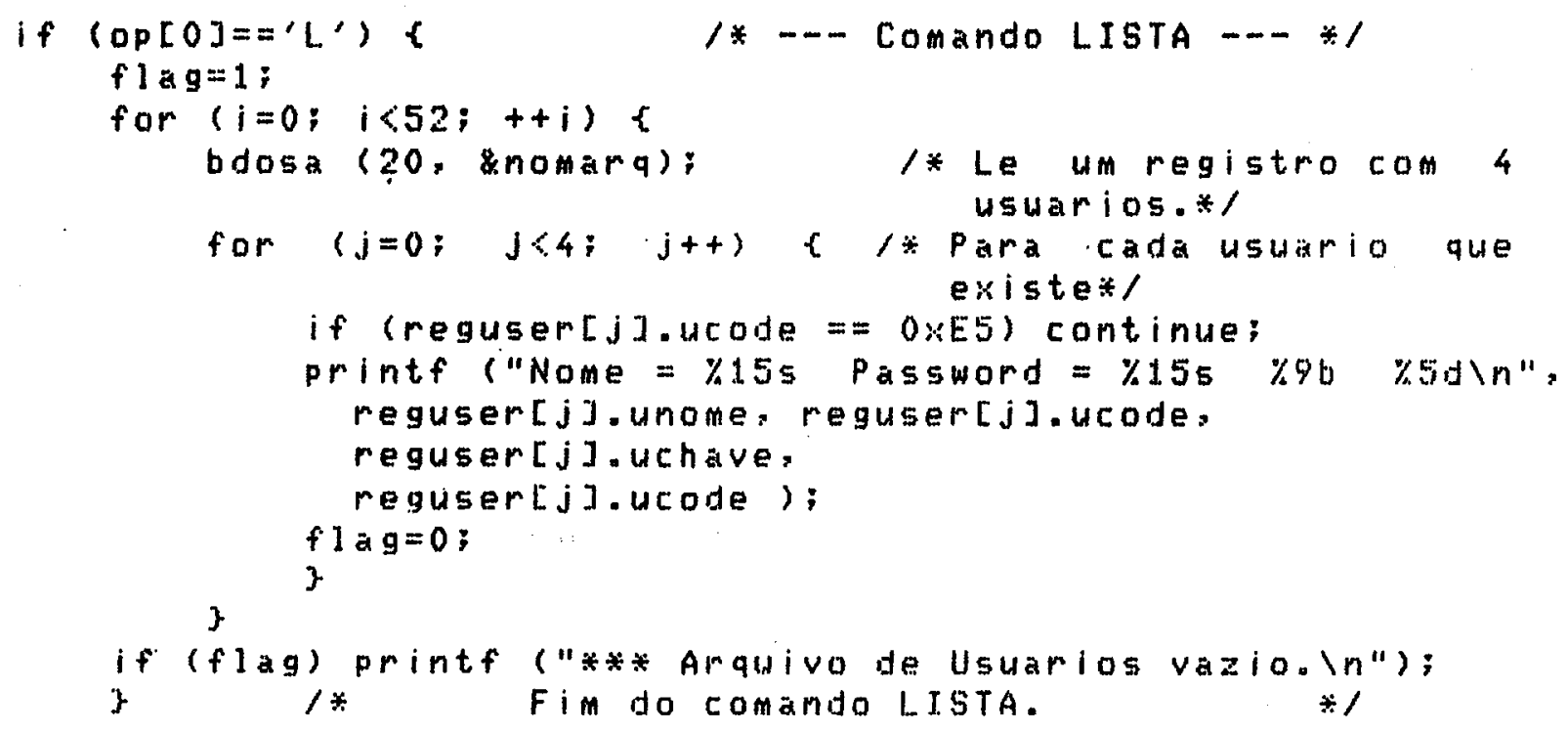




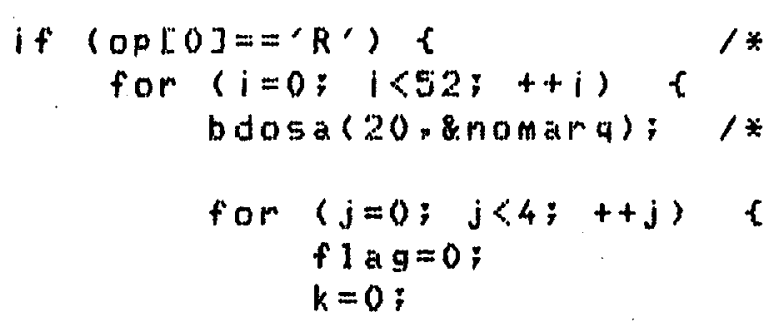




\section{BII $\underline{\text { BLIOEGRAEIB }}$}

[A5-85] Ashdown, I. E. - "Archiving Files with CP/M-80 and CP/M86", Dr. Dobb's Journal, January 85; M \& T Publishing, Inc., pp. 36-60.

[BA-84] Banzhof, W. C. - "A Controller/Cache Combination Boost System Performance", Computer Technology Review, Fall 84 , PP. 119-125.

[BL-84] Blum, R. - "CP/M Exchange" - Dr. Doob's Journal, December 84, M \& T Publishing, Inc., PP. 20-23.

[BR_83] Brown,: D. K.; Strutynski, K.; Wharton, J. H. - "Tweaking More Performance from an Dperating System", Computer Design, May 83, pp. 193-204.

[CR_81] - "Cromemco CDOS Instruction Manual", Cromemco, Inc., June 81 .

[DI_79a] - "CP/M 2 Interface Guide", Digital Research, 1979.

[DI_79b] - "CP/M 2 Alteration Guide", Digital Research, 1979.

[EN_78] Enslow Jr., P. H. - "What is a 'Distributed' Data Processing System?", IEEE Computer, Vol. 11, Nro. 1, 
January 78, pp. 13-21.

[FA_83] Fathi, E. T.; Krieger, M. - Multiple Microprocessor Systems: What, Why, and When", IEEE Computer, Vol. 16, Nro. 3, March 83, pp. 23-32.

[FU_85] Fuchs, D. R.; Knuth, D. E.- "Dptimal Preparing and Font Caching", ACM Trans. on Programming Languages and Systems, Vol. 7, Nro. 1, January 85, pp. 62-79.

[GR_85] Grossman, [. P. - "Cache-DASD Storage Design for Improving System Performance", IBM Systems Journal, Vol. 24, Nro. 3/4, 1985, pp. 316-334.

[GU_80] Guimaräes, C. C. - "Principios de Sistemas Dperacionais", Editora Campus, Ltda, 1980.

[GY_BG] Gray, J. N. - "An Approach to Decentralized Computer Systems", IEEE Trans. on 5oftware Engineering, Val. SE12, Nro. 6, June 86, pp. 684-692.

[KR_85] Krajewski, R. - "Multiprocessing: an Overview", Byte, May 85, pp. 171-1.81.

[MA_B3] Marshall, T. G.; Attikiouzel, J. A. - "Floppy Disk Data Transfer Techniques", IEEE Micro, Vol. 3, Nro. 6, December 1983, pp. 17-23.

[MU_86] Mullender, 5. J.; Tanenbaum, A. 5. - "The Design of a 
Capability-Based Distributed Operating 5ystem", The Computer Journal, Vol. 29, Nro. 4, 86, pp. 289-299.

[PA_B2] Patel, J. H. - "Analysis of Multiprocessors with Private Cache Memories" - IEEE Trans. on Computers, Vol. [-31, Nro. 4, April 82 .

EPT_B6] Patnaik, L. M.; Sundaraman, K. - "Performance Evaluation of a Distributed Concurrency Control Algorithm", Comput. \& Elect. Engng, Vol. 12, Nro. 1/2, 1986, pp. 73-88.

(RE_84) Reinhart, J.; Serrano, [. - "High-Speed Components and a Cache Memory Lower Access Times", Computer Technology Review, Winter $84, p p .37-43$.

[RI_78a] Ritchie, D. M.;. Thompson, K. - "The UNIX Time Sharing System", The Bell System Technical Journal, Val. 57 , Nro. 6; July-August 78 .

[RI_78b] Ritchie, D. M. - "UNIX Time-Sharing System: a Retrospective", The Bell System Technical Journal, Vol. 57, Nro. 6, July-August 78.

[RX_79a] - "RSX-11M/M-Plus, MCR Dperations Manual", Digital Equipment Corporation, May 79.

[RX_79b] - "IAS/R5X-11 I/0 Operations Reference Manual" Digital Equipment Corporation, May 79. 
[5H_74] Shaw, A. [. - "The Logical Design of Dperating systems", Prentice-Hall, Inc., 1974.

[5M_82] 5mith, A. J. - "Cache Memories" - ACM Computing Surveys, Vol. 14, Nro. 3, September 82, pp. 473-529.

[TA_85] Tanenbaum, A. S.; Van Renesse, R. - "Distributed Operating Systems", ACM Computing Surveys, Vol. 17, Nro. 4, December 85, pp. 419-470.

[TE_82] Terry, [. - "The CP/M Connection", Parts 1-4, in Programmer's Guide to CPIM - Edited by Sol Libes, Microsystems Press, 1982, pp. 40-58.

[TH_78] Thompson, K. - "UNIX Implementation" The Bell System Technical Journal, Vol. 57, Nro. 6, July-August 78.

[TR_86] Traina Jr., C. - "Máquina e Modelo de Dados Dedicados para Aplicacốes de Engenharia", Tese apresentada ao Instituto de Fisica e Quimica de Sa Carlos para obtença do Titulo de Doutor, Dezembro 1986.

[YE_83] Yeh, P. [.; Patel, J. H.; Davidson, E. 5. - "Shared Cache for Multiple-Stream Computer Systems" - IEEE Transactions on Computer, Vol. [-32, Nro. 1, January 83, pp. $38-47$.

[YN_85] Yen, W. C.; Yen, D.W. L.; Fu, K-5 - "Data Coherence Problems in a Multicache System" - IEEE Transactions on 
Computer, Vol. [-34, Nro: 1, January 85, pp. 56-65.

[YG_85] Young, M. 5. - "Controllers Wring Peak Performance out of Disk Drives", Computer Design, May 85.

[YO_.22] Yourdan, E. - "Design of On-Line Computer Systems" Prentice-Hall, Inc. 72 .

[ZU_76] Zuffo, J. A. - "Sistemas Eletronicos Digitais Drganizacgo Interna e Projeto", Vol. 2, Editora Edgard Blocher Ltda., 76. 